\title{
The life course, gender and alcohol use
}

Citation for published version (APA):

Neve, R. J. M. (1998). The life course, gender and alcohol use. [Doctoral Thesis, Maastricht University]. Maastricht University. https://doi.org/10.26481/dis.19980130rn

Document status and date:

Published: 01/01/1998

DOI:

10.26481/dis.19980130rn

Document Version:

Publisher's PDF, also known as Version of record

\section{Please check the document version of this publication:}

- A submitted manuscript is the version of the article upon submission and before peer-review. There can be important differences between the submitted version and the official published version of record.

People interested in the research are advised to contact the author for the final version of the publication, or visit the DOI to the publisher's website.

- The final author version and the galley proof are versions of the publication after peer review.

- The final published version features the final layout of the paper including the volume, issue and page numbers.

Link to publication

\footnotetext{
General rights rights.

- You may freely distribute the URL identifying the publication in the public portal. please follow below link for the End User Agreement:

www.umlib.nl/taverne-license

Take down policy

If you believe that this document breaches copyright please contact us at:

repository@maastrichtuniversity.nl

providing details and we will investigate your claim.
}

Copyright and moral rights for the publications made accessible in the public portal are retained by the authors and/or other copyright owners and it is a condition of accessing publications that users recognise and abide by the legal requirements associated with these

- Users may download and print one copy of any publication from the public portal for the purpose of private study or research.

- You may not further distribute the material or use it for any profit-making activity or commercial gain

If the publication is distributed under the terms of Article $25 \mathrm{fa}$ of the Dutch Copyright Act, indicated by the "Taverne" license above, 
The Life Course, Gender, and Alcohol Use 
The study presented in this thesis was conducted at the Nutrition Toxicology and Environment Research Institure Maastricht (NUTRIM), which participates in the Graduate School for Metabolism and Nutrition (MENU), acknowledged in 1994 by the Royal Dutch Academy of Science (KNAW).

The life course, gender, and alcohol use /

Neve, Rudolf Johannes Maria. Thesis Maastricht

- With Ref. - With summary in Dutch

ISBN 90-5681-026-X

Lay-out: Rudie Neve

Cover design Unigraphic

Printed by Unigraphic 


\section{The Life Course, Gender, and Alcohol Use}

\section{PROEFSCHRIFT}

ter verkrijging van de graad van doctor aan de Universiteit Maastricht, op gezag van de Rector Magnificus Prof. Dr. A.C. Nieuwenhuijzen Kruseman, volgens het besluit van het College van Decanen, in het openbaar te verdedigen

op vrijdag 30 januari 1998 om 16.00 uur

door

Rudie Neve 


\section{Promotor:}

Mw. Prof.dr. M.J. Drop

Co-promotor

Dr. P.H.H.M. Lemmens

Beoordelingscommissie

Prof.dr.ir. P.A. van den Brandt (voorzitter)

Prof.dr. M.P.F. Berger

Prof.dr. H.F.L. Garretsen (Erasmus Universiteit Rotterdam)

Mw. Dr. I.P. Spruit (Trimbos Instituut, Utrecht)

Prof.dr. G.A.M. Widdershoven

Publication of this dissertation was made possible by grants from Faculty of Health Sciences, Maastricht University Janivo Stichting, Breda 
dedicated to my son/ opgedragen aan mijn zoon

Ivo Johan Neve 


\section{Contents}

Chapter 1. Introduction: the life course, social roles and alcohol use.

Chapter 2. Developments in drinking behavior in the Netherlands from 1958 to 1989, a cohort analysis. Published in Addiction, 88, $611-621$, 1993

Chapter 3. Gender differences in drinking behavior in the Netherlands: Convergence or Stability? Published in Addiction, 91, 357-373, 1996.

Chapter 4. Gender differences in alcohol use and alcohol problems: mediation by social roles and gender-role attitudes. In press: Substance Use and Misuse.

Chapter 5. Changes in alcohol use and in drinking problems in relation to role transitions in different stages of the life course. Submitted for publication

Chapter 6. Older and younger male alcoholics in outpatient treatment:

a comparison of type and severity of drinking problems and treatment career.

Submitted.

Chapter 7. Drinking careers of older male alcoholics in treatment as compared to younger alcoholics and social drinkers of the same age. Published in Journal of Studies on Alcohol, 58, 303-311, 1997.

Chapter 8. Main results and conclusions.

Samenvatting

Acknowledgements

Curriculum Vitae 


\section{Introduction: the life course, social roles and alcohol use.}

\subsection{Introduction}

The studies presented in this thesis deal with age and gender differences in alcohol use and alcohol related problems, and relate these differences to developments in society. Three developments in society especially were at the basis of the formulation of research questions. Firstly, demographic changes, known as the 'greying' of society, raised the question whether an increase in the number of older problem drinkers is to be expected in the near future. Secondly, developments in gender relationships led to research questions on changes in gender differences in alcohol use and alcohol related problems. Thirdly, the general trend in alcohol use as indicated by per capita alcohol sales figures showed a pattern that might lead to "cohort effects" on alcohol use. The three basic themes of this thesis will be briefly introduced.

The population of the Netherlands, and as a matter of fact of the entire Western, industrialized world, has on average become older than ever before and will still become older than it is now. Older people form an increasingly important part of the population, in terms of their sheer numbers, and in terms of the ratio to the number of people in the productive age groups. This ratio, the demographic pressure, is shown in figure 1.1. Changes in the composition of the population have led to the idea that the development of alcohol consumption should be studied across the entire life-course, whereas in the past alcohol research had often concentrated on younger people (Fillmore, 1988). At the time when the project started, signals came from treatment agencies indicating that the number of older alcohol clients was actually increasing, which was also confirmed by reports in the literature (Atkinson, 1990). One goal of the project was to investigate whether the aging of the population as a whole would lead to an increase in the number of older problem drinkers, in the general population as well as in treatment agencies.

Even in the Netherlands, which has always been a somewhat 'backward' country on this point, many women have build a career, and the number of children has become much smaller than it used to be (De Jong-Gierveld and Liefbroer, 1992). In this respect, men and women have become more equal, although gender differences have by no means disappeared. The birth of children still has more consequences for women than for men. In the case when-one of the parents decreases work hours or even quits the job, it is almost always the mother (Hooghiemstra and Niphuis-Nell, 1993). The development of alcohol consumption, as well as the occurrence of adverse consequences of this behavior, varies between the sexes. Two studies reported in this thesis are devoted to the question whether more similarity in social positions of men and women has led to a decrease in gender difference in alcohol use and allcohol related problems.

The third development that has been basic to this research project was the stabilization of per capita alcohol consumption in the 1980 s after a period of very strong increase, which development is depicted in figure 1.2. It was hypothesized that people who had learned to drink during this period, that lasted until about 1975 , would show a higher consumption also in later phases of life. This might cause so called cohort 


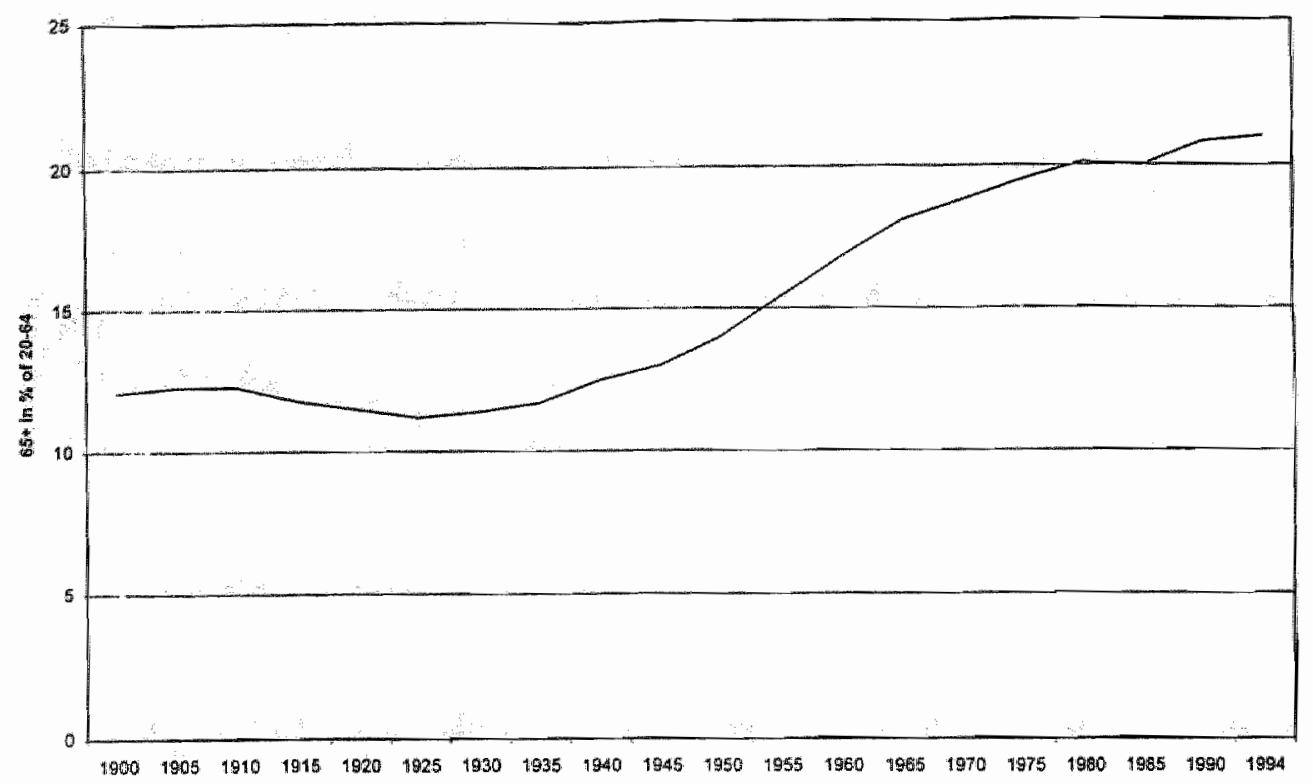

Figure 1.1 Demographic pressure in the Netherlands since 1900. Source: CBS, 1994.

effects, differences across groups of people that experience certain life changes (in this case: learning to drink) in different time periods. These cohort effects might add to the effects of demographic changes, which expectedly would lead to an increase in older problem drinkers.

The research questions of this project are developed and discussed in the articles that form the chapters of this book. The theoretical concepts that are used in the analyses and interpretations of the results are derived from the sociology of the life course, role theory, and social interaction theory. The confinements of the article format limit the possibility to elaborate on the theoretical backgrounds of the study. Therefore, in this introduction, a more detailed reflection on the theoretical assumptions will be presented. As a result of this procedure, some ideas will be developed that are not included in the chapters that follow this introduction.

As was mentioned before, societal and population changes have inspired the study of alcohol use across the life course as a whole. Therefore, the discussion starts with a reflection on the life course as a sociological concept. Section 1.2.1 will describe the 'institutionalization' of the different life phases from the beginning of industrialization to the middle of this century, and the weakening of the 'standard life course' in recent decades. After this brief historical-sociological account, a more specific aspect of the life course, central to the work presented here, is discussed. The life course can be 


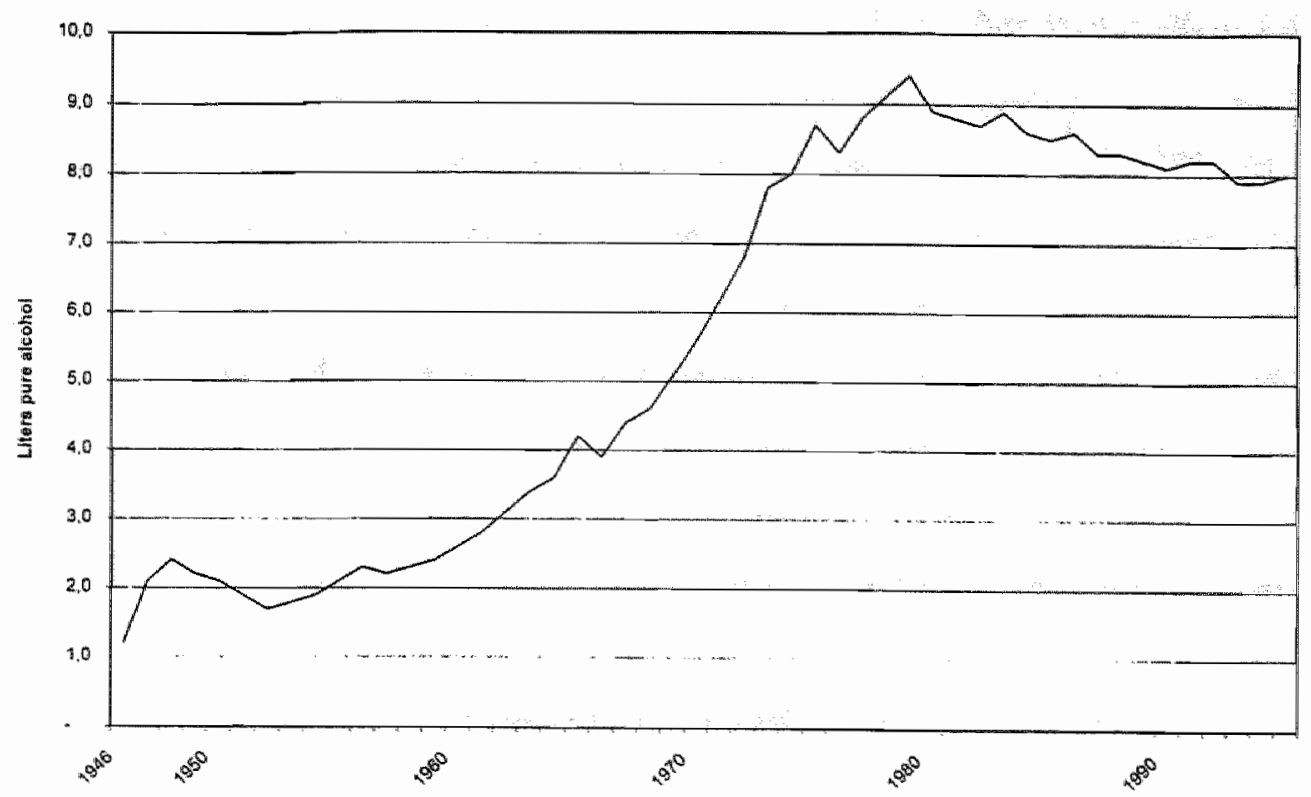

Figure 1.2 Per capita alcohol consumption in liters pure alcohol since 1946. Source: PGD, 1995.

defined as a sequence of social positions or 'roles' in various spheres of life, here called 'role domains'. A critical discussion of role theory and its implications for the study of alcohol use is presented in section 1.2.2. This section also includes comments on recent criticisms of role theory, and offers a few suggestions to incorporate these criticisms. In the analysis of alcohol use, it is important to note that it concerns to a large extent a habitual behavior. Once a drinking pattern is adopted, it may form a reason in itself for its continuation. The character of drinking alcohol as a social custom and as a hazardous habit is discussed in section 1.2.3.

Section 1.3 is devoted to the conceptualization of drinking behavior as a specific 'career', which has a relationship with the life course domains discussed in section 1.2. The 'drinking career' becomes problematic when it becomes a separate domain of life that dominates over relationship, family, and work roles.

One part of this thesis (chapter 2) is devoted to the analysis of more general trends in alcohol consumption. Cohort analysis' was used in order to test the hypothesis of a cohort effect on alcohol use for the cohort born in the 1940 s and 1950s. This research strategy is discussed in section 1.4.1. The Norwegian sociologist O.J. Skog formulated a theory that gives insight in changes in alcohol consumption at the population level. This 'social interaction theory' was reformulated in order to cover differences across birth cohorts, and is critically discussed in section 1.4.2. Finally, all separate chapters will be briefly introduced in section 1.5. 


\subsection{The life course and role analysis.}

\subsubsection{The life course as a sociological concept: institutionalization and de- institutionalization.}

From a sociological point of view, the life course can be defined as a sequence of social roles and positions in several domains of society, such as the family, work, leisure time and so on. The lifetime of individuals is embedded in social institutions, which divide it into socially meaningful units or stages. Actually, the idea of a life course in this sense became relevant only recently through the conceptualization of modernization as a process of 'structural differentiation, specialization and functional integration' (Adriaansens, 1983). Differentiation of structures and specialization of functions created new forms of life phases as well as the separation of distinct (albeit interdependent) life course dimensions.

In modern Western societies, age is much more relevant than in pre-modern societies. The emergence of separate life stages as are known today, most predominantly youth (preparation phase), adulthood (activity phase) and old age (retirement), was brought about from the 19 th century onwards by the introduction of extensive school and pension systems (Kohli, 1985; 1986). Developments in the Western, industrialized world are characterized by an increase in longevity that had profound consequences for the life course of cohorts and the way it was experienced by individuals. The 'socially expected duration' (Merton, 1984) of periods occupied by roles in education, relationships and the family are prolonged, and a large part of people's adult lives is now occupied by retirement.

A central aspect of modemization, the transition from a household economy to industrial production, also caused the emergence of separate life course domains, most predominantly work and family, or as some like to put it, the public and the private domains. The development of the nuclear family involved the division of labor by sex, bringing men mostly in the public domain and women in the private domain. One of the questions that can be raised in relation to this division, is whether the institutionalization of the life course of men is different from that of women. According to Kohli (1986), the occupational field is the main source of institutionalization of life for men as well as women, a point of view that "... is not so much a male argument as an argument appropriate for a male-dominated and work-dominated society" (Kohli, 1985, note 5). A case in point can be found in the fact that the age of women at the birth of their first child is strongly influenced by their education and chances on the labor market (De Jong-Gierveld and Liefbroer, 1992). In turn, however, the position of women in procreation has profound consequences for the work life of women (Rossi, 1985). Therefore, the family cycle will not be viewed as derivative from the work domain here. It has its own dynamics; with its own consequences for life style, behavior, and attitudes.

The institutionalization and chronologization of the life course brought forward a 'standardized life sequence' in the work domain as well as in the family. In the work domain, the 'tripartition' of life into preparation in youth, work activity in adult life and retirement at old age reached a height in the middle of this century. Virtually every individual spends the first part of life in education. As the age of mandatory retirement 
was lowered, while longevity still increased, a large majority of the population not only was entitled a pension after reaching a certain age, but actually spent a growing part of life in retirement. There are signs that the institutionalization of the life course in the work domain has come to a halt or has even been reversed in the last two decades. For growing numbers of employees and workers, the working phase is interrupted by periods of education and unemployment. Not any more do most people have steady jobs with planned careers, that allow them to entertain more or less grounded expectations for their future (Held, 1986). Although actual employment improved again in the late $1980 \mathrm{~s}$, old securities had diminished. In many professions, the number of temporary contracts has increased. On the lower part of the labor market, home work and stand-by contracts have emerged, especially for women. On the other hand, many women whose children have grown up start working again, and often find their qualifications outdated. A recent survey confirmed that an increasing part of the Dutch population views unemployment as a real threat (SCP, 1996, p. 469).

In the domain of the family cycle, the 'standard life course' is defined in terms of leaving one's parental home to marry and form a family, living with that family until the children leave the house to form their own family. For those who's spouse dies first, the final stage of life is that of the widowed elderly person. In this constellation, men are assigned the role of father and wage earner, while women's place is within the family as housewife and mother. In the Netherlands, this pattern applied to growing numbers of people from the 19th century to the Second World War and reached its height in the $1960 \mathrm{~s}$. In that period, the standard life course and the resulting limited number of household types had become the norm, and other living arrangements were considered to be deviant (Van Leeuwen en Ploegmakers, 1990). After the 1960s, the relevance of the standardized family-cycle as a model of the individual life course, although still important, has been declining due to the emergence of a multitude of new types of relationships and households. This heterogeneity can be seen as a challenge for the idea of an institutionalized life course (George, 1993). For instance, in a recent Dutch survey on life course patterns $(n=1601$ ), it was possible to construct five empirical types of life course patterns, only by concentrating on a very limited number of transition events: living independent, first marriage or cohabitiation, and birth of the first child (Van Leeuwen en Ploegmakers, 1990). The inclusion of marital dissolution and the formation of new relationship in the analysis would lead to a number of patterns too large for meaningful classification. However, it is also worth noting that a majority of the adult population, although decreasing, is found living according to a 'standardized' life course pattern, at least if it is accepted that cohabitation is now a 'normal' preparation for marriage.

\subsubsection{Connecting dimensions of the life course with alcohol use: role theory, a critical discussion.}

As was stated above, the life course can be viewed as a sequence of social positions or roles in several domains, such as relationship, family, work, leisure, etc. In this section, these 'changeable' social characteristics are distinguished from more static 
characteristics of persons, which will be called 'basic characteristics'. The most important basic characteristics considered in this thesis are age and gender, but also ethnicity, education, social class and religion can be considered important. From the point of view of role theory, basic characteristics as well as social positions are connected with "social roles".

In the alcohol research group of Maastricht University, a specific version of role theory was developed by R.A. Knibbe, building on a foundation laid by H. Philipsen (Knibbe, 1984, Knibbe et al., 1987; Philipsen, 1976). This work inspired part of the projects presented in this thesis; and it has proven to be illuminating in alcohol studies. On the other hand, role theory has increasingly become criticized in general sociological theory. The following section shows the result of a critical theoretical reflection at the final stage of the project.

Role theory, and its contribution to alcohol research.

A specific sociological approach of 'normal' as well as 'problematic' drinking behavior was developed by Knibbe $(1984,1987)$. This approach was based on the work of the German sociologist Uta Gerhardt (Gerhardt, 1971), which had already been introduced in Dutch alcohol research by Philipsen (1976). From the perspective of role theory, basic characteristics as well as changeable social positions are viewed as connected with roles. Roles are generally defined as sets of expectations, or norms, that guide behavior, according to the status and position to which an individual belongs. Roles are learned through socialization, and they do not determine behavior in an absolute way, but give direction to behavior (Merton, 1976). In the International Encyclopedia of the Social Sciences, the role concept is defined as "..a comprehensive pattern of behavior and attitudes, constituting a strategy for coping with a recurrent set of situations, which is socially identified -more or less clearly - as an entity. A social role is played recognizably by different individuals, and supplies a major basis for identifying and placing persons in a group, organization, or society." (Turner, 1968, p. $552)$

Gerhardt's role theory distinguishes 'status roles', which are attached to basic characteristics of the individual, and 'position roles' which are attached to social positions. Status roles involve social expectations based upon characteristics that the individual cannot easily influence. Gender and age are considered status roles, along with religious background, ethnicity, and social class. Whereas status roles are attached to the individual, positional roles are expectations related to positions in society, such as work positions and family positions.'

\footnotetext{
${ }^{1}$ Other role theorists have also distinguished basic characteristics from changeable positions. For instance, R.H. Turner (1990) defines 'basic roles', such as gender and age, as roles that are grounded in society at large rather than in particular organization. 'Structural status roles', are occupational, family and recreational roles that are attached to position, office, or status in a particular organizational setting. Note the confusingly different use of the term 'status' in both treatments of role theory. Whereas Gerhardt uses 'status' for basic characteristics, Turner denotes social positions with the term status. In the present work, Gerhardis lead will be followed on this
} 
Gerhardt further distinguishes situational roles, which refer to more fluid short-term roles, that may occur when situations show a certain degree of stability and coherence (Philipsen, 1976). In Knibbe's view, the consumption of alcohol takes place in the context of situations, and should therefore be studied within this context. His theoretical analysis departs from the idea that status and position roles circumscribe the range of appropriate behaviors in drinking situations. (For an attempt to operationalize this position in concrete empirical work, see Van Gelooven, 1991).

Status roles and alcohol use.

With respect to status roles, it is clear that there is a direct impact of basic characteristics on alcohol use. For instance, it has been found in the Netherlands that Protestants drink less than other categories of the Dutch population, which is directly related to socialization in a distinct normative system (Gadourek, 1963; Knibbe, 1984). In this specific case, there is ample evidence that the Protestant work ethic prohibits drinking, whereas the morals of Catholics and non-affiliated are more loose on this point. To give another example, besides biological differences between the sexes, gender differences in drinking are probably related to gender specific socialization, both in general and with respect to alcohol use as such. Thus, it seems that the idea that norms and expectations are attached to basic characteristics of individuals is theoretically plausible and has an empirical basis. ${ }^{2}$

According to Knibbe, "status roles' are general orientations, that allow the individual a great deal of freedom in the actual fulfilment. The enactment of social roles is connected with situations, which in turn are placed on a dimension between 'diffuse' and 'specific' (one of Parsons' pattern variables, see Adriaansens, 1980). Contrary to specific situations, which involve specific obligations (e.g. being a car driver), diffuse situations allow the individual, as Knibbe puts it, to give expression to elements of his status role. Therefore, since drinking mainly takes place in diffuse situations (that is, free of obligations), drinking behavior can become a 'style element' that is related to the status role. Not only can status roles influence drinking behavior in certain situations, but they also determine the choice of situations in which the habit of drinking is normal, or perhaps rather: in which it is deviant. Examples from everyday life can easily give this idea some plausibility: anyone would be surprised seeing a well dressed, middle-aged lady drinking beer from the bottle in the street. However, it appears difficult to specify which status role expectations lead to specific types of drinking behavior. Knibbe has tried to circumvent this problem by using empirical generalizations, such as 'prevailing drinking patterns' (drinking styles) to describe differences in drinking behavior across status categories. Homogeneity of drinking patterns within

point.

${ }^{2}$ For this reason, it has been proposed to categorize variables like age, gender, and ethricity as "normative social demographics ${ }^{*}$ (e.g. Gruenewald et al., 1995). Although this idea does hold water, it will not be followed here in order not to complicate matters further. 
status groups is viewed as evidence that the status role actually prescribes certain drinking patterns. This procedure may be criticized from a theoretical point of view: if one wants to explain behavior from role expectations, these expectations should be operationalized as such. Nevertheless, Knibbe succeeded in showing that the integration of drinking varies across status categories, which also has implications for the relationship between alcohol consumption and problem drinking.

Position roles, alcohol use, and problem drinking.

From the perspective of life course analysis, basic characteristics form constant factors in life. In life course analysis, emphasis is on change and stability in characteristics of a person. Concepts such as role-transition, role-loss, or role gain point at roles that a person does not occupy all his life: positional roles. Knibbe views positional roles mainly in terms of structure of everyday life of the individual. Positional roles largely consist of specific obligations that have to be fulfilled at regular times, thus filling part of the time with meaningful activity. In this way, positional roles also influence the kind of social situations that an individual may enter. With a few exceptions, normal social drinking is restricted to situations in which no position role obligations have to be fulfilled; to 'diffuse' situations, or in other words: to time off, leisure. Exceptions of position roles in which moderate drinking is considered normal are such professions as barman and the like.

In the family context, things are more complicated. Some of the responsibilities associated with the positional role of parent may preclude alcohol use (e.g. taking care of small children), whereas others would in many cases involve drinking (however with an emphasis on moderation), such as celebrating a birthday with adult and adolescent family members. However, these exceptions are not systematically elaborated and in his analysis, Knibbe views positional roles mainly as restrictions on drinking behavior: positional role obligations prevent people from (heavy) drinking, unless all obligations are fulfilled and no new obligations are due. One has a drink in the evening, moderate enough to allow proper functioning next morning. As a consequence, problem drinking is interpreted as the domination of diffuse situation roles involving drinking over position roles that constitute societal responsibilities (Philipsen, 1976). That is, a person is viewed as a problem drinker when he is unable to fulfil his positional role obligations because of his drinking. In accordance, Knibbe found that especially young men with few position roles showed an elevated risk for intensified drinking. Thus, social roles as such do not really tell us much about drinking, but the obligations and responsibilities connected to social roles put restrictions on drinking. Social expectations and norms do not explicitly refer to drinking, but to role obligations that may or may not be compatible with drinking.

In sum, role theory in the version of Gerhardt, introduced in alcohol research by Philipsen and Knibbe, has proven to give insight in a number of aspects of drinking behavior. For the purpose of the present project, it is relevant that a distinction is made between basic characteristics ('status roles') and positions in society ('position roles'). The latter allow further elaboration of the life course concept within the framework of sociological theory. 
General comments.

Some general comments must be made. Firstly, role theory states that behavior is governed by normative expectations, but these are not at all included in the analyses. When a difference between role categories is observed, for example men drink more than women, it is assumed that this can be explained by difference in expectations. Even stronger, the very existence of difference in expectations is derived just from the existence of a difference in behavior. As has been shown before (Turner, 1991), on logical grounds it appears very difficult to overcome this problem, since expectations are not easily measurable, at least not separate from the subject showing the behavior of interest. This makes explanations of drinking behavior derived from role theory highly tautological.

Researchers are left with a categorizing scheme which, however valuable in another sense, does not give a real explanation for differences in drinking behavior between categories, or for changes over time. Boudon (1981) has proposed to restrict the role concept to positions within functional systems such as an organization, a family, etc., and to view basic characteristics (status roles) as extraneous factors in role analysis. Boudon is probably right as far as role as an explanatory concept is concerned. However, this view overlooks other aspects of role theory. As Linda $\mathrm{K}$. George has put it: "Role theory is attractive as a heuristic or general metaphor for thinking about links between social structure and individual behavior. Because role theory is so general, however, it is difficult to specify results that would refute it" (George, 1993: 355). Boudon disregards the first half of this quote, thereby throwing away the baby with the bath water.

Knibbe has effectively used role analysis to illuminate alcohol use across categories of the population. His treatment of status roles has led him to rely very much on empirical generalizations in an attempt to operationalize the prescriptive aspect of roles. His treatment of position roles strongly emphasizes roles as restrictions of drinking behavior, leaving other aspects largely implicit. In the following section, a few possible extensions to role analysis are suggested.

\section{Social positions as resources .}

A less emphasized aspect in role theory is that the occupation of certain positional roles not only creates obligations but also provides the individual with resources, which in turn may relate to alcohol consumption in various ways. Generally, the availability of some resources related to social positions may facilitate social, moderate drinking, whereas the lack of other resources may be substituted by turning to alcohol as a surrogate resource, increasing the risk for more problematic drinking. Of course, both features may be combined in one resource. For instance, having a job will provide an individual not only with income, but also with a more extensive social network. Whereas money provides the means to almost any end, including alcohol use, the social network may produce situations that involve (social) drinking. Drinking patterns enhanced this way mainly involve social drinking, however, rather than heavy drinking, although this may depend on various characteristics of the network and its members, such as size, density and 'wetness'. Being unemployed, on the other hand, would lead to lower income, putting restrictions on consumption, but it may create the 
need to substitute a regular social network by all to frequent bar visits, unrestricted by the alarm clock in the morning.

Following the rational choice theoretician Lindenberg (1992) it can be argued that social positions, such as holding a certain professional position, being married to someone, or having a family with one or more children, create resources, such as a social network and social status. These resources may be utilized in the production of the universal goals: physical and social well-being. Resources are goals themselves at a lower level, indicated by Lindenberg as 'instrumental goals', which are in turn produced by lower level resources. In order to arrive at the universal goals, the individual uses the available resources. Social resources, such as social position, social status, a social network, are denoted as 'social capital' (Bourdieu 1980, Coleman 1988). Decrease or lack of a certain resource will induce substitution by other resources that are available and that may also facilitate the goal in the perception of the individual. From this point of view, it may be argued that the lack or loss of positional roles may lead the individual to turn to diffuse, wet situations under two conditions. First, the individual perceives alcohol use as enhancing physical well-being and/or social approval, and second, he or she does not see other resources that may better produce these goals. An example taken from Knibbe (1984) may clarify this process. Compared to younger singles, people over thirty years of age who never married appeared to have a higher chance for intensified drinking, compared to people of the same age. This could be explained by feelings of incompetence in starting or continuing a relationship and lack of social approval that is substituted by entering into 'wet' situations with heavy drinking friends.

This example points at some possible ways to give social roles "hands and feet": social networks, time budgets and coping strategies. First, as was already mentioned, the occupation of social roles involves social networks. The study of social networks is a result of the theoretical progress in rational choice theory, as has been shown by recent publications (e.g. Tijhuis, 1994). In alcohol research, measures of social networks were included in a large number of studies, often in relation to treatment of problem drinkers or alcoholics, in which little attention has been paid to their connection with social structure (e.g. Akerlind and Hornquist, 1992; Moos, 1995). Qualitative and quantitative study of social networks in relation to social roles seems to be a way to increase the understanding of drinking behavior. Social networks are important with respect to social support and social resources. Structural and quantitative aspects of social networks may also be connected with role aspects such as expectations through the mechanisms of social control.

The way in which social role obligations and expectations related to social roles influence the situations in which individuals enter can be operationalized in time budget research. Gerhardt's idea that role behavior actually crystallizes in concrete situations can be studied by measuring the amount of time spent in specific types of situations by persons with certain role characteristics. Van Gelooven (1990) has done an initial effort in this respect, showing that several hypotheses derived from role theory could not be refuted. A more comprehensive version of role theory, including more variation in position roles, and attention for transitions across the life course, could enhance this approach in the study of drinking behavior. 
Role transitions, especially the loss of roles, lack of desired roles and the occupation of 'unwanted' roles (Wilsnack, 1992) frequently form a source of stress, making high demands on individuals' coping abilities. A 'stress and coping' approach (Finney and Moos, 1995; Moos, 1995), applied to role analysis, could answer the questions raised by the example given above.

Differences in drinking behavior (especially in problematic drinking) between categories of people according to social roles may thus be interpreted as consequences of the availability of alternative resources (and abilities in the case of coping) to produce physical and social well-being. The extent to which resources can be substituted by other resources, rather than alcohol use, varies across social positions. Thus, it is argued that amount and type of resources vary across the life course. For instance, the loss of important position roles at older age, such as a certain occupational role at work and the role of parent at home, may be replaced by meaningful activities with age peers, or by the position of grandparent. As Knibbe remarks, this substitution will be expected to occur more easily when life changes are part of the normally expected life course. In that case, the adaptation of the individual e.g. to the loss of a role is prepared for by socialization, and anticipation. Retirement is an example of such a "normal' life change. However, someone who becomes disabled at the age of 42 will have considerably more difficulties to find a substitute for the structured daily life, and for the social contacts and the income that used to be associated with his job. A person confronted with sudden or unexpected lack or loss of social roles may be tempted to start drinking too much if he has the option to do so and if a certain benefit is expected from either entering into situations that may easily lead to drinking or from drinking as such. The latter may be observed in case of stress-reducing "self-medication" by using alcohol (Pohorecky, 1991).

Under some circumstances alcohol consumption itself may represent a kind of "social capital'. This is the case when it is rewarding, social approved of, or even highly valued, in the social surroundings of a person, or when important aspects of social life take place in 'wet' social contexts. This seems to be especially the case among young people.

To conclude, when studying life course transitions (in whatever field, but in this case in alcohol studies) it seems unproductive to dismiss the role concept. However, the recent critiques on the tradition of 'role theory' can hardly be ignored. It seems possible to reformulate certain aspects of role theory, such as the distinction between "status roles' and 'position roles" by extending the "norms-and-expectations' content and including other features associated with social roles, such as a social network, social support, time spend in situations, coping, and specific obligations and restrictions. Rational choice theory in this sense provides a complement for the shortcomings of role theory. 


\subsubsection{Alcohol use: a social custom and a risky habit.}

In the former section, it was argued that role analysis in alcohol research should be appended with elements from what can be called a 'methodological individualist' perspective, such as rational choice theory. At this point, it is worthwhile to reflect upon the character of drinking behavior as such in the light of sociological theory on habit and custom. An important aspect of drinking behavior is that it often takes the form of a habit, which may easily, but incorrectly, lead to the idea that it is a static characteristic, rather insensitive to change. In this section, it will be argued that drinking behavior is more susceptible to changes across the life course, and that it is more likely to become problem drinking, when it becomes an individual habit rather than a custom rooted in social institutions.

In 1963, the Dutch sociologist Ivan Gadourek published his monumental work 'Hazardous habits and human well-being', one of the earliest large-scale empirical studies on drinking and smoking behavior in Europe. In the introduction to his book, Gadourek devotes attention to conceptual reflection on the terms habits, customs and mores, as they relate to drinking behavior. In his view, alcohol use as a social custom is embedded in the culture and traditions of a particular country or category of the population. In western society, drinking takes many forms, varying from the ritual use in Christian church services to the celebration of special occasions and rites de passage such as marriage. As Gadourek puts it, these celebrations mark the rhythm of social life and give structure to social time. Still at an integrated, but slightly less collective level, alcohol use plays a role in returning events of social life: family parties, promotion, business success etc. Alcohol use may turn hazardous as it increasingly becomes an individual habit rather than a social custom. Alcohol use may become important in the individual social life, such as regular meetings with friends, and eventually in the structuring of strictly individual daily life, such as the end of the working day. In that case, alcohol use becomes a means for the structuring of individual time, rather than social time, and drinking may more easily become problem drinking.

The distinction between 'custom' and 'habit' relates to another distinction in alcohol sociology: integrated versus unintegrated drinking (Blacker, 1966). When drinking is embedded in cultural practices, it is less subject to individual choice, and therefore may be considered less risky in terms of the individual's possible "loss of control'.
Unintegrated habitual drinking had even earlier been described as 'utilitarian drinking"
in a typology of drinking by Bales (1946). in a typology of drinking by Bales (1946). Knibbe's use of the term 'integration of drinking in every day life' is connected with his use of the term 'status roles'. In his treatment, 'integration' is derived from a low variability of drinking styles within status categories, combined with a high variability between status categories. Such a pattern is interpreted is an indication of ".....the extent to which actual drinking style is determined by status role expectations or largely left to individual preferences"
(Knibbe, Drop and Muytjens, 1987: 466). Knibbe found that the relationship between
"structure of daily life" (the occupation of socing "structure of daily life" (the occupation of social roles) and intensified alcohol conthe case in Limburg as compared to Rotterdam. 
To the extent that alcohol use has become an individual 'habit', unintegrated in culture and traditions, it seems that it should be approached from the perspective of methodological individualism, of which rational choice theory is at present the form dominating in sociology. As the use of alcohol is less determined by cultural institutions, as a social usage or custom, and becomes more subject to individual choice, it seems warranted to study this development in detail and to investigate the factors that influence individual choice with respect to alcohol use.

\subsection{Life course and drinking career: reciprocal relationships?}

The notion of social and cultural integration of drinking has implications for the study of alcohol use across the life course. When drinking is integrated in status roles, it would be expected that the age grading of drinking behavior, besides biological factors, is determined mainly by culture and tradition. When, on the other hand, drinking is individualized, and individual choice is the main reason for drinking, it would be expected that drinking is more related to a person's position in society, with its possibilities and restrictions. In that case, positional roles are expected to be associated with drinking behavior, and therefore, changes in positional roles (role transitions) may be expected to cause a change in drinking behavior. In addition, the use of alcohol, as with other drugs, is a habit with a special characteristic. Whereas normally it is a subordinate aspect of life, it can become a dominant aspect of life for some persons. Thus, the association of positional roles with drinking behavior may be the other way around as well. It can be expected that persons who drink very heavily in early life phases, may influence their perspectives on role positions that would structure everyday life. Furthermore, those who occupy positional roles could loose these roles as a consequence of excessive drinking in later life phases. Drinking becomes problematic if it becomes a separate, or even dominant, dimension of life, if it becomes a career on its own. This is in agreement with the sociological account of problem drinking as the domination of 'situational roles' over 'positional roles' (Philipsen, 1976). Thus, life course and drinking career seem to have reciprocal relationships. Some general results on alcohol use across the life course will be briefly discussed now.

It has been observed in the international research literature (Cahalan, 1970) as well as in the Netherlands (Knibbe, 1982) that excessive drinking is most common among young men. Most younger problem drinkers seem to 'mature out' when their life becomes more structured by everyday responsibilities related to societal positions. This had led Room (1977) to the observation that problem drinking among young men is "a form of normal deviance'. Although their heavy drinking is often criticized by significant others (as they report in surveys), it does not prevent a normal development of social role taking at a later stage. Only when the young heavy drinker does not adapt to adult life because of his drinking, he is really to be considered a problem drinker.

Among women, the age curve of excessive or problematic drinking is somewhat different. The incidence as well as the chronicity of drinking problems is highest among women in their thirties. As a result, the duration of drinking problems is on 
average shorter among women than it is among men. Until now, little has been offered as an explanation for this phenomenon in the alcohol research literature. According to Fillmore (1987), this pattern may be explained by younger women's relative lack of power and prestige, denying them the privilege to drink, as well as to their vulnerability to victimization by others' drinking. This condition points to the need for more detailed analysis of women's social positions in relation to alcohol use and problem drinking. In this context, Wilsnack (1992) has rightly proposed to study not only women's social positions as such, but also the quality of social roles, role deprivation, and "unwanted" social positions. In other words, the analysis of social positions should be qualified in order to arrive at better explanations of patterns in female alcohol use.

In both sexes, incidence as well as duration of alcohol problems decreases very strongly after age 60, and as a consequence, prevalence is low in the older age category. However, drinking as well as alcohol related problems do occur among the older age group as well. Some "early onset" problem drinkers do not remit and develop very severe problems, often combined with role loss. On the other hand, it has been observed that problem drinking sometimes only starts at older age, after a life of nonproblematic drinking and the fulfillment of societal responsibilities. Less adequate coping strategies in dealing with the stress of loss and bereavement in later life can lead to problem drinking (Finney and Moos, 1984). This 'late onset' problem drinking has caused a great deal of debate among alcohol researchers. Clinical researchers and workers in treatment institutions encounter older people with alcohol problems who say that they never had problems before older age (which' definition may vary across studies, by the way). On the other hand, survey researchers do not find many cases in the general population.

Late-onset problem drinking has been hypothesized to be related to the stresses of later life, such as retirement, widowhood, loss of friends and family members, decline of income, and also to health problems. Social isolation, which is more prevalent among older people, may be associated to higher abstinence, but also to higher prevalence of problematic drinking behaviors (Gomberg, 1985; Skog, 1995). With respect to stressful, role changing 'life events', it has been reported that divorce and separation, rather than retirement and widowhood, are associated with higher risk of problem drinking among older people.

It will be argued here that a perspective that departs from 'life events' over the entire life course (which will be called role transitions here), rather than 'stresses of older age', should be employed in order to arrive at somewhat better explanations of the onset of drinking problems. In this sense, Gomberg is right in claiming that "...a focus on critical life events will permit us to integrate individual differences and age/cohort differences in assessing positive and negative life events."

Cohort analysis is the subject of the following section, however on the collective level rather than on the individual level. 
Table 1.1 Standard cohort table.

\begin{tabular}{l|l|l|l|l|l|} 
Age & 1950 & 1960 & 1970 & 1980 & 1990 \\
\hline $21-30$ & $\begin{array}{l}\text { Cohort 5 } \\
(1920-29) \\
\text { A }\end{array}$ & $\begin{array}{l}\text { Cohort 6 } \\
(1930-39)\end{array}$ & $\begin{array}{l}\text { Cohort 7 } \\
(1940-49)\end{array}$ & $\begin{array}{l}\text { Cohort 8 } \\
(1950-59)\end{array}$ & $\begin{array}{l}\text { Cohort 9 } \\
(1960-69)\end{array}$ \\
\hline $31-40$ & $\begin{array}{l}\text { Cohort 4 } \\
(1910-19)\end{array}$ & Cohort 5 & Cohort 6 & Cohort 7 & Cohort 8 \\
\hline $41-50$ & $\begin{array}{l}\text { Cohort 3 } \\
(1900-09)\end{array}$ & Cohort 4 & Cohort 5 & Cohort 6 & Cohort 7 \\
\hline $51-60$ & $\begin{array}{l}\text { Cohort 2 } \\
(1890-99)\end{array}$ & Cohort 3 & Cohort 4 & Cohort 5 & Cohort 6 \\
\hline $61-70$ & $\begin{array}{l}\text { Cohort 1 } \\
(1880-89)\end{array}$ & Cohort 2 & Cohort 3 & Cohort 4 & Cohort 5 \\
\hline
\end{tabular}

Source: based on Hagenaars, 1977.

\subsection{Analyzing trends in alcohol consumption in general populations: age catego- ries, cohort analysis and Skog's social interaction theory.}

\subsubsection{Cohort analysis.}

Life course analysis of alcohol use is relevant not only to analysis of changes in drinking patterns at the individual level, but it can also be related to the analysis of alcohol use at the aggregate or collective level. From the point of view of life course sociology, changes in aggregate characteristics of a population may occur because people who get old and die are replaced by others who are born and grow up in the same time period, provided that the new generation has different characteristics, and that these characteristics have a certain stability in time. Or, in other words, change occurs when the "new" young generation is different from the 'old" generation at the time when its members were young. In life course research, the term 'cohort' is often used instead of the common notion "generation". A cohort is defined as "...an aggregate of individuals (within some population definition) who experienced the same event within the same time interval" (Ryder, 1965: 845). Most commonly, birth is used as the constituting event for cohorts, but other events (e.g. marriage, conscription, etc.) may be used as well.

Applied to the study of alcohol use, the notion of cohort succession can be used to analyze changes at the aggregate population level. For example, in the Netherlands a general increase in alcohol consumption occurred in the $1970 \mathrm{~s}$. At closer examination, the increase in alcohol consumption appeared to be the strongest in the younger age categories (Knibbe et al. 1985). This might lead to the hypothesis that this younger age group will later develop more alcohol related problems than their predecessors. It thus becomes relevant to compare cross-sections of this population, observed at different time points before and after the change of interest. Exposition of data in two-dimen- 
sional age by year tables yield a "third" dimension in the diagonals, representing the cohorts. The resulting table 1.1 is called a 'cohort table' (Glenn, 1977).

The fact that this third dimension is not independent from the other two makes it impossible to analyze age, period (year) and cohort as separate independent variables'. However, through careful examination and using as much as possible additional information from outside the cohort table, tentative conclusions can be drawn with respect to the relative weight of age, period and cohort in the overall change. To return to the example: when high alcohol use in a young cohort ( $A$ in table 1.1) is found back in later period ( $\mathrm{B}$ and $\mathrm{C}$ in table 1.1) it is to be expected that the deviation from other cohorts will remain in future periods as well. In other words: in that case elevated alcohol problems are to be expected in the older age category in the near future.

In this type of analysis, it is less relevant to look at social roles or changes in social positions at the individual level. However, it is possible to account for aggregate level shifts in certain characteristics. For instance, when it is known that women with a paid job outside the home drink more than homemakers, and that the percentage of women with a job increases, an increase in female alcohol consumption should be expected to result.

\subsubsection{Social interaction theory.}

In the interpretation of cohort analysis of alcohol consumption, social interaction theory appears to be useful as a framework for the interpretation of developments in alcohol consumption (Skog, 1980, 1985). According to this theory, interaction between people in interconnected social networks leads to reciprocal influence of drinking behavior throughout society. 'Exogenous' stimuli lead some people to change their alcohol consumption. Individuals who increase consumption will influence their friends to do the same, and individuals who deviate most strongly from the current trend in the group will be under the strongest social pressure to adapt to the group. Eventually, societies, considered as enormous social networks, will 'move more or less in concert up and down the consumption scale', a phenomenon that Skog refers to as the "collectivity of drinking cultures' (Skog, 1985).

Social interaction theory is not a theory that explains the reasons for drinking behavior or changes in individual drinking behavior, nor for changes in general consumption level. Rather, it has something to say on how changes come into being, that is, the impact of changes in consumption level on its distribution. It may be added that social interaction theory also illuminates how subpopulations" consumption levels change relative to each other in times of general change; and how changes in subpopulations may lead to changes in drinking in the entire population (Skog, 1980).

To the extent that social networks of different categories of the population are separated from each other, these categories constitute different 'drinking cultures', which may develop in a different direction than other groups. Variability of drinking behavior across subpopulations (e.g. cohorts) can thus be interpreted as a product of segmentation of their social networks. When social networks are more separated, exogenous stimuli that change drinking behavior will affect drinking behavior of subpopulations (cohorts) differently, and not all stimuli will eventually cause change 
in behavior in the entire population. Thus, when a certain cohort, as in the example, deviates from the entire population with respect to the development of alcohol consumption, this could be interpreted as the result of segmentation. The cohort of interest should to a certain extent be seen as a separate 'drinking culture'.

In order to explain drinking behavior and to compare changes in drinking behavior across status and position categories of the population, Skog's social interaction theory should be supplemented with theories that are informative with respect to the density and segmentation of social networks. It can be argued that status and position factors have impact on social networks. Of course, in order to test social interaction theory, one would need detailed information on the social networks of individuals included in a study.

\subsection{Summary and conclusions.}

Developments in the life course as an institution were discussed in a historical sociological perspective. The standardization of the life course reached a height in the middle of this century, as a result of earlier development of school and pension systems, as well as ever increasing chances on a stable marriage and family life. During the last decades, developments in the domain of work (female labor market participation, risk for unemployment, flexibility, educational and parental leave), and even stronger in the family domain (increase in divorce figures) have caused a degree of deinstitutionalization of the life course.

The life course is connected with life style, and more specific with drinking behavior, through the sociological role concept. Roles are defined as normative expectations that direct individual behavior. Status roles, attached to basic personal characteristics (such as gender, age, ethnicity), are distinguished from position roles, which are attached to positions in social networks that are usually not constant in the entire life (such as being an employee or a mother). Status roles are predominantly prescriptive with respect to alcohol use: it has been shown that they are connected with prevailing drinking styles. Position roles are more proscriptive, since they put restrictions on drinking by imposing specific obligations and responsibilities on individuals. Recent general criticisms of role theory from the side of "rational choice" theorists were discussed and gave inspiration to propose some extension to role theory in alcohol research. Since drinking has increasingly become an individualized habit, unintegrated in social institutions and cultural practices, it is even more necessary to adopt a methodological individualist perspective in the study of alcohol use in relation to social roles. Therefore, it is suggested that the study of alcohol use in relation to position roles would improve by the inclusion of underlying factors, such as social network and social support, time budgets, and coping strategies. This new idea is not yet employed in the chapters following this introduction, but the relationship between positional roles and alcohol use and alcohol related problems is studied empirically. Special attention is paid to differences between men and women, and to testing the 'convergence hypothesis', which predicts that gender differences in alcohol use and alcohol related problems will become smaller when women's roles in society become more like men"s. 
The study of "drinking careers" and their relation to other careers in different domains of life should also take into account that drinking for some people may become an aspect of life dominating other domains. When drinking thus becomes a career in its own, someone is to be considered a problem drinker. Therefore, alcohol related problems are studied from a career perspective in this thesis.

In the analysis of general trends in alcohol use, most attention has been paid to possible cohort effects and to gender differences in alcohol use. Both subjects were studied within a cohort framework. To the extent that cohorts form separate "drinking cultures', they are expected to show different developments in drinking over time. A specific cohort effect for the generation that started drinking in the period of strong increase in alcohol consumption, would add to the increase in the number of older problem drinkers that is expected in the near future on the basis of demographic developments: the 'greying' of society.

\subsection{Overview of the chapters.}

Chapter 2 reports on a cohort analysis of alcohol use in the Netherlands from 1958 to 1989. The Netherlands saw an exceptionally rapid increase of per capita consumption in the period from 1960 to 1975 . Therefore, the cohorts that reached drinking age in this period form a unique group. It was already known from surveys in the 1970 s and early 1980 s that the increase among young people, especially young men, had been higher than in other age categories. At the same time, officials from treatment centers made mention in the press of an increase in the number of older clients. The aim of this chapter is to investigate the possibility that this age-cohort would remain at a relatively high consumption level, relative to older cohorts, which would lead to an increase of alcohol related problems among the elderly in the near future. This would confirm the concerns of treatment officials. Skog's social interaction theory is used as an interpretative framework: to the extent that cohorts of men and women show separate developments in drinking behavior over time, they can be considered as separate 'drinking cultures'. All analyses are presented separately for men and women, in order to account for gender differences in the cohort analysis results.

Chapters 3 and 4 report on work that was not included in the original project description, but emerged in the course of the study. Both chapters are concerned with gender differences in drinking behavior. Chapter 3 reports on an analysis of repeated surveys (the same data as were used in chapter 2), which was conducted in order to test the socalled "convergence hypothesis". This hypothesis holds that as women 'become more like men' in many respects, such as in social positions, they will also become more like men with respect to less desired sides of life, such as crime and substance use and abuse. It was originally intended to follow the cohort framework as in chapter 2 , but
cohort differences appeared insignificant and thus were not reported.

Chapter 4 extends the role theoretical framework adopted in chapter 3 with gender role attitudes as an explanatory variable in the analysis of gender differences in drinking behavior. Contrary to the former two chapters, this chapter is based on cross- 
sectional analyses. The rationale for this analysis is based on the idea that if the convergence hypothesis holds, when gender differences in drinking behavior decrease as a result of the emancipation process of women, it should also be true that this process would be stronger among categories of the population who belief that women and men should be more equal. In cross-sectional terms: gender differences should be smaller among groups holding more 'egalitarian' views with respect to gender roles. Thus, chapter 4 investigates the effect of attitudes towards traditional gender roles on drinking behavior, both independently as well as in combination with gender effect. Status and positions roles are included in the analyses.

In chapter 5 , the emphasis returns to role analysis. This chapter builds most directly on the work of Knibbe, who first introduced the 'positional role' and 'structure of everyday life' concepts in alcohol research. In this chapter, this approach is extended in a longitudinal study. Knibbe showed that the occupation of positional roles has effect on drinking behavior and on the relationship between consumption and alcohol related problems. In chapter 5 , it is investigated whether this relationship holds when changes in roles (role transitions) are considered. Special attention is given to differences between age categories or generations. Given the available data, the analysis is restricted to the 'traditional' social demographic variables concerning work, marital status and parental status (having children at home). The chapter investigates whether the relationships are homogeneous across age groups and what can be done to improve and extend role analysis, especially for the older age categories.

Chapters 6 and 7 report on a study of age differences in drinking behavior and type and severity of problems among problem drinkers in treatment, or "alcoholics" as they are denoted in these chapters. Due to practical reasons, only male respondents are included in the study. Two age groups of alcohol clients of a provincial addiction treatment agency were compared: the older age group was defined as over 50 years of age, the cut-off points for the "younger" groups were chosen between 35 and 45 years of age. The latter group forms the "modal' age groups in treatment agencies in the Netherlands. Chapter 6 reports on type and severity of drinking problems and treatment careers in both groups. Chapter 7 compares drinking careers of male alcoholics over 50 years of age with those from the modal age category $35-45$. The drinking career is assessed with the Lifetime Drinking History (LDH), a retrospective interview. Starting with the first drinking experience, the drinking career is reconstructed across the entire life course. The respondent is invited to connect changes in drinking behavior with role transitions and other life changes (in this chapter denoted as 'life events'). Comparisons are made with respect to the development in alcohol consumption, onset of heavy drinking and onset of risky drinking styles such as solitary drinking and morning drinking. Special attention is paid to the issue of early versus late onset among older alcoholics. 


\section{References}

Adriaansens, H.P.M. (1983) Algemene sociologie, "s Gravenhage: Vuga.

Adriaansens, H.P.M. (1980) Talcor Parsons and the conceptual dilemma, London: Routledge.

Akerlind, I. and Hornquist, J.O. (1992) Loneliness and alcohol abuse: A review of evidences of an interplay, Social Sctence and Medicine, 34, 405-414.

Atkinson, RM. (1990) Aging and alcohol use disorders: diagnostic issues in the elderly, International Psychogeriatirics, $2,55,72$.

Bales, R.F. Cultural differences in rates of alcoholism. Quarterly Journal of Studies on Alcohol, 6, 480-499.

Blacker, E. (1966) Sociocultural factors in alcoholism. Int. Psychiat. Clin. 3(2) 51-80.

Boudon, R. (1981) The logic of social action: an introduction to sociological analysis, London, Routledge.

Boudon, R. (1996) The "cognitivist model", a generalized 'rational-choice' model, Rationality and Society 8(2), 123-150.

Bourdieu, P. (1980) Le capital social. Notes provisiores [The social capital. Preliminary notes] Actes de la Recherche en Science Sociales

Cahalan, D. (1970) Problem drinkers. San Fransisco: Jossey Bass.

C.B.S. (1994) 95 jaar statistiek in tijdreeksen, s'Gravenhage: Centraal Bureau woor de Statistiek. Coleman, J.S. (1988) Social capital in the creation of human capital. American Journal of Sociology 94: supplement $s 95-s 120$.

Coleman, J. S. (1990) Foundations of social theory. Cambridge: Belknap Press.

De Jong-Gierveld, $J_{n}$ and Ljefbroer, A.C. (1992) Een verkenning van de invloed van weranderingen in opleidingsdeelname en arbeidsparticipatie op het demografische gedrag van vrouwen, In: Bronsema, H.J. and Van der Erf, R.F. (Eds.) Emancipatie en bevolkingsontwikkeling: hechte partmers?" pp. 1-17. "s Gravenhage: Nederlandse Vereniging voor Demografie.

Fillmore, K.M. (1987) Women's drinking across the adult life course as compared to men's, British Journal of Addiction, 82, 801-811.

Fillmore, K.M. (1988) Alcohol Use Across the Life Course, Toronto: Addiction Research Foundation. Finney, J.W. and Moos, R.H. (1984) Life stressors and problem drinking among older adults, Recent Developments in Alcoholism, 2, 267-288.

Finney, J.W. and Moos, R.H. (1995) Entering treatment for alcohol abuse: a stress and coping model, Addiction, 90, 1223-1240.

Gadourek, I. (1963) Riskante gewoonten en zorg voor eigen welzijn (Groningen, J.B. Wolters). Gadourek, L. (1996) Gedrag en handeling in de sociollogie, enkele beschouwingen over de sociologie als sociale en als gedragswetenschap, In: H. Ganzeboom en S. Lindenberg (Eds) Verklarende sociologie, opstellen voor Reinhard Wippler, Amsterdam. Thesis Publishers.

George, L.K. (1993) Sociological perspectives on life transitions, Anmad review of sociology, 19 , $353-373$.

Gerhardt, U. (1971) Rollenanalyse als kritische Soziologie, Berlin: Luchterhand.

Glenn, N.D. (1977) Cohori analysis, Beverly Hills: Sage.

Gomberg, E.L. (1985) Gerontology and alcohol studies, in: Gottheil, E., Druley, K.A., Skoloda, T.E. \& Waxman, H.M. (eds.) The Combined Probiems of Alcoholism, Drug Addiction and Aging, pp. 51 73 (Springfield, Ii, Chas. C. Thomas).

Gruenewald, P.J., Treno, A.J., Nephew, T.M., and Ponicki, W.R. (1995) Routine activities and alcohol use: constraints on outlet utilization, Alcoholism: Clinical and Experimental Research, 19(1), $44-53$.

Hagenaars, J.A.P. (1977) Leeftijd, Kohort en Periode: een algemeen model voor de analyse van sociale veranderingen, Sociale Wetenschappen, 20, 32-64.

Hartley, R.E. (1970) American core culture: changes and contimuities. Pp. 126-149 in: G.H. Seward and R.C. Williamson (eds.) Sex roles in changing saciety. New York: Random House.

Held, T. (1986) Institutionalization and de-institutionalization of the life course. Human Development, $29(3), 157-162$. 
Hooghiemastra B.T.J., and Niphuis-Nell, M. (1993) Social allas van de vrouw, deel 2: Arbeid. inkomen en faciliteiten om werk en de zorg voor de kinderen te combineren, Den Haag: VUGA. Knibbe, R.A. (1982) Probleemdrinken in Limburg. Maastricht: Rijksuniversiteit Limburg. Knibbe, R.A. (1984) Van gangbaar tot problematies drankgebraik, dissertation. Maastricht: Rijksuniversiteit Limburg.

Knibbe, R.A., Drop, M.J., Van Reek, J., and Saenger, G. (1985) The development of alcohol consumption in the Netherlands, 1958-1981, British Joumal of Addiction, $80,411-419$.

Knibbe, R.A., Drop, M.J. and Muytjens, A. (1987) Correlates of stages in the progression from everyday drinking to problem drinking. Social Science and Medicime, 24(5), 463-473.

Kohli, M. (1985) The World We Forgot: A Historical Review of the Life Course. In V.W. Marshall (Ed.), Later Life, Beverly Hills: Sage.

Kohli, M. (1986) Social organization and subjective construction of the life course. In A.G. Sörensen, F.E. Weinert, \& L.R. Sherrod (Eds.), Human development and the life course: Multidisciplinary perspectives (pp. 271-292). Hillsdale, NJ: Erlbaum.

Lindenberg, S. (1992) The explanation of preferences. In: Van Goor, $\mathrm{H}_{.}$(Ed.) Empirische Sociologie als Opdracht, pp. 49-66, Groningen: MB Boek.

Merton, R.K. (1976) Sociological Ambivalence and Other Essays, New York: the Free Press.

Merton, R.K. (1984) Socially expected durations: I. A case study in concept formation in sociology. In: W.W. Powell and R. Robbins (Eds) Conflict and consensus: a festschrift for Lewis A. Coser, New York: Free Press.

Moos, R.H. (1995) Development and applications of new measures of life stressors, social resources, and coping responses, European Journal of Psychological Assessmemt, 11, 1-13.

Parsons, T. and E.A. Shils (Eds.) (1951) Towards a general theory of action, Cambridge, MA. P.G.D. (Productschap voor Gedistilleerde Dranken) (1995) World Drink Trends, Henley-on-Thames, NTC Publications.

Philipsen, H. (1976) Maatschapij en verslaving. Cahiers voor Biowetenschappen, 3, 25-31.

Pohorecky, L.A. (1991) Stress and alcohol interaction: an update of human research. Alcoholism:

Clinical and Experimental Research, 15(3): 438-59

Room, R.(1976) Ambivalence as a sociological explanation. American Sociological Review, 41, $1047-1065$.

Room, R. (1977) Measurement and distribution of drinking patterns and problems in general populations, In: Edwards, G., Gross, M.M., Keller, M., Moser, J. and Room, R. (Eds), AlcoholRelated Disabilities, WHO Offset publication no. 32, Geneva.

Rossi, A.R. (1985) Gender and the life course, New York: Aldine Publ Co.

Ryder, N.B. (1965) The cohort as a concept in the study of social change, American Sociological Review, 30, 843-861.

Skog, O.-J. (1980) Social interaction and the distribution of alcohol consumption, Journal of Drug Issues, $10,1,79-92$.

Skog, O-J. (1985) The Collectivity of Drinking Cultures: a Theory of the Distribution of Alcohol Consumption, British Journal of Addiction, 80, 83-99.

Skog, O-J. (1995) Public health consequences of the J-curve hypothesis of alcohol problems, paper presented at the 21 st Annual Alcohol Epidemiology Symposium, Porto, Portugal, June 3-9, 1995. Sociaal en Cultureel Planbureau (SCP) 1996. Sociaal en Cultureel Rapport 1996, Rijswijk: SCP. Turner, J.H. (1991) The structure of sociological theory, Fifth Edition, Bellmont, Ca: Wadsworth. Turner, R.H. (1968) Role: saciological aspects. In: International Encyclopedia of the Social Sciences, 13: 552-557. New York: Macmillan and Free Press.

Turner, R.H.(1990) Role change. Annual review of Saciology, 16, 87-110.

Tijhuis, M.A.R. (1994) Social networks and health, Utrecht: Nederlands Instituut voor onderzoek van de eerstelijnsgezondheidszorg (NIVEL).

Van Gelloowen, R.M.W. (1990) Drinksituaties en drinkgedrag, alcoholgebruik in her dagelijs leven. Maastricht: Rijksuniversiteit Limburg.

Van Leeuwen, L.Th. \& Ploegmakers, M.J.H. (1990) Patronen in de individuele levensloop, een verkennende studie. Den Haag: Nederlandse Gezinsraad. 
Wilsnack, R.W. (1992) Unwanted statuses and women's drinking, Joumal of Employee Assistance Research $1,239-270$. 


\title{
Developments in drinking behavior in the Netherlands from 1958 to 1989 , a cohort analysis.
}

\author{
Rudie J.M. Neve, Joseph P.M. Diederiks, Ronald A. Knibbe, Maria J. Drop. \\ Reprinted with permission from Addiction, Vol. 88, pp. 611-621, 1993 \\ Copyright by Carfax Publishing Ltd., Abington, UK
}

\begin{abstract}
Alcohol consumption in the Netherlands increased at a very fast rate from 1960 to 1975, especially among young men. The question is raised whether members of the cohort that started drinking during the 1960s show a lasting deviation from earlier born cohorts with respect to drinking behavior. Cohort analysis is used to assess the effects of aging, period and cohort membership on changes in abstinence, mean consumption and heavy drinking in the Netherlands in the last three decades. Social interaction theory (Skog, 1980) is used as an interpretative framework. Conclusions are that abstinence is related to aging, while mean consumption and heavy drinking are associated with period effects. Populations of men and women appear to change drinking behavior collectively. Results on women are more regular than those on men.
\end{abstract}

\subsection{Introduction}

In most countries of the industrialized world, consumption of alcoholic beverages has increased substantially since 1960 . In the Netherlands, per capita consumption increased from 2.8 liters per year in 1961 to 8.7 liters in 1975 (PGD, 1990). According to De Lint (1977), who compared 25 countries, the Netherlands showed the highest increase in per capita consumption. Among younger people, especially young men, the increase in alcohol intake between 1960 en 1970 was even stronger than in other subpopulations, as population surveys have shown (Knibbe et al., 1985). As a result, cohorts that reached drinking age in the Netherlands in the 1960s form a unique group with respect to socialization in drinking in a period of rapidly increasing consumption. The question arises, what consequences this might have in later life stages of these cohorts, who are now appróaching midd]e age. If higher consumption levels last into adulthood and old age, one would expect an increase in alcohol related problems among the elderly in the near future. It is known that chronicity of drinking problems is higher in older age groups (Fillmore and Midanik, 1984). In the light of demographic changes that are taking place, the question of stability or change of drinking patterns over the life course becomes even more urgent. According to the Dutch Central Bureau of Statistics, the percentage of people over 65 years old in the Dutch population will double from $12 \%$ in 1990 to $24 \%$ in 2035 (Leering and Lerou, 1990). Assuming about similar prevalence in the future, this increase in the percentage of older people is enough in itself to cause an increase in the number of older problem drinkers. Specific trends in certain cohorts would add to this increase. 
In the alcohol research literature, it is generally assumed that aging is associated with a decrease in alcohol consumption and related problems. Results of longitudinal research mostly are in agreement with this assumption. In a meta analysis of longitudinal studies from different countries, covering different periods, Fillmore (1988) shows a negative association between aging and the prevalence and incidence of 'unwanted drinking behaviors'. However, the form of the relationship between aging and drinking variables (the age curve) seems to vary across different cultures, periods and birth cohorts. Several authors report variability of drinking behavior across cohorts or generations; both terms being used interchangeably to denote groups of people born in a certain time interval (Meyers et al., 1981; Fitzgerald and Mulford, 1983; Glynn et al., 1985). It is concluded from analysis of U.S. general population surveys, that a cohort effect might have occurred in men under 50 years old during the $1960 \mathrm{~s}$ and $1970 \mathrm{~s}$ (Fillmore, 1987). Higher prevalence of heavy drinking in these cohorts, compared with earlier cohorts, is attributed to an increase in per capita consumption in the period when the members reached drinking age. However, through what mechanism increasing per capita consumption in youth is related to higher prevalence of heavy drinking in later life of a cohort remains unclear.

In clarifying this mechanism, two aspects must be distinguished. Firstly, it should be asked what meaning increasing alcohol consumption in a certain period has to those who reach drinking age at the same time. Secondly, it should be made clear how this meaning, once it is attached to alcohol consumption, affects drinking behavior in later life stages. Moreover, it should be considered that increasing per capita alcohol consumption is not entirely external to those who reach drinking age; on the contrary, they are part of it and they contribute to it.

A possible explanation for a cohort effect can be found in 'social interaction theory' (Skog, 1980). According to this theory, interaction between people in interconnected social networks leads to reciprocal influence of drinking behavior throughout society. 'Exogenous' stimuli, such as changes in the price of beverages, media campaigns, or other economic or cultural changes, will lead some people to change their alcohol consumption. Those individuals who increase consumption will subsequently influence their friends to do the same. Social pressure will be highest on those individuals who deviate most strongly from the current trend in the group, which eventually leads to convergence in alcohol consumption. When exogenous stimuli are strong enough and social networks are interconnected to a large extend, changes in drinking behavior will spread to the entire culture. Eventually, entire societies, considered as enormous social networks, will 'move more or less in concert up and down the consumption scale', which phenomenon is called the 'collectivity of drinking cultures' (Skog, 1985). This theory also predicts that an increase in per capita consumption does not affect the rank order of consumption, since the individual increase of consumption will be proportional to the initial consumption. Therefore, an increase in consumption level will lead to an even larger increase in the percentage of 'heavy' drinkers, when this group is defined in terms of a fixed quantity of alcohol per time unit. Although in Skog's treatment the unit of analysis is the national state, it is certainly possible to compare subpopulations within countries with respect to drinking behavior and social 
networks. To the extend that the social networks of different groups are separated from each other, such groups constitute different 'drinking cultures'.

Variability of drinking behavior across cohorts can thus be interpreted as a product of segmentation of their social networks. As a result, exogenous stimuli that change drinking behavior will affect drinking behavior of cohorts differently, and not all stimuli will eventually cause change in behavior in the entire population.

Cohorts born after 1940 attracted sociologists' attention because of crucial differences in social and cultural circumstances, compared with preceding cohorts, during their formative years (Ryder, 1965). Economic prosperity and educational possibilities had become a matter of course and norms and values were loosened (Inglehart, 1977, 1990). New life-styles and in particular patterns of leisure activities, which also involved new drinking situations, emerged among the new generation. This 'endogenous' stimulus, stemming from characteristics of the group itself, probably has increased alcohol consumption in young people. The relative lack of contacts between younger and older people that resulted from the then experienced 'generation gap', may have prevented the diffusion of new drinking styles in older people. On the other hand, economic prosperity and relatively low prices of alcoholic beverages constitute an exogenous factor that may have influenced the entire population. Still, a specific cohort effect on drinking behavior may have occurred when the development in a cohort deviates lastingly from that in cohorts born earlier and that little interconnection exists between the networks of older and younger cohorts. Through exogenous and endogenous stimuli and mutual influence a specific 'drinking culture' can grow within a cohort.

In order to prove that this mechanism has occurred within a cohort, one would need longitudinal data, in which changes in drinking behavior on the individual level are related to changes within subpopulations and in the entire population.

In a Dutch longitudinal study on changes in alcohol consumption in a cohort of older men (between 40 and 60 years old in 1960) from the town Zutphen findings were mostly in accordance with the theory of collectivity of drinking cultures (Knibbe et al. 1988). From 1960 to 1985 (measurement points were $1960,1965,1970$ and 1985), consumption in this cohort of men increased by amounts that are close to the increase in per capita consumption. Large shifts in the composition of percentile categories appeared to be rare. The increase of the proportion in the highest consumption category was higher than the increase in average consumption. The authors conclude that the Zutphen cohort changed drinking habits collectively. Since all respondents in the Zutphen cohort study are born between 1900 and 1920 , no conclusions are allowed concerning cohort effects.

When results of analyses similar to those on the Zutphen cohort are compared across cohorts, it could be decided whether cohorts can be considered as separate 'drinking cultures'. In such an analysis, a base line hypothesis would state that the population of the Netherlands as a whole is one drinking culture, that is, that no difference across cohorts exists. When this null hypothesis holds, changes in drinking behavior should be explained either by aging or by period effects or by a combination of both aging and period effects. Unfortunately, individual level longitudinal data on 
multiple cohorts with more than two measurement points, covering the cohort of our interest (i.e. those who reached drinking age in the 1960 s in the Netherlands), are not available. For this reason, we had to rely on survey data to find an answer to our research question. Compared with individual level longitudinal data, the major drawback of survey data is that analyses can not go beyond the aggregate level. At present, survey data are available covering a period of 30 years, which allow following multiple cohorts in time on the aggregate level.

Our research question can now be formulated more clearly.

a. Does the cohort that reached drinking age in the 1960 s, a period in which patterns of higher consumption became prevalent, deviate from earlier birth cohorts with respect to changes in time of the following aspects of drinking behavior: abstinence, mean alcohol consumption and heavy drinking?

b. Are changes in drinking behavior within cohorts attributable to aging or to period effects or to a combination of both?

c. If any association of drinking behavior with aging exists, does this association vary across cohorts born before and after 1940 ?

\subsection{Methods.}

Data. Samples of the Dutch adult population (ages 21 to 70) were interviewed on, among other things, alcohol consumption in 1958 (Gadourek, 1963), 1970 (Jessen, 1974), 1981 (Adriaanse et al., 1981), 1985 (Lemmens, Tan and Knibbe, 1988) and 1989 (Swinkels, 1991). All data are weighted for age, sex and marital status. Number of respondents, effective response rates and underestimation of alcohol consumption in the surveys are reported in table 2.1.

Lemmens, Tan and Knibbe (1988), in a follow-up study among non-respondents in the 1985 survey, conclude that the danger of biased results due to non-response is small. We assume that this conclusion applies to other surveys as well, and that differences in response rates across the surveys do not affect the validity of our results.

Table 2.1. Number of respondents, response rate and underestimation of alcohol consumption in surveys used in the presented research. Data weighted by sex, age and marital status.

\begin{tabular}{lrrrrr}
\hline Year & 1958 & 1970 & 1981 & $1985^{\circ}$ & 1989 \\
\hline N & 1133 & 1524 & 1272 & 1145 & 5287 \\
$\begin{array}{l}\text { Response \% } \\
\text { Per Capita sales (PGD, 1990) }\end{array}$ & 78 & 85 & 73 & 69 & 58 \\
(glasses per week) & 4.94 & 11.6 & 17.29 & 16.21 & 15.8 \\
$\begin{array}{l}\text { Reported consumption } \\
\text { (mean glasses per week) }\end{array}$ & 2.23 & 6.23 & 7.91 & 9.51 & 8.1 \\
Underestimation \% & 55 & 46 & 54 & 41 & 49 \\
& & & & & \\
Data on 1985 were used for reference purposes only. & & & & \\
\hline
\end{tabular}


In order to obtain comparable time intervals between measurements points, data on 1985 were omitted in the cohort analysis and used for reference purposes only. In this survey, multiple measurement methods were included in order to investigate underestimation of consumption in survey research (Lemmens, Knibbe and Tan, 1988; 1992).

All analyses were conducted separately on men and women. In order to obtain more precise estimates on drinkers, abstainers were excluded from all analyses on data concerning mean consumption and heavy drinking.

Comparability of operationalizations. In all surveys questions were asked about abstinence and weekly intake of alcohol. No period was specified in which respondents should have abstained from alcohol in order to be classified as abstainer, except for the 1985 survey, in which a period of six months was specified. In 1958, those who answered 'never' on the question 'Do you drink at regular times?' were labeled abstainers. In 1970 and 1981, respondents were asked if they ever drink alcohol in a separate question. In 1989, those who answered 'none' on the question 'what kind of beverage do you usually drink' were labeled abstainers.

Three different operational definitions of weekly consumption have been used over the years. In 1985 all three operationalizations were used. To measure weekly alcohol consumption, a version of a 'weekly recall' (WR) measurement was used in 1958 and 1981. In this index, the number of glasses consumed at any of the days of the week preceding the interview is assessed. In 1958 a categorization was used, in which those reporting 22 glasses or more (1.8\%) form the highest category. In 1970 respondents were asked how many glasses of alcohol they usually consumed per week, a measure known as 'Typical consumption' (T). In 1989, a Quantity-Frequency (QF) index measure was computed from the number of drinking occasion per week and the average number of drinks per occasion.

In the 1985 data, these three indices used appeared to correlate highly $(r>.7)$. We also assessed the degree in which differences in measurements are associated with age of respondents at a certain moment. Variability according to age of the three indices appeared quite similar. The results of these analyses, which are not presented here, lead us to conclude that the risks taken by using different operational definitions of alcohol consumption remain within acceptable limits.

For the purpose of this study, men drinking more than 21 glasses or more weekly are considered heavy drinkers. Only very few women drink more than 21 glasses per week, reason why in women the cut-off point is set at 14 glasses. The cut off points are chosen for ease of interpretation, also in terms of daily consumption, and because in the 1958 survey the questioning makes a cut off point higher than 21 meaningless, since consumption of 22 glasses and more is not differentiated.

Background variables education, religion and marital status are present in all four surveys.

Analysis. In order to answer our research question, the effects of age and cohort must be separated analytically from period effects. A cohort analysis was performed, 
The results on men are more irregular. Although the percentages are lower than in women, the cross-sectional association of age and abstinence resembles that in women up to age category 51-60 in 1970, 1981 and 1989. Compared with men in their fifties, the oldest age group (ages 61 to 70) has lower percentages of abstinence in 1981, while in 1958 their is hardly any relationship between age and abstinence at all. Considering the possibility of an association of abstinence with cohort membership in men, the diagonals of the left part of table 2.2 are compared. It is likely, that decreasing abstinence in the youngest cohorts (born in the 1940s and 1950s) between 1981 and 1989 is in part due to questioning. In the cohorts born in the 1900 s and in the $1920 \mathrm{~s}$, an increase of abstinence in time could be due to aging, but it is absent in cohorts born in the 1910s and after 1930. On the whole, the interpretation that abstinence increases as the members get older seems to fit the data slightly better than an interpretation in the direction of cohort succession.

Table 2.3. Mean consumption per week (glasses), weighted N's and decade of birth by age and period of men and women. Data weighted by sex, age and marital status

\begin{tabular}{|c|c|c|c|c|c|c|c|c|}
\hline \multirow[b]{2}{*}{ Age } & \multicolumn{4}{|c|}{ Men } & \multicolumn{4}{|c|}{ Women } \\
\hline & 1958 & 1970 & 1981 & 1989 & 1958 & 1970 & 1981 & 1989 \\
\hline $21-30$ & $\begin{array}{l}5.0 \\
1.29 \\
30 \mathrm{~s}\end{array}$ & $\begin{array}{r}15.4 \\
186 \\
40 \mathrm{~s}\end{array}$ & $\begin{array}{r}14.0 \\
157 \\
50 \mathrm{~s}\end{array}$ & $\begin{array}{r}12.9 \\
612 \\
60 \mathrm{~s}\end{array}$ & $\begin{array}{r}1.5 \\
114 \\
30 \mathrm{~s}\end{array}$ & $\begin{array}{l}4.9 \\
154 \\
40.5\end{array}$ & $\begin{array}{l}5.2 \\
141 \\
505\end{array}$ & $\begin{array}{l}5.6 \\
540 \\
60 \mathrm{~s}\end{array}$ \\
\hline $31-40$ & $\begin{array}{l}3.3 \\
115 \\
20 s\end{array}$ & $\begin{array}{r}10.6 \\
131 \\
30 \mathrm{~s}\end{array}$ & $\begin{array}{r}12.7 \\
152 \\
40 \mathrm{~s}\end{array}$ & $\begin{array}{r}14.1 \\
586 \\
50 \mathrm{~s}\end{array}$ & $\begin{array}{l}1.8 \\
105 \\
20 \mathrm{~s}\end{array}$ & $\begin{array}{r}4.3 \\
93 \\
30 \mathrm{~s}\end{array}$ & $\begin{array}{l}7.6 \\
126 \\
40 \mathrm{~s}\end{array}$ & $\begin{array}{l}6.8 \\
498 \\
50 \mathrm{~s}\end{array}$ \\
\hline $41-50$ & $\begin{array}{l}3.2 \\
100 \\
10 \mathrm{~s}\end{array}$ & $\begin{array}{l}8.8 \\
113 \\
20 s\end{array}$ & $\begin{array}{r}14.5 \\
117 \\
30 \mathrm{~s}\end{array}$ & $\begin{array}{r}14.5 \\
470 \\
40 \mathrm{~s}\end{array}$ & $\begin{array}{r}1.5 \\
97 \\
10 \mathrm{~s}\end{array}$ & $\begin{array}{r}4.3 \\
98 \\
20 \mathrm{~s}\end{array}$ & $\begin{array}{r}6.8 \\
92 \\
305\end{array}$ & $\begin{array}{l}9.0 \\
422 \\
40 s\end{array}$ \\
\hline $51-60$ & $\begin{array}{r}4.0 \\
84 \\
1900 \mathrm{~s}\end{array}$ & $\begin{array}{r}9.7 \\
91 \\
10 \mathrm{~s}\end{array}$ & $\begin{array}{r}11.1 \\
80 \\
20 \mathrm{~s}\end{array}$ & $\begin{array}{r}12.6 \\
331 \\
305\end{array}$ & $\begin{array}{r}1.4 \\
78 \\
1900 \mathrm{~s}\end{array}$ & $\begin{array}{r}3.4 \\
85 \\
10 \mathrm{~s}\end{array}$ & $\begin{array}{r}6.0 \\
56 \\
205\end{array}$ & $\begin{array}{l}8.0 \\
250 \\
30 \mathrm{~s}\end{array}$ \\
\hline $61-70$ & $\begin{array}{r}2.4 \\
56 \\
1890 \mathrm{~s}\end{array}$ & $\begin{array}{r}5.3 \\
64 \\
1900 \mathrm{~s}\end{array}$ & $\begin{array}{r}10.4 \\
48 \\
10 \mathrm{~s}\end{array}$ & $\begin{array}{r}11.8 \\
239 \\
20 s\end{array}$ & $\begin{array}{r}1.8 \\
41 \\
1890 \mathrm{~s}\end{array}$ & $\begin{array}{r}2.6 \\
61 \\
1900 \mathrm{~s}\end{array}$ & $\begin{array}{r}5.6 \\
38 \\
10 s\end{array}$ & $\begin{array}{l}7.7 \\
187 \\
20 \mathrm{~s}\end{array}$ \\
\hline Total & $\begin{array}{l}3.7 \\
484\end{array}$ & $\begin{array}{r}11.1 \\
584\end{array}$ & $\begin{array}{r}13.0 \\
553\end{array}$ & $\begin{array}{r}13.4 \\
2238\end{array}$ & $\begin{array}{r}1.6 \\
435\end{array}$ & $\begin{array}{l}4.1 \\
585\end{array}$ & $\begin{array}{l}6.3 \\
455\end{array}$ & $\begin{array}{r}6.5 \\
1897\end{array}$ \\
\hline
\end{tabular}




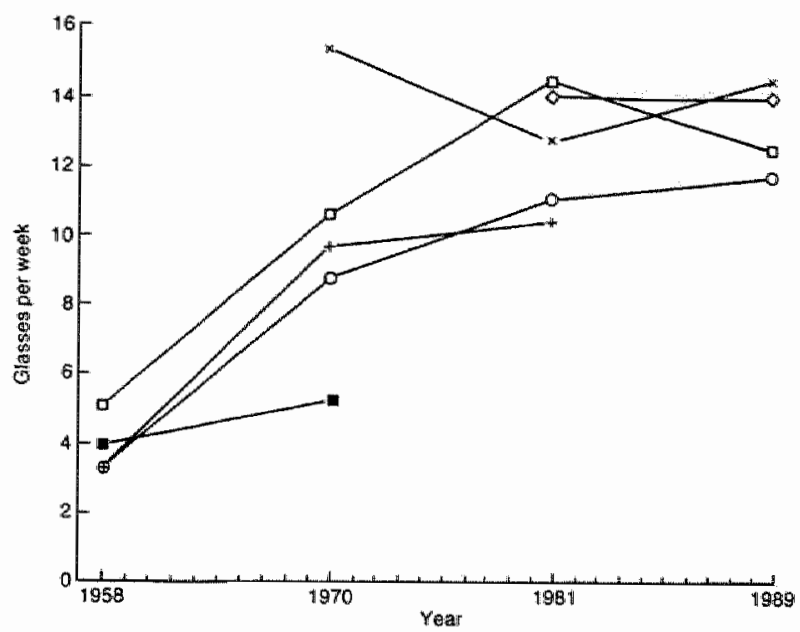

Figure 2.1 Mean alcohol consumption by year in six birth cohorts of men, abstainers excluded.

(a 1900s; + 1910s; o 1920s; $\square$ 1930s; X 1940s; $\diamond 1950 \mathrm{~s})$

Mean consumption. As could be expected, the data reflect the increase in per capita alcohol consumption. Table 2.3 presents the mean consumption of men and women by age and period. Comparison of the cross-sectional data for men in the columns of table 2.3 shows little association of age and mean consumption, except for 1970, in which year the negative association is statistically significant $(F=8.09, p<.001)$. This association of consumption with age in 1970 was reconfirmed when analysis of variance was repeated, controlling for education, religion and marital status (not reported here). The patterns in most cohorts resemble each other very closely, except for the cohorts born between 1900 and 1910 and in the 1940s. The latter cohort shows the highest consumption in 1970, when its members were between 20 and 30 years of age. In 1981 and 1989 men of the cohort born in the 1940s seem to have joined again the 'main stream' of the development in drinking in the Netherlands (diagonals table 2.3, graphed in figure 2.1).

Women still drink much less than men in all categories. Male to female ratios (not presented) show a somewhat decreasing tendency after 1970, especially in the older age groups. In women period effects seem to have determined the drinking patterns even more strongly than in men, as the right side of table 2.3 indicates. Within the cohorts, the association of age and alcohol consumption is almost linear. It is interesting, that across cohorts the developments are parallel to each other. From the viewpoint of cohort analysis, this indicates a 'pure' period effect. The increase of consumption within the cohorts continues even after 1981, when per capita consumption had 
largely stabilized. Age variation in the columns is small. In 1989, the youngest women drink less than those of over 40 years of age.

Data on heavy drinking closely resemble those on mean weekly consumption, except that differences across age groups and periods seem to be larger in the highest consumption category than in mean consumption (table 2.4). In order to assess the association between both variables, we plotted the percentage heavy drinkers against the mean consumption of the 40 subpopulations from the cohort tables, including all age groups of both men and women. In separate analyses, percentages drinking more than 14 glasses and percentages drinking more than 21 glasses were regressed on mean consumption. In both cases, a quadratic curve fits these points very well: $Y=$ $.098 \mathrm{X}^{2}, \mathrm{R}^{2}=.94$, in which $\mathrm{Y}$ denotes the percentage of people drinking more than 21 glasses and $\mathrm{X}$ is the mean weekly consumption in the group. Regression of the percentage drinking more than 14 glasses on the average consumption in the 40 groups resulted in a best fitting curve $Y=.19 \mathrm{X}^{2}$, explaining $R^{2}=.97$ of the variance between the groups. These results indicate a strong regularity of the association between the average consumption in a subpopulation and the percentage of drinkers in the highest category, regardless of the cut-off point.

Table 2.4. Percentage heavy drinkers, weighted N's and decade of birth by age and period of men and women. Data weighted by age, sex and marital status.

Men (21+) Women (14+)

\begin{tabular}{lrrrrrrrr}
\hline Age & 1958 & 1970 & 1981 & 1989 & 1958 & 1970 & 1981 & 1989 \\
\hline $21-30$ & 4.4 & 17.7 & 25.6 & 15.3 & 0.8 & 7.3 & 11.8 & 6.0 \\
& 129 & 186 & 157 & 612 & 114 & 154 & 141 & 540 \\
& $30 \mathrm{~s}$ & $40 \mathrm{~s}$ & $50 \mathrm{~s}$ & $60 \mathrm{~s}$ & $30 \mathrm{~s}$ & $40 \mathrm{~s}$ & $50 \mathrm{~s}$ & $60 \mathrm{~s}$ \\
$31-40$ & 1.7 & 13.4 & 17.3 & 17.1 & 0.9 & 7.0 & 10.9 & 10.9 \\
& 115 & 131 & 152 & 586 & 105 & 93 & 126 & 498 \\
& $20 \mathrm{~s}$ & $30 \mathrm{~s}$ & $40 \mathrm{~s}$ & $50 \mathrm{~s}$ & $20 \mathrm{~s}$ & $30 \mathrm{~s}$ & $40 \mathrm{~s}$ & $50 \mathrm{~s}$ \\
$41-50$ & 2.3 & 10.6 & 26.8 & 20.1 & 2.0 & 5.7 & 12.2 & 17.8 \\
& 100 & 113 & 117 & 470 & 97 & 98 & 92 & 422 \\
& $10 \mathrm{~s}$ & $20 \mathrm{~s}$ & $30 \mathrm{~s}$ & $40 \mathrm{~s}$ & $10 \mathrm{~s}$ & $20 \mathrm{~s}$ & $30 \mathrm{~s}$ & $40 \mathrm{~s}$ \\
$51-60$ & 2.4 & 8.8 & 11.8 & 12.3 & 2.4 & 4.0 & 9.0 & 13.0 \\
& 84 & 91 & 80 & 331 & 78 & 85 & 56 & 250 \\
& $1900 \mathrm{~s}$ & $10 \mathrm{~s}$ & $20 \mathrm{~s}$ & $30 \mathrm{~s}$ & $1900 \mathrm{~s}$ & $10 \mathrm{~s}$ & $20 \mathrm{~s}$ & $30 \mathrm{~s}$ \\
$61-70$ & 0.0 & 7.2 & 12.1 & 10.8 & 0.0 & 3.5 & 5.3 & 12.7 \\
& 56 & 64 & 48 & 239 & 41 & 61 & 38 & 187 \\
& $1890 \mathrm{~s}$ & $1900 \mathrm{~s}$ & $10 \mathrm{~s}$ & $20 \mathrm{~s}$ & $1890 \mathrm{~s}$ & $1900 \mathrm{~s}$ & $10 \mathrm{~s}$ & $20 \mathrm{~s}$ \\
Total & 2.4 & 12.8 & 20.4 & 15.9 & 1.3 & 5.8 & 10.8 & 11.5 \\
& 484 & 584 & 553 & 2238 & 435 & 490 & 455 & 1897
\end{tabular}


It is interesting though, that one of the cases that deviate most from the expectation in both regression analyses were men of ages 21 to 30 in 1970. Whether the cut-off point was 14 glasses or 21 , the percentage heavy drinkers observed in this group was lower than predicted. In 1981 and 1989 , the observed percentages in the cohort (born in the 1940s) deviate less from the prediction. Drinking behavior in the group of men of ages 21 to 30 in 1970 is distinguished from other groups by high mean consumption, combined with low dispersion. Apparently, many drinkers in this group consumed an amount of alcohol close to the mode, while in other categories more people are in the 'tail' of the distribution.

\subsection{Discussion.}

Before discussing our results, we will make a methodological comment. In order to answer our research questions, we used data on abstinence, mean consumption and heavy drinking that were analyzed in a straightforward and descriptive way. Analysis of variance was used to test the statistical significance of cross-sectional age variability in alcohol consumption and to include some background variables to control for demographic differences between age groups. We decided not to use more rigorous statistical methods of cohort analysis, such as 'APC-modeling' (Mason et al., 1973). Some of the problems that are involved in this method, such as the very strong assumptions that must be made, can be handled in practical research, as was shown by one of the authors (Neve, 1992). In the present case, however, the main reason not to use APC-modeling is that handling interaction effects is very problematic with this method (Glenn, 1976). Our research question concerns deviation of developments in younger cohorts from cohorts born earlier, which constitutes interaction of aging and period effects. We are convinced that careful interpretation of the cohort tables would have detected deviations in younger cohorts, had there been any, even without statistical rigor.

To conclude this article, we return to the research questions raised above. We discuss results on abstinence, mean consumption and heavy drinking respectively, and a remark is made concerning differences between men and women. Consequently, four issues are elaborated upon. Firstly, abstinence appears to be associated with the age of respondents, while no evidence was found for cohort or period effects. Secondly, no cohort effects were found in the analysis of developments in levels of alcohol consumption. The Dutch population as a whole to a large extend behaves collectively with respect to drinking behavior. Thirdly, developments in heavy drinking appear to be related strongly to those in mean consumption; results on both variables are very similar. Fourthly, while large differences in drinking behavior between men and women persist throughout the period covered, results on women show more regularity than those on men.

Abstinence is related with age; this association is stronger in women than in men. In every survey, more abstainers are found in older people than in younger people. No period or cohort effects were observed. Higher abstinence among older people is most probably a result of life cycle factors, such as changes in life style and in drinking 
norms among older people and higher vulnerability due to increasing health probless Our results differ from results of Finnish surveys reported by Sulkunen (1987), whes found evidence for the existence of a 'wet generation' with significantly lower levelts abstinence.

Analysis of the data on mean consumption levels shows little evidence for effectis. of aging and cohort membership. Both populations of men and women seem to chass consumption collectively. The increasing general trend in alcohol consumption is reflected in all groups. Events and developments during the period covered seem to have influenced alcohol consumption in all cohorts of men and women alike. Except in 1970 , little cross-sectional association was found between age category and meas: consumption. It should be noted, however, that a certain average weekly consumptiuts: in older people usually results from higher frequency of drinking, while in younger drinkers the amount consumed per occasion is higher than in older drinkers (Knibbe $\mathrm{al}, 1986$ ). Data on quantity and frequency of drinking in the Dutch population do not allow cohort analysis, since they were collected for the first time in 1985 .

Contrary to expectation, very high consumption of younger people in 1970, compared with 1958, did not result in a lasting deviation in the cohort born in the $1940 \mathrm{~s}$ from other cohorts. In later years, this cohort behaved mostly in concert with the population as a whole. After a decrease between 1970 and 1981, consumption of the cohort increased between 1981 and 1989, in which year it was the highest in ranking of alcohol consumption again. Differences from other cohorts in 1989 are relatively small, however, which leads us to conclude that the population of men as a whole ac as one drinking culture.

The increase of consumption in cohorts of women continued even after 1981, when the consumption of male drinkers had stabilized. Male to female ratios of consumption level are lowest in 1989. This raises the question, whether this indicates a trend towards convergence of men and women or rather as independent developroment of drinking behavot in both sexes. A posible explenation can be, that women through emancipation are molved in more drinking situations in recent years or, on the offer hand, that speciffe stimull affect women through their own networks.

Our resultw devate from earlier studies, in whel developments of drinking behav-

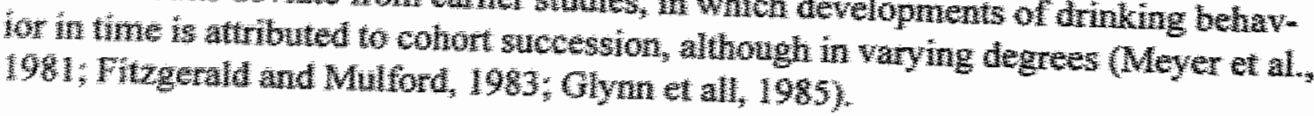

Results on heavy drinking appeared to resemble those on mean consumption. No systematic cohort or aging effects were observed. However, differences between
groups it prevalence of heavy drinking were stronger than in mean consumption. We
ftred a giudatic curve, which appears to be in a fitted a giuadratic curve, which appears to be in accordance with findings published by Brum at al. (1975) and by Skog (1985). The cohort bon in the 1940 s deviates from this general finding as prevalence in 1970 was lower than was to be expected from the exceptionaly high mean consumption. In later years, the observed proportion in the highest consumption category was closer to expectation. Men in their wenties in to deviate from other subpopulations with respect to mean consumption as well as 
dispersion of consumption. We suspect that these findings can be explained by speci fic social and cultural circumstances of the end of the 1960 s, which impact seems to have faded away in later years.

Results in women show more regularity than they do in men. The association of abstinence with age is more pronounced in women than in men. The increase in alcohol consumption among women is almost linear in all cohorts.

At this point, we cannot explain the higher regularity, compared to men, of drinking behavior in women. However, from the perspective of Skog's social interaction theory, it could be speculated that women are more than men susceptible to social pressure and more inclined to behave in accordance with social norms. Skog (1980) reviews findings from the literature, which suppont this interpretation. More research is needed on this issue.

To conclude, the alcohol consumption of drinkers, a stable proportion of the population of the Netherlands, appears not to be determined by either aging or cohort membership. On the whole, the collective behavior of drinkers seems to be largely determined by period effects. Diverse societal developments may have been of influence, such as the economic boom in the 1960 s and crisis in the 1970s, changes in norms and values that have taken place, the emergence of women's emancipation movements and the introduction of an alcohol reduction policy by the Dutch government in the course of the $1980 \mathrm{~s}$. At this point, we are not in the position to determine which events or developments in the past decades are behind the rise and subsequent stabilization of alcohol consumption in the Netherlands. Consequently, no reasonable predictions for the future can be derived from our results. Neither older age, nor later birth tell us very much about future alcohol use.

\section{Nererences:}

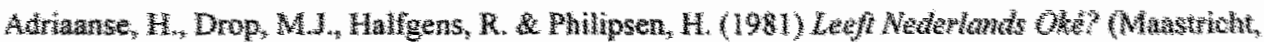
(1)

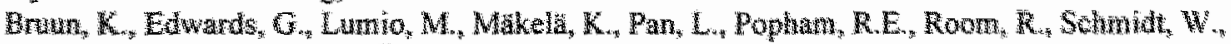

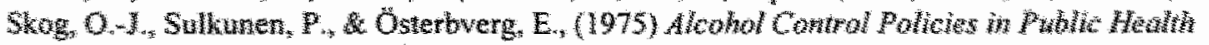
Ferspective (Kelsink, Finnish Foundation for Alcohol Studies).

De Lint. 1. (1977) Alcohol control policy as strategy of prevention: atrical examinten of the

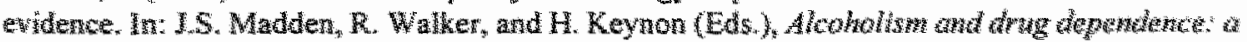
whilidisciphary approach Wew York Plenum Press).

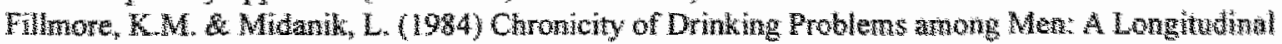
Stufy, Jowmal of Sudies on Alcohol, $45,3,228-236$.

Filmore, K. (1987) Prevalence, Incidence and Chronicity of Drinking Pattens and whishs

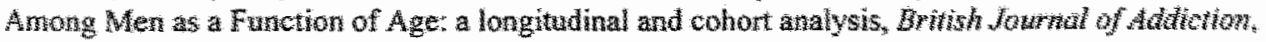
2, 77-83.

Finore, K.M., (1988) Alcahol Use Acrow the Life Cowrse (Toronto, Addiction Research Fondation.

Fitzgend, JL. \& Mutor, H.A. (1983) Maturatonal and Generational Changes in Drinking

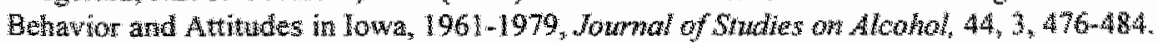

Gadourek, 1. (1963) Riskonte gewoonten en zorg woor ength welzin (Groningen, I.B. Wolters). 
Glenn, N.D. (1976) Cohont analysts' futille quest: statistical attempts to seperate age, period and cohort effects, American Sociological Review, 41, 900-908.

Glenn, N.D. (1977) Cohori Analysis (Beverly Hills and London, Sage Publications).

Glenn, N.D. (1981) Age, Birth Cohorts and Drinking: An Illustration of the Hazards of Inferring Effects from Cohort Data, Joumal of Gerontology, 36, 3, 362-369.

Glynn, R.J., Bouchard, G.R., Locastro, J.S. \& Laird, N.M. (1985) Aging and Generational Effects on

Drinking Behaviors in Men: Results from the Normative Aging Study, American Journal of Public

Heall $, 75,12,1413-1419$.

Inglehart, $\mathbb{R}$. (1977) The Silent Revolution, Changing Valwes and Political Styles among Western

Publics (Princeton, Princeton University Press).

Inglehart, R. (1990) Culture Shift in Industrial Society (Princeton, Princeton University Press).

Jessen, J.L. (1974) Medische Consumptie (Groningen).

Knibbe, R.A., Drop, M.J., Van Reek, J. \& Saenger, G. (1985) The Development of Alcohol

Consumption in the Netherlands: 1958-1981, British Journal of Addiction, 80, 411-419.

Knibbe, R.A., Drop, M.J. \& Muytjens A. (1986) Correlates of stages in the progression from everyday drinking to problem drinking, Social Science and Medicin, 24, 5, 463-473.

Knibbe, R.A., Lemmens, P.H.H.M. \& Kromhout, D. (1988) Changes in alcohol consumption in a cohort of men: 1960-1985, Paper presented at the 14th Annual Alcohol Epidemiology Symposium, Berkeley, USA.

Leering, T. \& Lerou, W. (1990) Verkenning van de veroudering in Nederland, Bevolkingsprognoses ten behoeve van de planning van voorzieningen voor ouderen (Rijswijk, Ministerie van Welzijn, Volksgezondheid en Cultuur).

Lemmens, P.H.H.M., Knibbe, R.A.\& Tan, F.E.S. (1988) Weekly Recall and Diary Estimates of Alcohol Consumption in a General Population Survey, Joumal of Studies on Alcohol, 49, 2, 131-135. Lemmens, P.H.H.M., Tan F.E.S. \& Knibbe, R.A. (1988) Bias due to non respons in a Dutch Survey on Alcohol Consumption, British Journal of Addiction, 83, 1069-1077.

Lemmens, P.H.H.M., Tan F.E.S. \& Knibbe, R.A. (1992) Measuring Quantity and Frequency of Drinking in a General Population Survey, A Comparison of 5 Indices, Journal of Studies on Alcohol, $53,476-486$.

Mason, K.A., Mason, W.M., Winsborough, H.H. \& Poole, W.K. (1973) Some methodological issues in cohort analysis of archival data, American Sociological Review, 38, 242-258.

Meyers, A.R., Goldman, E., Hingson, R. \& Scotch, N. (1981) Evidence for cohort or generational differences in the drinking behavior of older adults, Intemational Joumal of Aging and Human Development, 14, 1, 31-44.

Neve, R.J.M. (1992) Developments in the attitudes towards women's emancipation in the Netherlands from 1970 to 1985, as cohort analysis. In: H.A. Becker (Ed.), Dynamics of Cohort and Generations Research, (Utrecht, ISOR, forthcoming).

Riley, M.W., (1973) Aging and cohort succession, interpretations and misinterpretations, Public Opinion Quarterly, 37, 35-49.

Ryder, N.B. (1965) The Cohort as a Concept in the Study of Social Change, American Sociological Review, 30, 843-861.

Skog, O.J. (1980) Social interaction and the distribution of alcoholl consumption, Joumal of Drug Issues, 10, 1, 79-92.

Skog, O.-J. (1985) The Collectivity of Drinking Cultures: a Theory of the Distribution of Alcohol Consumption, British Journal of Addiction, 80, 83-99.

Sulkunen, P. (1987) Abstinence. In: J. Simpura (Ed.) Fimnish Drinking Habits. Results from Interview Surveys Held in 1968,1976 and 1984 (Helsinki, Finnish Foundation for Alcohol Studies). 


\title{
Gender differences in drinking behavior in the Netherlands: Convergence or Stability?
}

\author{
Rudie J.M. Neve, Maria J. Drop, Paul H. Lemmens, Henk Swinkels* \\ Reprinted with permission from Addiction, Vol. 91, pp. 357-373, 1996 \\ Copyright by Carfax Publishing Ltd., Abington, UK \\ * Central Bureau of Statistics, Heerlen
}

\begin{abstract}
Gender differences in drinking behavior are analyzed with emphasis on their relationship with changes in roles and positions of men and women in society. The 'convergence hypothesis' is used as a starting point. From it's implications, a number of specific hypotheses are derived and tested using data from 6 surveys of the general population of the Netherlands, held between 1958 and 1993. No convergence of gender differences is found for abstinence and heavy frequent drinking. Convergence of male-female differences in average weekly consumption appears in the 1980s, but it is no longer significant at $5 \%$ level after controlling for age, education and family situation. Further elaboration of the gender by year interaction shows that convergence is related to a decrease in consumption among higher educated men. Contrary to expectation, an increase in consumption has occurred among women over 40 years of age. No relationship appears with female employment and religion. Having a family is related to lower consumption among women, while it has no significant effect on men's consumption.

Although some evidence for convergence was found, results are not in agreement with expectations formulated from the perspective of the convergence hypothesis.
\end{abstract}

\subsection{Introduction.}

Over the years and in many different countries, men have always been reported to drink more alcohol and to experience more alcohol-related problems than women (Plant, 1990). Large changes in the position of women in society have recently raised the question whether women, when they become more like men in many respects, will also take over negative behaviors that used to be more typical for men. This line of thought has become known as the convergence hypothesis. The convergence discussion started in a period of increasing alcohol consumption; so it was expected that women's alcohol use and alcohol related problems would grow disproportionately, relative to men's. In periods of stable or declining overall alcohol consumption, convergence could also consist of a decrease in alcohol use among men, in combination with smaller decrease or increase among women. This would still be in agreement with the convergence hypothesis if the lessening of gender differences is related to increasing resemblance of women's roles to men's. 
Convergence of male-female differences in alcohol use is usually viewed as a general process in the entire population. However, one may assume that it will occur especially in specific categories of the population, i.e. those categories in which women's roles and positions in society most closely resemble men's.

The convergence hypothesis has led to much discussion, especially in the U.S, and it has inspired several empirical studies, which will be briefly reviewed here.

\subsection{A brief review of the literature.}

Few studies explicitly evaluate the convergence hypothesis as such, but comments on convergence and related findings are scattered over the more general alcohol research literature. Depending on the specific research questions, some authors discuss the relationship between developments in drinking behavior and changes in social positions of men and women. Remarks on convergence of male and female drinking patterns are found in reports on consumption and on alcohol-related problems. Part of the relevant literature concerns youth, high school and student populations. Literature reviewed in this section was selected by a computer search on the combination of alcohol and sex or gender differences or alcohol and convergence, as well as by cross- referencing. Studies among youth and college populations are discussed separately from general population studies.

\subsubsection{Consumption patterns.}

General population studies. With respect to consumption, Fillmore (1984) reports limited support for the convergence hypothesis with respect to heavy/frequent drinking in the youngest cohorts in the U.S., mainly among employed women. The author relates this finding to increased female employment rates.

Neve et al. (1993) performed cohort analysis of general trends in alcohol consumption in the Netherlands. A linear increase of consumption in female cohorts occurred during the 1980s, in which period men's consumption stabilized or even decreased somewhat. This finding seemed to support the idea that women were catching up with men regarding their alcohol consumption.

Two studies from Northern Europe confirm the convergence hypothesis. A Danish study (Sælan, Moller \& Koster, 1992) followed a sample from the 1936 birth cohort during its fourth life decade, from 1976 to 1987. Men's alcohol consumption appeared to have decreased, while women's had increased. The authors conclude that convergence had occurred and call for special measures directed at women. Convergence of male and female alcohol consumption is also reported from Norway (Hammer \& Vaglum, 1989). The authors report that the relatively strong increase in women's frequency of drinking is related to accessibility, which in turn is related to lifestyle.

The findings reported by Sælan et al. and by Hammer \& Vaglum may be due to the situation of strongly increasing wine consumption, which is prevalent in Denmark as well as in Norway (P.G.D., 1993). Hupkens, Knibbe \& Drop (1993) have shown that wine is a relatively new beverage in traditionally beer drinking societies. Male-female differences in consumption of new beverages are generally smaller than in traditional beverages. Indeed, in the Sælan et al. study, male-female convergence is explained by 
an increase in wine consumption by women. Convergence of consumption in Norway could be due to wine consumption as well.

One study on consumption patterns does not show any evidence in support of the convergence hypothesis. Bell, Havlicek \& Roncek (1984) analyzed male-female differences in patterns of alcohol and tranquilizer use in an Illinois general population survey. The authors hypothesized that these differences diminish after controlling for respondent's sex roles, operationalized as employment status, work pressure and wage earner status. This hypothesis was not confirmed by the analysis.

College studies. Numerous studies of gender differences in drinking patterns among college populations were reviewed by Berkowitz \& Perkins (1987), Engs \& Hanson (1990) and Roman (1988). These studies conclude that convergence of gender differences in abstinence and consumption patterns has occurred in the last decades. Mercer \& Khavari (1990) draw ambivalent conclusions from their analysis of beverage-specific consumption data on U.S. colleges. Differences between men and women decreased in beer consumption, but not in consumption of wine and spirits. The authors conclude that a 'qualitative convergence' may have occurred. Other recent studies on college populations report stable differences in alcohol consumption over a number of years (Perkins, 1992; Smart, Adlaf \& Walsh, 1994; Temple, 1986).

With respect to consumption, it can be concluded that four out of five general population studies report at least partial evidence in favor of the convergence hypothesis. However, most authors avoid general conclusions as to diminishing male-female differences in alcohol consumption. Studies on collegiate gender differences in alcohol use show mixed results. While earlier reports mostly confirm the convergence hypothesis with respect to consumption, later studies show stable gender differences.

\subsubsection{Problem drinking/alcoholism.}

General population studies. With respect to problem drinking or alcoholism, Sandmaier (1980) is sometimes quoted in order to support the assertion that the gap in alcoholism between men and women is narrowing (e.g. Smith, 1986; Clemenger, 1993), despite the fact that she produces very little evidence for such a claim.

Sandmaier's material on changes in prevalence over time is very limited. For instance, Sandmaier (1980, p. 74) quotes sources who assert that the percentage of females among alcoholics 'may be' closer to 50 than to 20 , but she does not produce any evidence to support this claim.

Some authors stress that women are increasingly at risk for adverse consequences of alcohol consumption. For instance, Liban \& Smart (1980) conclude on the basis of high prevalence of problem drinking among young women in one single crosssectional study that '...the next generation is likely to have more female problem drinkers' and call for special preventive measures. Grant et al. (1991) show that alcohol abuse and dependence, as defined in DSM-III-R, are relatively high among young women and conclude that this finding suggests that '..females may be catching up'. However, single cross-sectional studies do not allow this kind of conclusion concerning changes over time. 
Other researchers analyzed general population data on problem drinking and did not find support for the hypothesis (Ferrence, 1980). Wilsnack, Wilsnack \& Klassen (1984) compared their 1981 data, which oversampled heavy drinking women, to earlier surveys and found no indications for an increase of problem drinking in women.

College studies. Studies in college populations until the mid-1980s (reviewed by Berkowitz and Perkins, 1987 and by Engs and Hanson, 1990) show no evidence for convergence in alcohol-related problems. However, more recent studies show diminishing male-female differences. Two studies report smaller declines in problem drinking rates among female students, compared with male students (Johnston et al., 1992; Smart et al., 1994). Perkins (1992) reports lessening of the gender gap in specific problems, such as damage to property, physical injury to others and impaired driving. Male-female difference in physical injury to self, which was already smaller than in other problems at the beginning of the study, disappeared completely over a 10-year period.

From this brief literature review, it may be concluded that there is at least some partial evidence for diminishing male-female differences in consumption. Evidence for convergence in problem drinking or alcoholism is very weak in general populations. In college populations, some evidence is reported for smaller decline in problem drinking among women than among men.

Only a few studies consistently relate gender differences in alcohol use to roles and positions in society. The most consistent finding from the literature is that employed women drink more than housewives. Other things being equal, this would cause convergence of male and female differences in consumption, provided that the proportion of employed women increases, which is the case in many industrialized countries. This finding links convergence to actual changes of women's position in society, which has always been the idea behind the convergence hypothesis.

\subsection{Research questions.}

The Netherlands offers a good opportunity to replicate and extend this approach to the convergence hypothesis. In the post-war period, differences between men and women in many aspects of life have diminished profoundly. Changes in the position of women in society, in employment and in many other aspects, have been stronger than in men's. At the same time, vast changes in alcohol consumption have taken place. In the period from 1960 to 1980 , a $300 \%$ increase of per capita alcohol consumption took place. In the 1980s, a slight decrease in consumption occurred (P.G.D., 1993). In the next section, the reasoning of the convergence hypothesis will be applied to specific developments in Dutch society that affected the position of women. These societal changes concern variables that are known from earlier research to be related to alcohol consumption. This procedure results in a number of specific hypotheses.

\section{Hypothesis 1:}

The convergence hypothesis predicts that a decrease in differences in drinking behavior between men and women will be observed over the last three decades. 
Both actual changes in social positions and changes in opinions have taken place at a faster pace in younger age cohorts than among older people (Neve, 1995). This effect is expected to occur in convergence of alcohol consumption as well. Moreover, alcohol consumption is negatively related to age in most cultures (Fillmore, 1988; Neve et al, 1993).

Hypothesis 2:

The decrease of differences in male and female alcohol consumption is expected to be stronger among the young, as compared to older age categories.

Women's participation in the labor force has increased in many countries, while men's has decreased. This is even more the case in the Netherlands, where female employment for many years has been much lower than in other countries. The increase in employment of women has been very strong, from $26.2 \%$ in 1960 to $47.0 \%$ in 1993 (S.C.P. 1994). Employment is known to be positively related to alcohol consumption (Fillmore, 1984; Van Gelooven, 1990).

Hypothesis 3:

Increase in women's alcohol consumption, relative to men's, is expected to take place more among employed women than among housewives.

In earlier years, women used to have a paid job only when they were not married or in the first years of their marriage. The percentage of women that do not quit their job after the birth of the first child has increased from $17 \%$ in 1970 to $52 \%$ in 1993 (S.C.P. 1994). Even though most women work in part time jobs, whereas men remain the 'main breadwinners', this is a spectacular change. The role of full-time housewife and mother is no longer self-evident. Men, on the other hand, are slowly beginning to take up more family responsibilities (Hooghiemstra \& Niphuis-Nell, 1993). According to the Dutch government (W.V.C., 1986), the decreasing number of children per family puts women at risk for increasing alcohol consumption. Having a family has been shown to be negatively related to alcohol consumption (Knibbe, 1984).

Hypothesis 4:

Having children should have decreased in importance as a determinant of drinking behavior among women and should have gained in importance among men.

In the last thirty years, differences between men and women in educational level have almost completely disappeared (S.C.P. 1994). In view of the positive association between education and alcohol consumption (Knibbe et al, 1985) the expectation is that:

Hypothesis 5:

Convergence of male-female differences in alcohol use will be related to higher education among women. 
Differences between men and women in religion and churchgoing have disappeared as well. In $1970,44 \%$ of men and $34 \%$ of women reported not to consider themselves as part of any church. These percentages have increased to 60 and 57 , respectively, in 1990 (Becker \& Vink, 1994). The secularization process has developed faster among women than among men. Furthermore, alcohol consumption in the Netherlands is lower among Protestants than it is among Catholics and non-religious people (Knibbe, 1984).

\section{Hypothesis 6:}

Convergence of male-female differences in alcohol use is expected to be related to being non-religious or catholic, rather than protestant.

\subsection{Methods.}

\subsubsection{Samples and Data.}

Secondary analysis was conducted on surveys of the general population of the Netherlands (ages 21 to 70), held in 1958 (Gadourek, 1963), 1970 (Jessen, 1974), 1981 (Adriaanse et al., 1981), 1985 (Lemmens, Knibbe \& Tan, 1988), 1989 (Swinkels, 1991) and 1993 (Swinkels, 1994). Number of respondents, effective response rates and undercoverage of consumption in comparison with sales data are given in table 3.1. The samples were drawn independently, implying that the data do not allow analysis of changes at the individual level. However, for the purpose of this paper it is sufficient to follow aggregate level changes in drinking behavior and related variables.

The decline in response rates over the years (table 3.1) might affect our results in case of selectivity by sex or by drinking behavior. The decline is in line with experience in general population survey research in the Netherlands and elsewhere (Bethlehem \& Kersten, 1986). For 1958 and 1985, published response figures show no significant sex differences. Furthermore, extensive non-response analysis was conducted on the 1985 data, which did not yield evidence in support of the hypothesis that non-response is associated with heavier alcohol consumption (Lemmens, Tan \& Knibbe, 1988). It can be concluded that there is no reason to expect that our analyses will be threatened by selective non-response.

Table 3.1. Number of respondents (ages 21 to 70 ), response rate and underestimation of alcohol consumption in surveys used in the presented research.

\begin{tabular}{lrrrrrr}
\hline Year & 1958 & 1970 & 1981 & 1985 & 1989 & 1993 \\
\hline N & 1133 & 1524 & 1272 & 1145 & 5191 & 5163 \\
Response \% & 78 & 85 & 73 & 69 & 58 & 62 \\
Per Capita sales (PGD, 1990) & & & & & & \\
(glasses per week) & 4.94 & 11.6 & 17.29 & 16.21 & 15.8 & - \\
Reported consumption & & & & & & \\
(mean glasses per weeR)23 & 6.23 & 7.91 & 9.51 & 8.1 & - & \\
Underestimation \% & 55 & 46 & 54 & 41 & 49 & - \\
\hline
\end{tabular}




\subsubsection{Measures.}

Consumption data. Abstinence, consumption and weekly heavy drinking were analyzed. Analyses on consumption and weekly heavy drinking were performed on data of drinkers only; abstainers were excluded.

Across surveys, the format of questions about abstinence from alcohol varied (table 3.2). In 1958, those who answered 'never' on the question 'Do you drink at regular times?' were labeled abstainers. In 1970, 1981 and 1985, respondents were asked in a separate question if they ever drank alcohol. No period was specified in which respondents should have abstained from alcohol in order to be classified as abstainer, except for the 1985 survey, in which a period of six months was specified. In 1989 and 1993, those who answered 'none' on the question 'what kind of beverage do you ustually drink" were labelled abstainers.

It was suggested before that differential formats, at least in part, may explain variability in abstinence across the years (Neve et al., 1993). Lemmens (1987) has shown that omission of a reference period in questions on abstinence elevates the abstinence rate somewhat. A 'grey area" consists of very light drinkers, who will be categorized as abstainers or drinkers depending on the question format. In the 1985 survey, respondents were asked how long ago they stopped drinking. Restricting the definition of abstinence by increasing the reference period from 6 months to 1 year would lower the abstinence rate by $3 \%$ (Lemmens, 1987). This will be taken into account when interpreting abstinence patterns for 1970 and 1981 .

Table 3.2. Operationalization of consumption indices.

\begin{tabular}{lll}
\hline Year & Abstinence: & Average consumption: \\
1958 & $\begin{array}{l}\text { Last of list of answers to question: } \\
\text { 'Do you drink ar regular times' } \\
\text { Answer: never }\end{array}$ & $\begin{array}{l}\text { Weekly recall, } \\
\text { categorized data }\end{array}$ \\
1970 & $\begin{array}{l}\text { Separate question } \\
\text { no reference period }\end{array}$ & $\begin{array}{l}\text { How much do you usually } \\
\text { dirink in a week? }\end{array}$ \\
1981 & $\begin{array}{l}\text { Separate question, } \\
\text { no reference period }\end{array}$ & Weekly recall \\
1985 & $\begin{array}{l}\text { Separate question, } \\
\text { last six months }\end{array}$ & Weekly recall, \\
1989 & $\begin{array}{l}\text { Last of list of answers to question: } \\
\text { 'what beverage do you } \\
\text { usually drink?' Answer: none }\end{array}$ & $\begin{array}{l}\text { Quantity/frequency } \\
\text { index }\end{array}$ \\
& $\begin{array}{l}\text { Last of list of answers to question: } \\
\text { 'what beverage do you } \\
\text { usually drink?' Answer: none }\end{array}$ & - \\
\hline
\end{tabular}


Three different operational definitions of weekly consumption have been used over the years (table 3.2). In the 1985 survey, all three measurement methods, weekly recall, 'typical' consumption and quantity/frequency index, were included in order to investigate underestimation of consumption in survey research (Lemmens, Tan \& Knibbe, 1992). In the present study, the weekly recall measure was used for the 1985 survey. A version of a 'weekly recall' measurement was also used in 1958 and 1981. In this index, the number of glasses consumed on any of the days of the week preceding the interview is assessed. In 1958 a categorization was used, in which those reporting 22 glasses or more $(1.8 \%)$ form the highest category. In 1970 respondents were asked how many glasses of alcohol they usually consumed per week (typical consumption). In 1989, a Quantity-Frequency index measure was computed from the number of drinking occasions per week and the average number of drinks per occasion.

In the 1985 data, the three indices used appeared to correlate highly $(r>.7)$. The results of analyses, which are not presented here, have led us to conclude that the risks taken by using different operational definitions of alcohol consumption remain within acceptable limits (Neve et al, 1993).

Consumption data were corrected for differential coverage, by multiplication with a factor that yields coverage equal to 1985 in all years. This factor is obtained by dividing the coverage in 1985 by the coverage in all other survey years. The goal of the operation is to get equal coverage in all surveys in order to make analyses comparable across the years. Since analyses are performed on data of drinkers only, this goal is reached by excluding abstainers from the calculation of the correction factors as well. A disadvantage of this procedure is that the correction may be influenced by the differential operationalization of abstinence. The largest difference is likely to occur for 1981, in which year a less restrictive definition of abstinence coincides with a relatively high undercoverage, both compared with 1985 . Nevertheless, the correction factor for 1981 is only $3 \%$ smaller than it would have been if calculation was done in the entire sample (or if no difference in abstinence had occurred). The only alternative would have been to analyze consumption data with the inclusion of abstainers. Since abstinence is analyzed as a separate aspect of drinking behavior, and it is considered better to avoid a large number of 'zeros' in analyses, it was decided to maintain the restriction of the analysis of consumption to drinkers.

From 1981 onwards, data are available on the frequency of drinking more than 6 glasses on one occasion. This variable was dichotomized, so as to result in a variable denoted as weekly heavy drinking, which is defined as drinking 6 glasses or more on one accasion at least once a week.

Available data result in three time series: from 1958 to 1993 for abstinence, from 1958 to 1989 for weekly consumption and from 1981 to 1993 for weekly heavy drinking.

Independent variables. Apart from indices of alcohol consumption, the following variables were used in the analyses: year of survey, gender, age, family situation, work status, religion, educational level and degree of urbanization. In the earlier surveys, age is available in 10-year categories only. The variable family situation is a dicho- 
tomy, coded 1 if the respondent has children living at home and 0 if not. Marital status is coded 1 for single people (either unmarried, divorced or widowed) and 0 when respondent is married. Work status has three categories: having a paid job, being a housewife or otherwise. Men who were categorized as housekeepers (only present in the most recent years) were categorized in the 'other' category because of their small numbers. Four categories of religion are distinguished: none, catholic, protestant and other. Educational level was dichotomized in order to make the operationalizations across surveys comparable: primary school and lower technical or vocational education were defined as 'lower', all higher levels, from middle secondary education up to university training, were categorized as 'higher'.

\subsubsection{Analysis.}

First, a test on interaction of year and gender was performed in the entire pooled database and in subpopulations defined by dichotomized age, education, work status, family situation and urbanization. Separate analyses were done in protestant, catholic and non-religious subpopulations. On the basis of the development of per capita consumption in the Netherlands, a period of strong increase (until 1980) was distinguished from a period of stabilizing or slightly decreasing per capita consumption that started in the early $1980 \mathrm{~s}$. Significant results were elaborated further. Only interaction terms indicating decrease in gender effect over the years were taken into consideration.

Second, multivariate analysis was performed in order to test whether the findings change when relevant variables are held constant. Variables were entered in the equation by forward selection in the following order: first, main effects; second, interactions with gender; third, interactions with year; and finally, three-way interactions of variables with year and gender. Age categories were included as dummy variables measuring the effect compared with the youngest category, which was omitted from the regression. Because not all variables are available in all years, multivariate analyses were performed separately in all years as well. These analyses involved main effects of variables and their interaction with gender.

Data on abstinence and frequency of drinking six or more glasses per occasion were analyzed using logistic regression and data on consumption using OLS regression. Logistic regression equations, as well as OLS regression equations, are presented with an ' $\mathrm{R}^{21}$. In logistic regression, this measure indicates the percentage improvement of the log likelihood ratio, compared with a model with only a constant (Hosmer \& Lemeshow, 1989: 148). A base 10 logarithmic transformation was applied in regression analysis of weekly consumption data. 


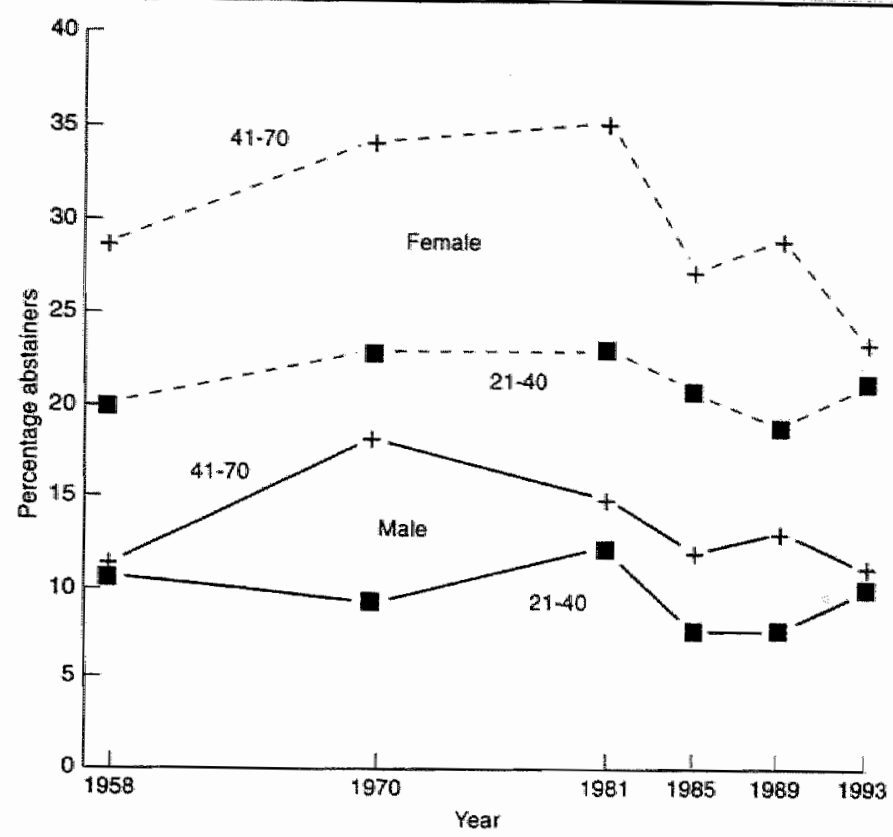

Figure 3.1 Percentage of abstainers by year in gender and age categories.

\subsection{Results.}

\subsubsection{Abstinence.}

None of the gender-by-year interactions appeared significant, neither in the entire sample nor in subpopulations and neither before nor after 1981. Therefore, presentation of results is limited to percentages of abstainers by gender and age over the years

Figure 3.1 shows percentages of abstainers among men and women. Separate lines are drawn representing men and women aged under 40 and those aged 41 and over. In all years, women are more likely to be abstainers than men. Compared with younger people, women as well as men, older people are more likely to abstain from alcohol.

\subsubsection{Weekly heavy drinking.}

Data on weekly heavy drinking have been collected in general population surveys since 1981, which is after the period of a strong increase in alcohol consumption. None of the gender-by-year interaction tests for weekly heavy drinking showed significant results, in the entire sample nor in any of the subpopulations. Results of further analyses are thus presented briefly.

The percentage of regular heavy drinkers among men had decreased slightly between 1981 and 1985 and has been very stable in later years until 1993 (figure 3.2). Among women, it reached its lowest value in 1989 . Weekly heavy drinking has been more common among people aged under 40 than among older people. This age effect was strongest in 1985 among both men and women, and it almost disappeared in 1993. 


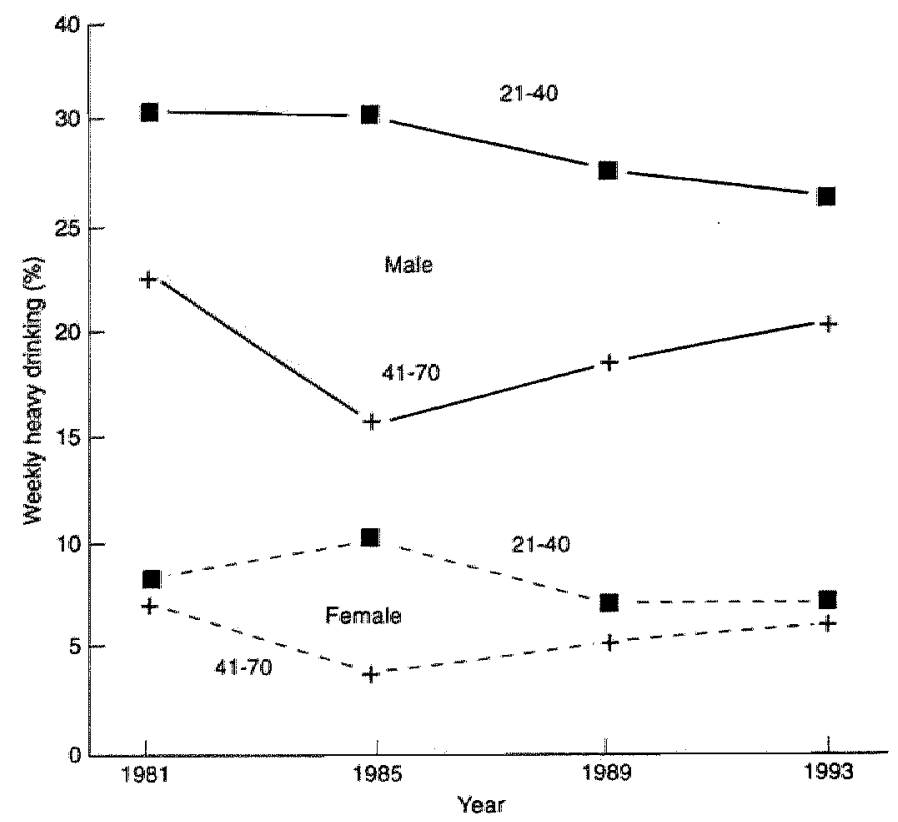

Figure 3.2 Prevalence of weekly heavy drinking ( $\%$ of drinkers) by year in gender and age categories.

\subsubsection{Average weekly consumption.}

Separate analyses were performed on the combined data sets for the years 1958 to 1981 and for the years 1981 to 1989. In the first period, a period of strong increase of alcohol consumption, no gender-by-year interaction terms were significant at $p<.10$ level.

Table 3.3. Multiple regression of consumption $(\mathrm{log})$ on gender and year and interaction, survey years 1981-1989. Only subpopulations in which interaction is significant at $p<.10$ level are reported. Unstandardized regression coefficients, standard error in brackets.

\begin{tabular}{|c|c|c|c|c|c|c|}
\hline & $\mathrm{N}$ & Constant & Year-1980 & Gender & Gender by year & $\mathbf{R}^{2}$ \\
\hline Total sample & 6263 & $\begin{array}{c}655 \\
(.020)\end{array}$ & $\begin{array}{l}.011 \\
(.003)\end{array}$ & $\begin{array}{c}.483 \\
(.105)\end{array}$ & $\begin{array}{l}-.007^{* *} \\
(.003)\end{array}$ & .097 \\
\hline Higher educated & 3608 & $\begin{array}{l}.690 \\
(.026)\end{array}$ & $\begin{array}{c}.010 \\
(.003)\end{array}$ & $\begin{array}{l}.485 \\
(.136)\end{array}$ & $\begin{array}{l}-.008^{\prime \prime} \\
(.004)\end{array}$ & .077 \\
\hline
\end{tabular}

Note. Gender and year coefficients are all significant at $p<.05$.

${ }^{*} p<.10 * * 0<.05$ 


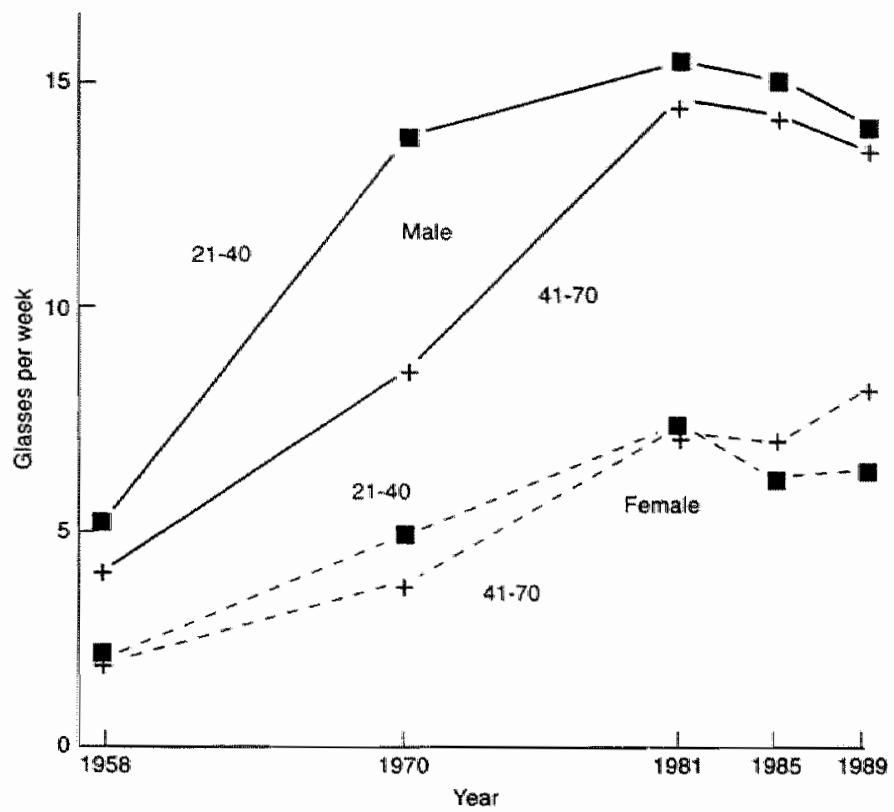

Figure 3.3 Average weekly consumption of drinkers by year in gender and age categories.

Table 3.3 shows the results for 1981 to 1989 of regression of consumption on gender, year and their interaction. Only results that involve a significant interaction term are reported. Convergence of male-female difference in consumption reaches significance at .05 level. Separate analyses in subpopulations show that convergence occurred especially among the higher educated. The estimated interaction effect is small, however. The estimated parameters among the lower educated and in subpopulations defined by age, job status, religion and having children have about the same values as in the total population, but are not statistically significant.

In order to gain more insight in these results, figures 3 to 5 present average consumption over the years. Figure 3.3 shows developments in weekly consumption by age and gender. In recent years, a decrease in consumption has occurred among men. In the same period, women's alcohol consumption has not decreased. Among women over 40 , an increase has occurred in the last period. Note that women over 40 years of age have been consuming more alcohol than women under 40 since 1981. However, gender-by-year interaction is not significant in either category.

Figure 3.4 shows that differences by educational level is very small among men, and stable over the years among women. Among lower educated women, an increase is observed over the entire period, except for a temporary decrease between 1981 and 1985. Among the higher educated, the significant gender-by-year interaction term (table 3.3) appears to be explained by a decrease in men's consumption after 1.985 , rather than an increase of women's consumption. 


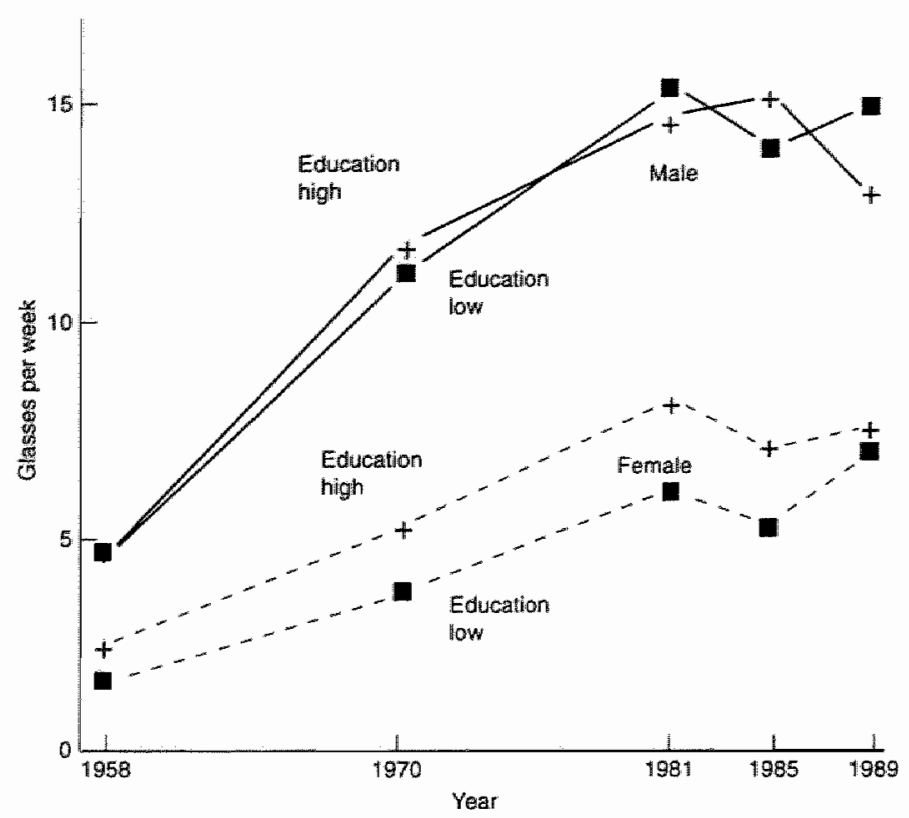

Figure 3.4 Average weekly consumption (glasses) of drinkers by year in gender and education categories.

Job status (figure 3.5 ) was recorded in all years except 1981. Since only a very small minority of men belong to the "other' category, only totals for men are given in the figure. Consumption has decreased slightly in recent years among men as well as among employed women. At the same time, consumption has continued to increase among housewives and among other women without a job, although gender-by-year interaction in both categories compared to all men was not significant.

\subsubsection{Further analysis.}

Multivariate analysis was performed to gain more understanding of the associations between gender, drinking behavior and the independent variables: age, education, family situation, job status and religious denomination. Table 3.4 shows the results of logistic regression analyses of data on abstinence and regular heavy drinking.

The results show significant effects on abstinence of gender, age and education. No interaction of gender, either with year or any other variable, appears to be significant. More educated people are less likely to be abstainers.

Variables job status and religion were not available in all years and consequently appear only in analyses in separate years (not presented here). In survey years in which the variable job status is available, the employed are less likely to be abstainers, while housewives are more often abstainers. Religious denomination has no significant effect on abstinence in any year. 


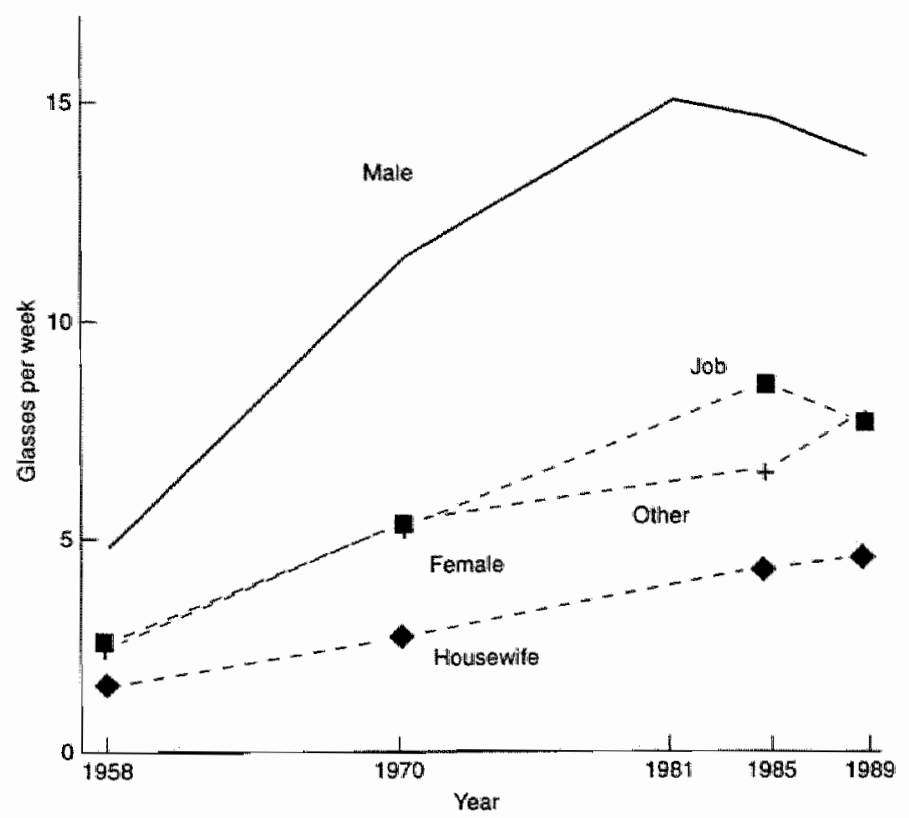

Figure 3.5 Average weekly consumption (glasses) of drinkers by year in gender and employment categories.

Logistic regression shows that higher prevalence of weekly heavy drinking is associated with being male, under 50 years of age, lower education and having children at home. No interactions between gender and any other variable appeared significant.

Table 3.4. Logistic regression of abstinence (1958-1993) and weekly heavy drinking (1981-1993). Unstandardized regression coefficients and standard errors in brackets.

\begin{tabular}{|c|c|c|c|c|}
\hline \multirow[b]{2}{*}{ Year* } & \multicolumn{2}{|c|}{ Abstinence } & \multicolumn{2}{|c|}{$\begin{array}{l}\text { Weekly heavy } \\
\text { drinking }\end{array}$} \\
\hline & n.s. & & n.s. & \\
\hline Gender (male 1-female 0) & -.900 & $(.047)$ & 1.618 & (.065) \\
\hline Age: compared with 21-30 & & & & \\
\hline Age $31-40$ & -.181 & $(.086)$ & n.s. & \\
\hline Age $41-50$ & .207 & $(.069)$ & n.s. & \\
\hline Age $51-60$ & .196 & $(.070)$ &. .676 & $(.094)$ \\
\hline Age $61-70$ & .618 & $(.070)$ & -1.415 & $(.124)$ \\
\hline Education (high 1-low 0) & -.716 & (.047) & -.319 & (.056) \\
\hline Having children (yes 1-no 0) & n.s. & & -305 & $(.063)$ \\
\hline $\begin{array}{l}\text { Constant } \\
\mathrm{R}^{2}\end{array}$ & $\begin{array}{r}-.894 \\
.065\end{array}$ & $(.054)$ & $\begin{array}{r}-2.260 \\
.102\end{array}$ & $(.149)$ \\
\hline
\end{tabular}

n.s. : not selected, $p>.05$ * In analyses of abstinence, 1957 is subtracted from the survey year; in analyses of weekly heavy drinking 1980 is subtracted. 
Table 3.5. Multiple regression analysis of weekly consumption in glasses $(12.5 \mathrm{ml}$ ethanol unit, log transformed). Unstandardized regression coefficients and standard errors in brackets.

\begin{tabular}{|c|c|c|c|c|}
\hline & $\begin{array}{l}\text { Consumptio } \\
1958-1981\end{array}$ & & $\begin{array}{l}\text { Consumptio } \\
1981-1989\end{array}$ & \\
\hline Year"* & .018 & $(.001)$ & .009 & $(.003)$ \\
\hline Gender (male $\|$-female 0 ) & .274 & $(.034)$ & .283 & $(.029)$ \\
\hline \multicolumn{5}{|l|}{ Age: compared with 21-30 } \\
\hline Age $31-40$ & n.s. & & .086 & $(.013)$ \\
\hline Age 41-50 & n.s. & & .175 & $(.020$ \\
\hline Age 51-60 & n.s. & & n.s. & \\
\hline Age $61-70$ & $-.016^{*}$ & $(041)$ & n.s. & \\
\hline Education (high 1-low 0) & 120 & $(.026)$ & n.s. & \\
\hline Having children (yes 1-no 0) & n.s. & & -.097 & $(.016)$ \\
\hline Single (unmarried 1, married 0 ) & n.s. & & n.s. & \\
\hline \multicolumn{5}{|l|}{ Interactions: } \\
\hline $\begin{array}{l}\text { Gender by year } \\
\text { Gender by Age }\end{array}$ & .005 & $(.002)$ & $-.006^{*}$ & $(.003)$ \\
\hline By age $31-40$ & n.s. & & n.s. & \\
\hline By age $41-50$ & n.s. & & -.096 & $(.026)$ \\
\hline By age $51-60$ & n.s. & & n.s. & \\
\hline By age 61-70 & -.148 & $(.055)$ & n.s. & \\
\hline Gender by education & -115 & $(.034)$ & n.s. & \\
\hline Gender by having children & n.s. & & .079 & $(.022)$ \\
\hline $\begin{array}{l}\text { Constant } \\
\mathrm{R}^{2}\end{array}$ & $\begin{array}{l}.226 \\
.24\end{array}$ & $(.024)$ & $\begin{array}{l}.062 \\
.11\end{array}$ & $(.073)$ \\
\hline
\end{tabular}

n.s. : not selected, $p>.01$

* in model, but not significant $p>.05$

** In analysis of the period 1958-1981, 1957 is subtracted from the survey year; 1980 is subtracted in analysis of the period 1981-1989.

The improvement of both models in table 3.4 , compared with models with only a constant, is small and the models as a whole do not fit the data well. The models allow testing of hypotheses that concern subpopulations, such as our own, but results also show that prediction on the individual level of abstinence or weekly heavy drinking is not possible with the independent variables included.

Table 3.5 shows regression of average weekly consumption. Analysis was performed separately for the years 1958 to 1981 and for 1981 to 1989 . In the period until 1981, main effects appear for gender, age and education. A significant, but positive gender-by-year interaction term shows that gender difference has increased slightly over the years from 1958 to 1981 . Age effect appears only for the category over 60 years of age, which drinks slightly less than younger people. This effect appears to be much stronger in males than in females, as the age-by-gender interaction term shows. Consumption is higher among the higher educated, and the gender-by-education interaction term shows that this effect is present only in women.

In the 1980s (second column, table 3.5), a positive main effect of year is found. The negative gender-by-year interaction term is no longer significant, but comes close: the p-value is .07. This interaction term shows that the estimated year effect is present 
only in women and to a much lesser extent in men, which is equivalent to a decrease in. gender effect over the years. Consumption shows a unimodal association with age: increase among people in their thirties and forties and decrease in later life decades. What is remarkable is an interaction term, showing that the effect of being between 40 and 50 years of age is much weaker among men. This unimodal pattern has emerged in the 1980 s especially among women. Consumption is slightly higher among the higher educated. Having children leads to lower consumption among women only, as the positive gender-by-having children interaction term shows.

Religion (not present after 1985) and employment (not recorded in 1981) were analyzed in separate years. Catholics' consumption, compared with protestants and non-religious, was higher in 1958 and 1981. In 1981 this effect occurred only among men. Consumption was found to be significantly lower among housewives, compared to other women, only in 1989 .

\subsection{Conclusions and discussion.}

The central hypothesis of this study, which states that a decrease in difference in drinking between men and women has occurred over the last few decades, is rejected without reservation with respect to abstinence and weekly heavy drinking. No convergence was shown in abstinence and weekly heavy drinking, either in the entire population or in subpopulations. Therefore hypotheses 2 to 6 , which offer explanations for convergence, are rejected as well. Before we continue our discussion of the hypotheses, which concentrates on developments in consumption, a remark is made with respect to our results on abstinence. The results of this study clarify a question raised by Gomberg (1991: 267), who suggests that stability in the overall percentage of abstainers may be explained by an increase in the proportion in the population of older people who are more often abstainers, in combination with decreasing abstinence among women in younger age categories. This would be an interesting interpretation of the convergence hypothesis, which would be confirmed even without an overall change in abstinence. Gomberg's remark makes clear that it is important to control for age when analyzing differences between men and women. However, as far as our results showed significant change in the association between age and abstinence over the years, the direction of change was not in agreement with the pattern expected by Gomberg. In fact, age difference in abstinence, as well as in heavy drinking, became smaller in recent years among both women and men.

Some convergence in average consumption per drinker was observed in the second half of the 1980s. While consumption increased slightly among women, it did not increase among men. However, although this convergence appeared clearly visible when the data were presented graphically, gender-by-time interaction was hardly significant in a multivariate test.

Hypothesis 2 states that convergence would be expected among the young, rather than among older people. Findings on average consumption are ambivalent. As far as any evidence for convergence was found in the data, this appeared to be stronger among people over forty years of age, and even then it is not statistically significant. Multivariate analysis shows that the association between age and consumption is 
stronger in women than in men. Convergence of male-female difference in consumption seems to occur not so much as a development in time, but rather as people get older: gender difference in consumption is smaller in older age categories than in younger age categories. Especially women in their forties show relatively high consumption in the 1980s.

According to hypothesis 3 , convergence of drinking is related to women's participation in the labor force. Although employed women seem to drink more than housewives, the relationship between job participation and consumption is significant only in 1989 when gender, age and education are controlled. Employment does not account for any convergence of male and female consumption.

Hypothesis 4 stated that the association of having children at home is increasing for men and decreasing for women. However, the analyses show that still in the $1980 \mathrm{~s}$ having children is related to lower consumption among women but not among men. Due to decreasing consumption among men, convergence of consumption occurred among higher educated in the 1980s. Thus, hypothesis 5 holds for this period, and is rejected for the earlier period from 1958 to 1980 .

With respect to religion, separate analyses in all survey years in which this variable is available show that its association with consumption varies over the years. No interaction with gender was found. Within categories, gender-by-year interaction appeared to be not significant. Contrary to the prediction in hypothesis 6 , convergence of alcohol consumption is not related to being either catholic, protestant or nonreligious.

On the whole, stability in differences between men and women has predominated in the period since 1958. Some convergence occurred in average consumption in recent years, although it was hardly statistically significant.

Evidence for convergence of alcohol consumption in Denmark and probably in Norway appeared to be related to increasing wine drinking, which occurred especially among women. In the Netherlands, per capita consumption of wine was stable in the 1980s (P.G.D., 1993), which makes this explanation 】ess plausible for the results presented above.

In contrast to other studies reviewed in the introduction, female employment does not explain convergence of alcohol consumption in the present study. In fact, in recent years, an increase of consumption was observed among housewives rather than among employed women, although employed women still show the highest consumption. It has been suggested that it is not job status as such, but the gender mix of occupations that should be related to drinking patterns (Wilsnack \& Wilsnack, 1991). According to Kraft et al. (1993), the gender mix of occupations influences consumption through the creation of opportunities to drink with colleagues. However, it is questionable whether consumption among employed women in the Netherlands is strongly associated with the possibility of going out drinking with colleagues. According to Van Gelooven (1990), $80 \%$ of all alcohol is consumed at home, but exact figures on drinking at work or after work are lacking. On the other hand, it may be hypothesized that the work environment influences drinking behavior at home or with friends as well. Kraft et al."s (1993) suggestion to include the gender composition of the work group rather 
than of the occupation as a whole may clarify the specific influence of the work situation on drinking behavior of both men and women in future studies.

Closer analysis of the lessening of male-female differences in alcohol consumption in the 1980s showed that two developments form the basis of it: decrease among men, especially higher educated men, and increase among women over 40 years of age. Both developments warrant further discussion.

The general decrease in consumption in the Netherlands in the $1980 \mathrm{~s}$, after a long period of increasing consumption (table 3.1 ), appears to have occurred mostly among men, and especial]y among higher educated men (figure 3.4), while women's consumption continued to increase. In other words, the trend has changed among men but not among women. This may raise the question, whether convergence in the $1980 \mathrm{~s}$ should be explained by developments among men, rather than by changes in women's roles and positions.

After a long period of increase after World War II, a general tendency towards stabilization or decrease of alcohol consumption has occurred in the $1980 \mathrm{~s}$ in most countries of Western Europe and North America. Since this development occurred in countries with different drinking cultures, a general explanation is not ready at hand (Edwards et al., 1994). For the Netherlands, as for the U.S., one may point towards a general increase in awareness of the problematic aspects of alcohol use, reflected by increasing support for control policies, and enhanced by government campaigns against alcohol abuse in the media (Lemmens, 1994). It is to be expected that the higher educated, because of their generally higher information level, are affected more by this downward pressure than those with less education. However, this does not explain why men should be affected more than women. An obvious explanation might be that men are more likely to decrease their consumption, simply because they used to drink at much higher levels at the time of the trend break. It should be noted that per capita consumption in the late 1970 s was higher than at the end of the last century, the previous peak period in alcohol consumption (Gerritsen, 1993: p. 160).

The development of alcohol consumption among women during the $1980 \mathrm{~s}$ warrants two explanations. First, why would consumption have decreased among women under 40 ? Second, why would consumption have increased among women over 40 ? It was speculated above that men (especially higher educated men) may have been influenced more by the increased awareness of the problematic aspects of alcohol use because of their higher consumption levels. For women between 20 and 40 , this awareness may have coincided with an increase in health concern, in general and especially with respect to childbearing. For instance, since the early 1980 s, publications on the Fetal Alcohol Syndrome have led the medicall profession to advise women not to drink at all when they are pregnant or sometimes even when they want to become pregnant. These cultural changes, in combination with the general increase in sensitivity with respect to alcohol, may explain why women under 40 decreased their drinking, as men did, even when their consumption level was already moderate compared to men.

The increase in consumption among women over 40 , which caused some convergence during the $1980 \mathrm{~s}$, demands a different explanation. Although it was expected 
that convergence would occur among the young, this increase would constitute some support for the convergence hypothesis in this age group, provided that it could be explained by changes in roles and positions in society. However, this explanation does not seem very plausible, since these mechanisms were specified in hypotheses that all had to be rejected but one. The one hypothesis that was not rejected predicted that convergence would occur more among the higher educated, and its retention was due to a decrease in consumption among higher educated men. Recently, consumption has increased among lower educated women and women who do not work outside the home, rather than among higher educated or employed women. A possible explanation could be that women over 40 are the only group that can escape the general downward trend in alcohol consumption. In this category, neither a high consumption level, nor the vicissitudes of childbearing age enhance a decrease in consumption. Further investigation is needed at this point.

The relationship of consumption and age among women has become unimodal in the 1980s. In 1989, women in their forties show the highest consumption. This finding is in agreement with results reported by Sælan et al. (1992), who showed increase of consumption among women in their forties, while men's consumption decreased. This finding also resembles findings reported by Fillmore (1987) who shows that differences between men and women in drinking behavior are smallest in the third life decade. The finding raises the question whether a new age-related pattern of drinking is emerging among women. On the other hand, it is possible that drinking behavior of the age cohort of women born in the 1940s is exceptional, in which case the association of age and alcohol consumption among women will return to its earlier form in the near future. An earlier cohort analysis (Neve et al., 1993) showed that consumption in the cohort of women born in the 1940s was highest in 1981 as well.

A side result of this study is that age seems to have become less relevant to drinking behavior in the Netherlands. Age differences in abstinence and heavy drinking, and in consumption among men, have declined recently. This change has occurred mainly in the very last survey of our series, while earlier analyses showed more stable age differences in abstinence and consumption (Neve et al., 1993). One might speculate that drinking patterns increasingly involve drinking at home and with meals, which are behaviors that are less restricted to younger age groups. However, more specific information is needed in order to draw such a conclusion definitively.

A few methodological remarks are in order. One could ask whether the small changes in gender differences in drinking behavior as reported in this paper are caused by methodological artifacts. Questionnaires used in the population surveys are considered to apply to men and women alike, which may not always be realistic. Not only the choice of questions, but also the reliability may differ between both genders. For instance, it has been reported that underestimation of consumption is higher among women (Garretsen, 1983; Lemmens, 1991; Swinkels, 1991). It may also be unrealistic to assume that drinking six glasses on one occasion has the same meaning for women as it has for men. Some authors have argued that analyses of gender differences in drinking behavior should also control for differences between men and women in body weight and body composition (Frezza et al., 1990; Vrij-Standhardt, 
1991). In future work, these remarks can and should be taken into account in the design of measurement methods and questionnaires. Employment of measures so adjusted will probably result in smaller gender differences in alcohol consumption and weekly heavy drinking in surveys.

The analysis of gender differences in this study is limited to the inclusion of gender as a variable and interactions with other variables. Closer scrutiny would involve investigation of attitudes towards gender roles, which have been reported to mediate sex differences (Huselid \& Cooper, 1992). A study is forthcoming, in which longitudinal data on drinking behavior in the Netherlands will include a measure of attitudes towards gender roles.

Developments in differences between men and women in three aspects of alcohol consumption were analyzed using existing data sets that have been collected over the years. Unfortunately, no problem drinking indices were included in the surveys used, for which reason it is impossible to derive conclusions on changes in alcohol related problems, which form the actual reason for concern over women's drinking. At this point, it is also unclear to what extent differences between men and women exist with respect to the relationship between consumption and alcohol-related problems. The literature review showed that convergence of consumption is a more common finding than convergence of drinking problems. The forthcoming longitudinal study, which includes consumption measures as well as a problem drinking index, will show whether this finding can be replicated.

Results presented above are to a large extent in agreement with most studies on consumption reviewed in the introduction. Some convergence of male-female differences in alcohol consumption is found in the 1980 s, but results warrant careful and nuanced formulation of conclusions. There is no reason for alarm on women's drinking, although research should keep an eye on developments in the near future, especially among middle-aged women. No evidence was found for the thesis that women will suffer more alcohol-related problems when they enter roles and positions in society that were formerly dominated by men.

\section{References.}

Adriaanse, H., Drop, M.J., Halfens, R., \& Philipsen, H. (1981) Leeft Nederland Oké? (Maastricht, Rijksuniversiteit Limburg).

Becker, J.W., \& Vink, R. (1994) Secularisatie in Nederland, 1966-1991 (Rijswijk, Sociaal en

Cultureel Planbureau).

Bell, E., Havlicek, P.L., Roncek, D.W. (1984) Sex Differences in the Use of Alcohol and Tranquilizers: Testing a Role Convergence Hypothesis, American Journal of Drug and Alcohol Abuse, 10 , pp. 551-561.

Berkowitz, A.D. \& Perkins H.W. (1987) Recent Research on Gender Differences in Collegiate Alcohol Use, Joumal of American College Heaith, Vol. 36, pp. 123-129.

Clemenger, M. (1993) Under the influence: women and allcohol, Nursing Times, 89 (2), pp. 24-26.

Edwards, G., et al. (1994) Alcohol Policy and the Public Good, (Oxford, Oxford University Press).

Engs, R.C. \& Hanson, D.J (1990) Gender Differencesin. Drinking Patterns and Problems Among College Students: A Review of the Literature, Journal of Alcohol and Drug Education, Vol. 35, pp. 36-4T. 
Ferrence, R.G, (1980) Sex Differences, the Prevalerce of Problem Drinking, in: Kalan, O.J. (ed.), Alschol and Drugg Problems in Women: Research Advances in Alcohol and Drug Problems, Vol. 5. (rew vork, Plenum Press).

Filmore, K.M. (1984) "Wher angels fall", Women's Drinking as Cultural Preocupation and as Reality, hin: Wisnack S.C., Beckman, L.J. (eds.) Alcohol problems in women, antecedents, consequences and intervention, (New York/London, Gulford Press).

Filmore, K.M. (1987) Women's drinking across the adult life course as compared to men's, British Journal of Addiction, 2 ; pp. $801-811$.

Filmore, K.M. (1988) Alcohol Use Across the Life Course, (Toronto, Addiction Research Foundation).

Frezza, M, di Padova, C., Pozzato, $G_{n,}$ Terpin, M., Baraona, E. \& Lieber, C. (1990) High Blood Alcohol Levels in Women, New England Jowmal of Medicine, 322, pp. 95-99.

Gadourek, 1. 1963) Riskane gewoonten en zorg voor eigen welzijn (Groningen, Wolters).

Garretsen, H. (1983) Probleemdrinken (Lisse, Swets \& Zeitlinger).

Gerritsen, J.W. (1993) De poilheke economie van de roes (The Political Economy of Intoxication)

(Amsterdam, Amsterdam University Press).

Comberg, E.L. (1991) Women and Alcohol: Psychosocial Aspects, in: Pittman D.J., White H.R., Society, Culture and Drinking Patterns Reexamined, New Brunswick, NJ, Rutgers Centre of Alcohol Studies).

Grant, F.G., Harford, T.C., Chou, P., Pickering, M.S., Dawson, D.A., Stinson, F.S. \& Noble, J. (1991) Prevalence of DSM-III-R Alcohol Abuse and Dependence, Alcohol Health and Research World, $15(1)$, pp. 91.96

Hammer, T. \& Vaglum, P. (1989) The Increase in Alcohol Consumption among Women: a phenomenon related to accessibility or stress? A General Population Study, British Journal of Addiction, 84, pp. 767-775.

Hosmer, D.W., Lemeshow, S., (1989) Applied Logistic Regression (New York, John Wiley \& Sons). Hooghiemstra, B.T.J., Niphuis-Nell M., (1993) Sociale Atlas wan de Froww, dl 2 Arbeid, inkamen en faciliteiten om werken en de zorg voor kinderen te combineren (Den Haag, Vuga).

Hupkens, C.L.H., Knibbe R.A. and Drop M.J. (1993) Alcohol consumption in the European Community: uniformity and diversity in drinking patterns, Addiction, 88, pp. 1391-1404.

Huselid, R.F. \& Cooper, M.L. (1992) Gender Roles as Mediators of Sex Differences in Adolescent Alcohol Use and Abuse, Joumal of Healh and Social Behavior, 33, pp. 348-362.

Jessen, J.L., (1974) Medische Consumptie, (Gronüngen).

Knibbe, R.A. (1984) Van gangbaar tot problematies drinkgedrag (Maastricht, University of Limburg).

Knibbe R.A., Drop M.J., Van Reek, J \& Saenger, G. (1985) The Development of Alcohol Consumption in the Netherlands: 1958-1981, British Journal of Addiction, 80, pp. 411-419. Kraft, J.M., Blum, T.C., Martin, J.K. \& Roman, P.M. (1993) Drinking Patterns and the Gender Mix of Occupations: Evidence from a National Survey of American Workers, Journal of Substance Abuse, 5, pp. 157-174.

Lemmens, P.H.H.M. (1987) Het Ledermamm-model Nader Bezien: Gevolgen van Onderschatting vaor de Verdeling van Alcoholconsumptie (Maastricht, University of Limburg).

Lemmens, P.H.H.M. (1991) Measurement and Distribution of Alcohol Consumption (Maastricht, University of Limburg).

Lemmens, P.H.H.M. (1994) Drinking for health: ballancing individual risk and public health hazards, Contemparary Dritg Problems, 21, pp. 251-271.

Lemmens, P.H.H.M., Knibbe, R.A., \& Tan, F.E.S. (1988) Weekly recall and diary estimates of alcohol consumption in a general population survey, Journal of Studies on Alcohol, 49, pp. 131-135.

Lemmens, P.H.H.M., Tan, F.E.S., \& Knibbe, R.A. (1992) Measuring quantity and frequency of drinking in a general population survey: a comparison of 5 indices, Joumal of Studies on Alcohol, 53 , pp. $476-486$.

Liban, C. \& Smart, R.G., (1980) Generational and Other Differences between Males and Females in Problem Drinking and its Treatment, Drug and Alcohol Dependence, 5, pp. 207-221. 
Mercer, P.W. \& Khavari, K.A. (1990) Are Women Drinking More Like Men? An Empirical Examination of the Convergence Hypothesis, Alcoholism, Clinical and Experimental Research, 14 (3), pp. $461-466$.

Neve, R.J.M. (1995) Changes in attitudes towards women's emancipation in the Netherlands over two decades: unraveling a trend, Social Science Research, Vol. 24, pp. 167-187.

Neve, R.J.M., Diederiks, J.P.M., Knibbe, R.A. \& Drop, MJ. (1993) Developments in Drinking Behavior in the Netherlands from 1958 to 1989, a cohort analysis, Addiction, Vol. 88, pp. 611-621. Perkins, H.W., (1992) Gender Patterns in Collegiate Alcohol Abuse: A 10-Year Study of Trends in an Undergraduate Population, Joumal of Studies on Alcohol, Vol, 53, pp. 458-462.

P.G.D. (1993) World Drink Trends, Produktschap voor Gedestilleerde Dranken (Henley on Thames, UK, NTC Publications).

Plant, M.L. (1990) Women and alcohol: A Review of the international literature on the use of alcohol by females (Copenhagen, World Health Organization).

Roman, P.M. (1988) Women and Alcohol Use: A Review of the Research Literature (Rockville, Md: U.S. Department of Health and Human Services).

Sælan, H., Moller, L. \& Koster, A. (1992) Alcohol consumption in a Danish cohort during 11 years, Scandinavian Journal of Social Medicine, 20, pp. 87-93.

Sandmaier, M. (1980) The Invisible Alcoholics (New York, McCraw-Hill).

S.C.P. (1994) Social and Cultural Report 1994, Sacial and Cultural Planning Office (Den Haag, VUGA).

Smart, R.G., Adlaf, E.M. \& Walsh, G.W. (1994) The Relationships between Declines in Drinking and Alcohol Problems among Ontario Students: 1979-1991, Joumal of Studies on Alcohol, Vol. 55, pp. 338-341.

Smith, A.R. (1986) Alcoholism and Gender: Patterns of Diagnosis and Response, Journal of Drugs Issues, 16, pp. 407-420.

Swinkels, H. (1991) Use of alcoholic beverages in the Netherlands, a comparison of some survey methods, Maandbericht Gezondheidsstatistiek, 12, pp. 5-12.

Swinkels, H. (1994) Hoe lichamelijk (in)actief zijn Nederlandse volwassenen in hun vrije tijd (How physically (in)active are Dutch adults during their leisure time), Maandbericht Gezondheidsstatistiek, 13.

Temple, M. (1986) Trends in Collegiate Drinking in California, 1979-1984, Joumal of Studies on Alcohol, Vol. 47, pp. 274-282.

Van Gelooven, R.M.W. (1990) Drinksituaties en drinkgedrag. Alcoholgebruik in her dagelijks leven (Maastricht, Rijksuniversiteit Limburg, thesis).

Vrij-Standhardt, W.G. (1991) The biokinetics of alcohol, in: Van der Hey, D.G. \& Schaafsma, G. (eds.) Biomedical and Social Aspects of Alcohol Use: A Review of the Literature (Wageningen, Pudoc).

Wilsnack, R.W., Wilsnack, S.C. \& Klassen, A.D. (1984) Women's Drinking and Drinking Problems: Patterns from a 1981 National Survey. American Journal of Public Health 74, pp. 1231-38.

Wilsnack, S.C. \& Wilsnack, R.W. (1991) Epidemiology of Women's Drinking, Joumal of Substance Abuse, 3, pp. 133-157.

W.V.C. Ministerie van Welzijn, Volksgezondheid en Cultuur (Ministery of Welfare, Public Health and Culture) (1986), Alcohol en Samenleving. Nota over een samenhangend alcohol-matigingsbeleid, (Alcohol and society, document on a coherent alcohol control policy), Tweede Kamer, 1986-1987, 19243 , nrs. $2-3$. 


\title{
Gender differences in alcohol use and alcohol problems: mediation by social roles and gender-role attitudes.
}

\author{
Rudie J.M. Neve, Paul H. Lemmens, Maria J. Drop.
}

Reprinted with permission from Substance Use and Misuse, Vol 32, pp. 1439-1459, 1997. Copyright by Marcel Dekker Inc., New York.

\begin{abstract}
This study assesses the causal place of Traditional Gender Role Attitudes (TGRA) in models for men and women, which also include social roles as explanatory variables for alcohol use and alcohol problems. Mediation of gender differences by TGRA occurs mainly in abstinence. Interaction effect is weak for alcohol consumption and frequency of heavy drinking. Most important explanatory variables are the status factors age and education, which are mediated by TGRA for a small part. Specific aspects of alcohol related problems are analyzed separately for the problem drinking category. Differences in results with other studies are discussed, and further study is proposed.
\end{abstract}

Key words: gender; status roles; gender-role attitudes; alcohol use; drinking problems.

\subsection{Introduction}

Drinking alcohol is bounded by socio-cultural factors. Beverages, amounts, occasions and places considered suited for drinking vary across cultures, and within cultures variation is observed accord ing to age, ethnicity, religion, and social status. (Gadourek, 1963; Pittman and Snyder, 1962; Pittman and White, 1991). Gender is a special case of a socio-cultural factor, as all other factors may have different implication for men and for women. Thus, it can be argued that differences in drinking behavior between men en women may vary across social and cultural categories, and they may vary over time. For instance, studies of acculturation after migration have shown that male and female alcohol consumption is adapted to the new culture, thereby changing the overall gender differences in alcohol use within the group (Adrian et al., 1995; Markides, Krause and Mendes de Leon, 1988).

A socio-cultural approach is also basic to the 'convergence hypothesis'. According to this hypothesis, in societies in which emancipatory processes occur, women become more like men with respect to roles and positions in society, and therefore, they will also become more like men with respect to behaviors that are considered negative and health threatening, such as heavy alcohol consumption. In periods of general increase of alcohol consumption, this would imply higher prevalence of alcohol related problems among women (for a critical review of the convergence discussion: see Fillmore, 1984; see also Roman, 1988). One way to test this hypothesis is to combine data from surveys covering several decades, which will show whether differences between men 
and women have actually become smaller. This approach has been applied several times, with varying results (for a brief review, see Neve et al., 1996). In the present study, a different approach is chosen. Convergence not only holds that gender differences in drinking become smaller over time, but also that they are smaller when differences in socio-cultural factors are smaller. Contrary to changes over time, the extent to which socio-cultural factors facilitate resemblance of men's and women's drinking can be investigated on the basis of cross-sectional data.

Two perspectives on socio-cultural differences in drinking behavior are employed. One possible explanation of gender differences in alcohol use is found in role theory (Knibbe, Drop and Muytjens, 1987), which predicts that behavior of men and women will look more alike to the extent that they hold the same type of roles and positions in society. An additional second approach holds that not only social roles, but also beliefs about proper masculine and feminine behavior could more directly explain behavioral differences between men and women (Parker and Harford, 1992). From this perspective, it is expected that drinking behavior of men and women is more equal to the extent that men and women are viewed as equal in a more general sense. Both role theory and the gender role attitudes perspective are discussed in more detail with respect to their explanation of gender differences in drinking behavior.

\subsubsection{Roles and alcohol use.}

One way to explain gender differences in drinking behavior is to look at women's roles in society, as compared to men's. Although often more implicit than explicit, it is argued that certain positions in society are related to sets of expectations, which give direction to behavior of individuals (i.e. drinking behavior) and to societal reactions to this behavior. The already mentioned discussion on convergence of male and female alcohol use can be viewed as an example of implicit role theorizing. A more articulated approach of role theory in the alcohol field was developed by Knibbe et al,, (1987), who built on Gerhardt's (1971) distinction of status roles and positional roles in order to develop a role perspective on the etiology of problem drinking. Status roles involve social expectations based upon characteristics that the individual cannot easily influence. From this point of view, gender is considered a status role, along with age, religion and social class. Status roles determine the appropriate 'wetness' of situations. Thus, the amount and style of drinking considered appropriate in certain situations may be different for women than for men (Knibbe et al., 1987). Women's roles in society, which emphasize nurturant and caring obligations, are more likely to conflict with heavy drinking and drunkenness than men"s (Gomberg, 1991).

Positional roles are expectations related to positions in social networks such as work and family. Positional roles structure everyday life of the individual, they determine what kind of situations an individual enters (Knibbe et al., 1987). From a sociological point of view, the life course can be viewed as a sequence of positional roles. Marked differences in the life course of men and women may be expected to lead to differences in effect of positional roles on drinking behavior (Neve, Knibbe et al., 1993). Work roles and family roles can be distinguished as two main sets of positional roles, which have a different impact on the lives of men and women. Important change 
in women's position in society has been attributed to increasing employment rates of women. In the Netherlands, female employment rates have increased from $26.2 \%$ in 1960 to $47.0 \%$ in 1993 (SCP, 1994). Caution is warranted with respect to the idea that increase in female employment rates will directly lead to increase in drinking problems among women (Wilsnack and Wilsnack, 1992). Nevertheless, it has been shown that employed women drink more than other women (e.g. Neve et al., 1996). Although men are observed to share more in care for children in the family than they used to, family roles are still more important in the lives of women, even when they work outside the home (Gerson, 1993). Altogether, it can be argued that women, because of their positions in society, still enter fewer situations that involve drinking than men.

Empirically, the relevance of status and positional factors for the study of drinking behavior is well established. Gender and age, as well as social class and positional role variables have been reported as important correlates of alcohol consumption for decades (e.g. Cahalan, Cisin and Crossley, 1969; for the Netherlands: Gadourek, 1963). We expect to confirm results from other Dutch surveys, holding that gender differences in drinking behavior are smaller at older age and among higher educated (Knibbe et al., 1985; Neve, Diederiks et al., 1993). With respect to positional roles, it is expected that drinking behavior among women who work and/or women who do not take care of a family with children resembles men's drinking behavior more than other women's (Neve et al., 1996).

\subsubsection{Gender-role attitudes and alcohol use.}

More or less implicit in discussions on gender differences in alcohol use has been the idea, that women's 'liberation' from traditional female roles will cause an increase in levels of alcohol consumption and problem drinking among women. In this way, women's alcohol consumption is connected to women's 'emancipation': the process in western society by which women gradually acquire equal rights and obligations in work as well as in family situations. Equal rights may also be seen as: the right to drink in equal amounts and in the same manner as men. Drinking norms may therefore be expected to be more equitable among layers of the population with more favorable attitudes toward gender equality. Not only have roles and positions in society changed, but also has gender equality ideology diffused in the population in varying degrees (Alwin, Braun and Scott, 1992; Neve, 1992; 1995). Traditionally, masculinity is associated with heavier drinking, while femininity is associated with abstinence and moderate drinking. Therefore, it is to be expected, that differences between men and women in drinking behavior as well as in alcohol related problems are smaller in groups with more egalitarian gender-role attitudes.

Thus far, only few studies have explicitly included attitudes towards gender-roles in explanations of gender differences in drinking behavior. Huselid and Cooper (1992) have shown that gender role attitudes intermediate gender differences among adolescents in part. Wilsnack et al. (1991) report a positive association between heavy episodic drinking and 'non traditional gender role attributes' among women (men were not included in this study). According to Parker and Harford (1992), the effect of egalitarian gender role attitudes on drinking behavior is gender specific and combined 
with employment. Among employed men, especially when job competition is high, alcohol use is higher when gender role attitudes are more egalitarian. The opposite is found among employed women: more traditional gender role attitudes are associated with higher consumption. The authors interpret their findings in terms of stress-inducing role overload that is self-medicated with alcohol. Responsibility for family affairs, associated with egalitarism among men and with traditionalism among women, is added to the daily competition on the workplace. This brief review shows that the few studies that include gender role attitudes in analyses of drinking behavior yield contradictory results. Whereas sex differences in drinking are larger among the more traditional in one study, the opposite is found in the other. A common factor is that gender role attitudes do explain a distinct portion of the variance in drinking behavior.

Earlier studies have shown that gender role attitudes are influenced by status and positional factors (Alwin et al., 1992; Neve, 1995). Therefore, it is to be expected that the effects of status and position variables on drinking behavior is mediated through gender role attitudes.

Expectations concerning alcohol related problems.

It is obvious that problems with alcohol are basically due to drinking, that is, by the amount of alcohol consumed and the way it is consumed. In turn, patterns of alcohol consumption are expected to be associated with status factors and social positions. From the perspective of role theory, it can be conceived of that vulnerability to certain drinking problems varies across sets of status roles and positional roles at comparable consumption levels. This will hold especially when drinking problems have a cultural dimension, e.g. when disapproval of behavior by significant others is involved. Different norms and expectations are attached to different social roles, causing differences in drinking practices as well as in modes of social control. For instance, heavy drinking and even occasional drunkenness is quite accepted for young men (Knupfer and Room, 1964), although more recently it causes worry because of its connection with automobile accidents (Gomberg, 1982). In the following, our discussion concentrates on gender differences and gender role attitudes, and we refrain from formulating specific expectations with respect to severity or type of alcohol related problems in relation to status and position factors other than gender.

Several types of alcohol related problems may be distinguished, such as symptoms of alcohol dependence, health problems due to drinking, and social consequences, such as disapproval from others. Because the latter type of drinking problem is of special interest for the present study, we formulate some specific expectations. Disapproval from significant others and the prevalence of conflicts with others or with the law may be expected to vary by sex. Competing hypotheses can be conceived of in this respect ${ }^{1}$. It is widely believed that women's drinking is generally less accepted than

"Use the term "competing hypotheses" may seem to imply that either of the hypothesis is 'true" under all circumstances and the other is not, which is not necessarily the case. In the 'real world' the causal link between roles, attitudes and drinking behavior on the individual level is probably contingent upon various, often unknown factors, which may be denoted as 'chaos' (Skinner, 1989). However, at present available data and research methodology do not allow overcoming a 'linear cause-and- 
men"s, and from this point of view, it would be expected that women meet more disapproval when they drink to the same extent as men. This idea may be denoted as the 'vulnerability hypothesis'. However, several studies have shown that women report less drinking problems, including disapproval from others, even when consumption level was controlled for (Knibbe et al., 1987; Robbins and Martin, 1994). This finding has been explained by women's more controlled behavior, even when intoxicated, which would cause women's heavy drinking to remain unnoticed (Robbins, 1989). In agreement, Fillmore et al. (1995) interpret the lower risk for problems with an 'acting out' nature among women by mediation of cultural expectations of the relationship between consumption and drinking problems (see also Ferrence, 1980). A related explanation holds that women can drink too much, but still do not fit the very negative image of female drunkenness. This may lead significant others to deny the drinking problem altogether (Robbins and Martin, 1994). This idea may be indicated as a 'cultural expectations' hypothesis. From this point of view, it would be expected that women's drinking would be less disapproved of than men's at the same consumption level. Women would rather be expected to have different problems, such as health problems or depression.

Both hypotheses also lead to different expectations with respect to the influence of gender role attitudes. It would seem that differentiation in social disapproval between men and women is related to gender role attitudes. The vulnerability hypothesis would predict that persons, who believe that men and women should be equal, would equally condemn men's and women's drinking. Thus, criticizing women more than men would be expected to be related to traditional gender role attitudes. This hypothesis predicts relatively more social consequences for women in categories of the population with more traditional attitudes. Contrary to the 'vulnerability hypothesis', the 'cultural expectations' hypothesis would predict that expectations denying women's problem drinking are stronger among persons who hold traditional gender role attitudes. Therefore, it would be expected from the cultural expectations hypothesis that women's drinking, within consumption categories, meets more disapproval from others among categories with more egalitarian attitudes towards women"s roles.

\subsection{Methods}

A representative sample was taken of the population of the Dutch province of Limburg, in the South-eastern part of the country, bordering on Belgium and Germany. Other than the North of the country, the population (about 1 million inhabitants) is predominantly Catholic. The Southern part of the province, with the capital Maastricht, is densely populated and industrialized, whereas the Northern part is somewhat less urbanized. 1980 persons (response rate $76 \%$ ) aged between 16 and 64 were interviewed in 1980 by a large survey agency by assignment of the University of Limburg (Knibbe et all., 1987). A follow up survey was conducted in 1989 (Hajema, Knibbe and Drop, 1994). Respondents identified as problem drinkers in 1980 were 
reinterviewed face-to-face at their homes by university personnel $(\mathrm{n}=309)$, response rate was $69.3 \%$ ( 137 refusals). Criteria used for identification as a problem drinker in 1980 were twofold. First, a consumption criterion was used: either 6 or more glasses at least once per week or 4 or 5 glasses at least 21 times per month. The second criterion was a positive score on a multidimensional drinking problems index (Knibbe, 1982), based on Cahalan's index (Cahalan, 1970). Other respondents $(n=1019,430$ nonrespondents) returned a mail questionnaire, which was sent accompanied by a letter from the university indicating that they were invited to participate in a follow-up of the first measurement in 1980 of health behavior. 85 baseline respondents deceased during the follow-up period. Thus, data were collected on a total of 1328 respondents for a $70 \%$ overall response rate at follow up. Deceased respondents account entirely for the elevated non-response among the older age category. Non-response was also relatively high among the lower educated. Alcohol consumption and problem drinking in 1980 were not associated with non-response at follow-up. Questions on gender role attitudes were added in the follow up survey, for which reason only the follow up data are used in the present study.

Status role variables included in the study are education and age. Education is included as a proxy for social status. Education has 8 categories according to the Dutch educational system. Age is included as year of birth. Since the sample consist of Catholics for $85 \%$, of whom $80 \%$ practicing, religion is not included in the analyses, as it lacks variation. Positional role variables are marital status (living with/without a partner), family status (children at home/no children at home) and employment (employed/not employed).

The four items that form the scale 'traditional gender role attitudes' (TGRA), were first introduced in research on 'progressiveness and conservatism' in 1970 (Middendorp, 1978) and later included in regularly held 'Cultural Changes' surveys by the Netherlands Social and Cultural Planning Office (SCP, 1992). In all studies in which they were included, the items have been found to load on a single dimension. The items and factor loadings in the present data are:

1. A woman is more competent in raising small children than a man (.70).

2. In a firm it is abnormal for women to hold a position of authority over men (.77).

3. It is not as important for a girl to get a good education as it is for a boy (.76)

4. After all, boys can be educated in a more liberal fashion than girls (.74)

The items are combined in an additive scale, Cronbach's alpha is .72. The distribution of the scale is skewed to the left, mean and median are both close to 2 on a 5 point scale. It was shown earlier (Alwin et al., 1992; Neve, 1992) that gender role attitudes are associated with cohort succession.

Abstinence is assessed by questions on whether respondents drank alcohol in the last six months before the interview. Alcohol consumption is measured by a 'weekly recall' method. Respondents were asked to report the number of glasses (containing about 10 grams ethanol for most beverages) they had on each of the seven days preceding the interview or the filling in of the questionnaire. Frequency of drinking 6 or more glasses on one occasion is assessed with an 8-category format, ranging from 'never' to 'every day'. The categories are converted to a weekly frequency measure. In 
Table 4.1. Means for all variables in the analyses and some background variables in percentages.

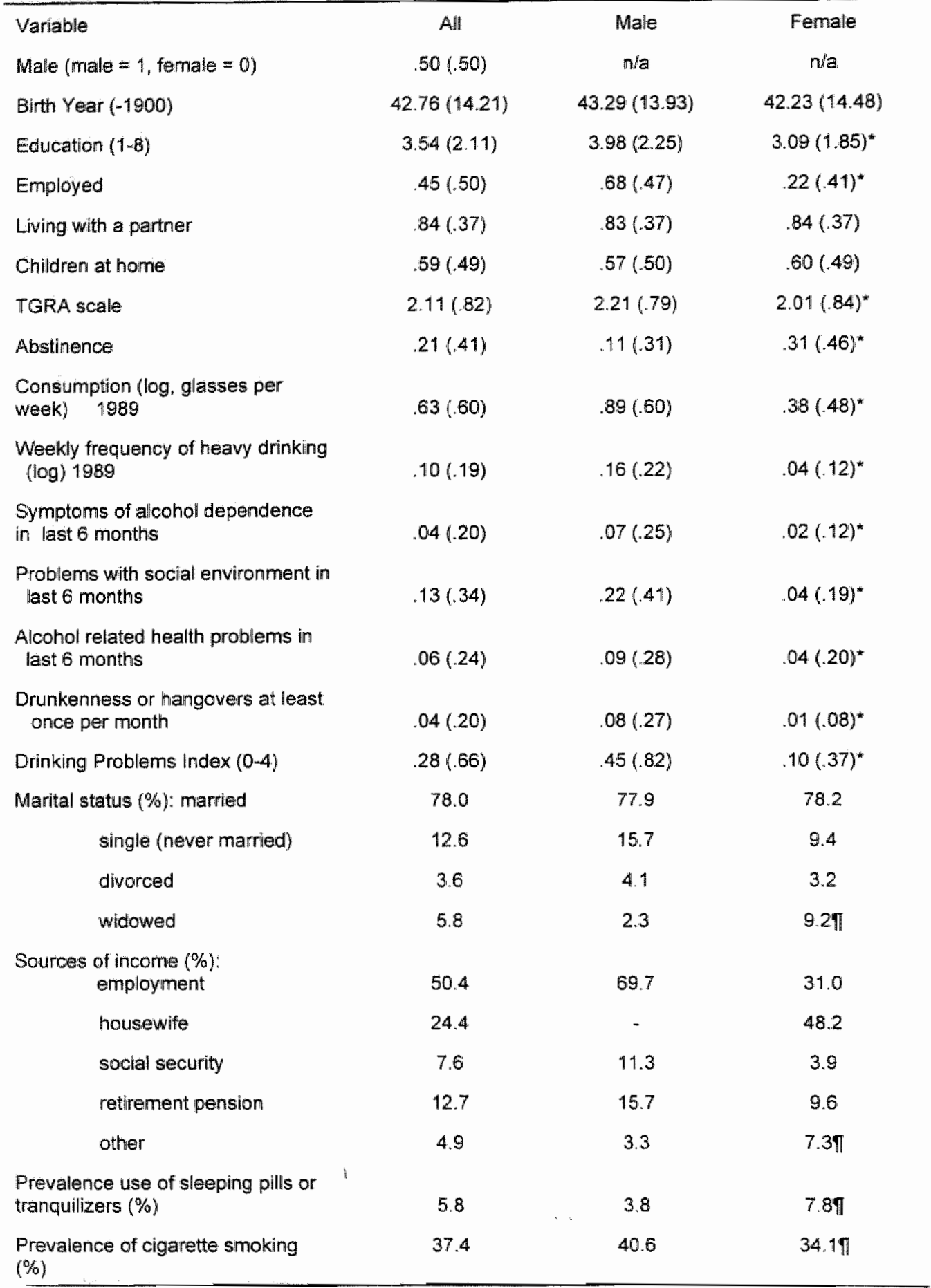

Note: standard deviations appear in parentheses. ${ }^{*} p<.05$ t-test If $p<.05$ Chi square test. 
Table 2. Coefficients of logistic regression of abstinence.

\begin{tabular}{lccl}
\hline & Total & Men & Women \\
Man & $-1.06^{*}$ & & \\
TGRA & $.22^{*}$ & .10 & .26 \\
Birth Year & $-.03^{*}$ & -.01 & $-.03^{*}$ \\
Education & $-.22^{*}$ & $-.23^{*}$ & $-.22^{*}$ \\
Employed & $1.18^{*}$ & 1.09 & .54 \\
Employed by TGRA & $-.80^{*}$ & $-1.04^{*}$ & -.33 \\
Constant & .46 & -.73 & -.28 \\
Improvement $\left(\mathrm{R}^{2}\right)$ & $15.4 \%$ & $11.0 \%$ & $10.0 \%$ \\
\hline
\end{tabular}

Note: * $p<.05$

order to mitigate skewness, a logarithmic transformation is used for consumption and frequency of heavy drinking. The Drinking Problems Index (DPI) is adapted from Cahalan's index (Cahalan, 1970; Hajema et al., 1994; Knibbe et al., 1987) and includes four distinct aspects: symptoms of alcohol dependlence ( 7 items), social consequences ( 6 items), health problems related to alcohol ( 4 items), and monthly or more frequent drunkenness or hangovers ( 2 items). Each of the four drinking problems accounts for one point on the drinking problems index (DPI), which ranges from 0 to 4.

Effects of status roles, positional roles and TGRA on drinking behavior and alcohol related problems are assessed using multivariate methods of analysis. Analyses are performed in the entire sample and separately for males and females. Abstinence is analyzed using logistic regression. Linear structural modelling is used in order to estimate effects on consumption, frequency of heavy drinking and alcohol related problems in an integrated way. In order to separate factors that explain consumption of drinkers from factors that explain abstinence, the analyses are conducted in the entire sample, as well as under exclusion of abstainers. The Drinking Problems Index (DPI), rather than the separate drinking problem dimensions are used in this analysis, because - especially among women - the prevalence of separate drinking problems is too low to allow inclusion in the model. Therefore, an additional third analysis is performed within the group reporting any alcohol related problem, in which the four separate dimensions of the drinking problems index (DPI) are analyzed using logistic regression.

\subsection{Results}

Table 4.1 shows the variables in this study by gender. Men are higher educated and more often employed then women. Women show less traditional gender role attitudes than men. Gender differences in abstinence, consumption, frequency of heavy drinking and alcohol related problems are all significant. Some background and behavioral 
characteristics of the sample are given as well. Compared to men, women are less often single and more often widowed, and they are more often homemakers. Prevalence of cigarette smoking is lower, and prevalence of use of sleeping pills and tranquillizers is higher among women than among men.

In logistic regression analysis of abstinence, interaction of all variables with gender and TGRA were included initially and removed backwards when not significant at 05 \|evel. The percentual improvement of the log-likelihood ratio is presented as an analog to $R^{2}$ in multiple regression (Hosmer and Lemeshow 1989:148). Table 4.2 shows that abstinence is associated with being female, holding a more traditional gender role attitude, older age and lower education. Of all three positional roles, only the effect of employment appears to be significant, and it interacts with gender role attitudes. The interaction term indicates that employed people with more traditional gender role attitudes are less often abstainers. Separate analyses for men and women show that especially employed men holding more traditional gender role attitudes are unlikely to abstain from alcohol. Among women, employment has no effect on abstinence.

Women seem to be slightly more likely to abstain from alcohol when they hold more traditional gender role attitudes, although this effect is not significant. Since men are employed far more often than women (table 4.1), it can be concluded that gender difference in abstinence is larger among those who hold more traditional gender role attitudes.

In order to assess the causal position of roles, traditional gender role attitudes with respect to drinking behavior and drinking problems, integrated structural models were estimated with Lisrel ${ }^{2}$. All non-significant parameters in initial saturated recursive models were set zero in order to arrive at the structural models presented. No causal direction was assumed between consumption and frequency of heavy drinking, which variables are known to correlate highly. Therefore, a parameter for this correlation is left free, while the corresponding effect parameters are fixed at zero in the initial model.

Presentation is limited to separate models for men and women. Gender effects in the entire sample (male coded 1, female coded 0 ) are briefly reported here. Compared to women, men report more traditional gender role attitudes (standardized effect .18), higher consumption (.35) and frequency of heavy drinking (.26). When consumption and frequency of heavy drinking are controlled, men show more alcohol related problems than women (standardized effect .11). Effect of TGRA appeared significant

\footnotetext{
${ }^{2}$ Because dichotomous and ordinal variables are included in the model, all analysis were performed also on the basis of correlation matrices with polychoric correlations for the ordinal variables (SPSS, 1990). Compared to mormal covariance matrices, this method yields higher parameter estimates and better fit, but it leads to no other conclusions. Analysis based on covariance matrices has the advantage of producing non-standardized parameter estimates that allow comparison of separate analyses of subsamples of men and women (Pedhazur and Schmelkin 1991:422). However, comparison based on unstandardized estimates leads to the same conclusions than comparison of standardized estimates. Therefore, standardized parameters are presented.
} 


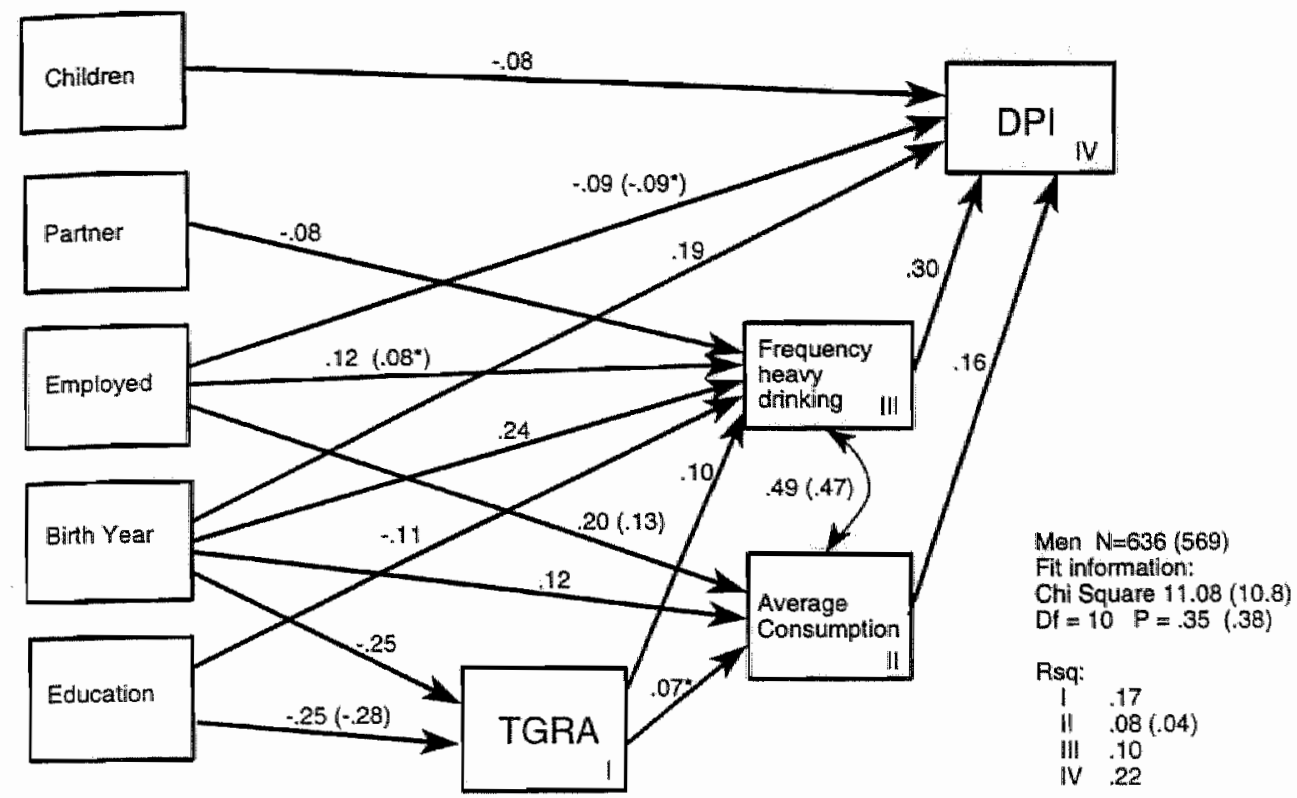

Figure 4.1 Structural model: men. Results under exclusion of abstainers are given in parentheses when they differ from the model for the entire sample. " N.S. $p>.05$

only for frequency of heavy drinking (.08), which means that gender effect on frequency of heavy drinking is mediated in part through TGRA.

Figures 4.1 and 4.2 show the estimated models for men and women separately. Results under exclusion of abstainers are given in parentheses. In order to avoid too complicated presentation, results under exclusion of abstainers are given only when the difference in the parameter is larger than .02 and/or when the parameter looses significance (.05 level). Models for men and women are discussed simultaneously.

Results with respect to TGRA indicate that consumption is lower among more traditional women, and higher among more traditional men. However, the parameter is not significant $(p<.10)$ among men. Effect of TGRA on frequency of heavy drinking is positive among men (.10), indicating that gender difference in frequency of heavy drinking is larger among more traditional people. Gender by TGRA interaction was tested separately with multiple regression by inclusion of a multiplicative term and appeared significant for both consumption (beta $.26, \mathrm{p}<.001$ ) and frequency of heavy drinking (beta $.19, \mathrm{p}<.05$ ). This analysis controlled for status and position factors. When abstainers were excluded, parameters for effect of TGRA on consumption among women was no longer significant. Also, gender by TGRA interaction terms for consumption and frequency of heavy drinking were no longer significant under exclusion of abstainers.

Younger men show less TGRA, higher consumption and frequency of heavy drinking and more alcohol related problems than older men. Among women, effect of birth 


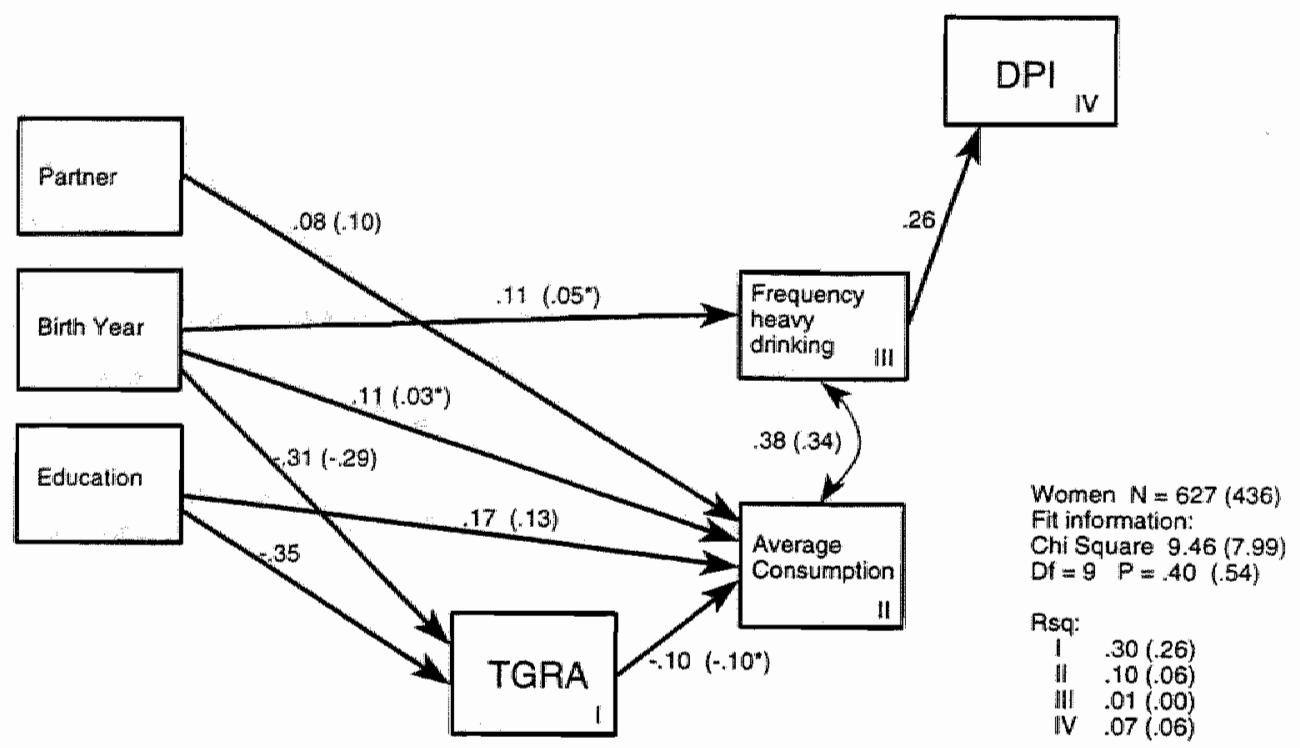

Figure 4.2 Structural model: women. Results under exclusion of abstainers are given in parentheses when they differ from the model for the entire sample. *N.S. $p>.05$

year on consumption and frequency of heavy drinking is both .11, but it appears to be non-significant when abstainers are excluded. Higher education is associated with lower frequency of heavy drinking among men and with higher consumption among women. Effect of birth year on consumption is mediated through TGRA among women. Among men, effects of education and birth year on frequency of heavy drinking are mediated through TGRA. However, since the effect of TGRA on frequency of heavy drinking is small, these mediation patterns account for only a small part of the total correlation.

Among women, only one single effect of positional roles is found: women who live with a partner report higher consumption. Men show a more complicated pattern of effects. Living with a partner is associated with lower frequency of heavy drinking among men. Having children at home does not affect men's consumption and frequency of heavy drinking, but when these drinking variables are controlled, alcohol related problems are lower. Employed men report higher consumption and frequency of heavy drinking than men who do not have a job, and when these variables are controlled, they also report less alcohol related problems. Positional role variables are not correlated with TGRA in either of the analyses. Thus, no mediation of effects on drinking behavior occurs.

When abstainers are removed from the analysis, effect of employment on frequency of heavy drinking and DPI is no longer significant at $5 \%$ level, while effect on consumption decreases. 
Table 4.3. Coefficients of logistic regression of separate drinking problems in the group that scores on the Drinking Problems Index. ( $N=256$ )

\begin{tabular}{lcccc}
\hline & Symptoms & Environment & Health & $\begin{array}{c}\text { Drunkenness/ } \\
\text { Hangovers }\end{array}$ \\
Man & 1.17 & $1.03^{*}$ & $-1.02^{*}$ & .70 \\
Birth Year & .02 & .02 & .01 & .04 \\
Education & $.45^{*}$ & .14 & $-.25^{\star}$ & $.62^{*}$ \\
Man by Education & -.43 & & & \\
Employment & -.07 & -.29 & .14 & .39 \\
Married/cohabiting & .45 & $.86^{*}$ & $-.95^{*}$ & $-1.07^{*}$ \\
Children at home & -.30 & $2.00^{*}$ & -.39 & -.01 \\
TGRA & .29 & .51 & .12 & 1.03 \\
TGRA by Children & & -.96 & & $-.31^{*}$ \\
TGRA by Education & & & & $.91^{*}$ \\
Consumption & $1.07^{*}$ & .26 & -.05 & \\
Frequency of & & & & $2.51^{*}$ \\
heavy drinking & .64 & -.02 & -.58 & -7.22 \\
Constant & -5.71 & -1.68 & 1.45 & $25.5 \%$ \\
\hline Improvement $\left(R^{2}\right)$ & $11.2 \%$ & $8.1 \%$ & $10.0 \%$ & \\
\hline Note* * $P<05$ & & & &
\end{tabular}

In the subsample of people scoring 1 at least on DPI $(n=256)$, prevalence of separate aspects of drinking problems is analyzed using logistic regression. Table 4.3 shows results after backward deletion of non-significant interaction terms of gender and TGRA with status and positional role variables.

Table 4.3 shows that gender differences in problems with others and health problems are significant when drinking behavior, status and positional roles and TGRA are held constant. Men report more social consequences, while women report more alcohol related health problems.

With respect to status roles, table 4.3 shows that birth year has no significant effects on any type of drinking problems. A man by education interaction term offsets the main effect of education on symptoms of alcohol dependence, which shows that level of education has effect only among women. Among higher educated women, alcohol related health problems are less prevalent than among lower educated women. A positive association is found between education and the prevalence of frequent drunkenness and/or hangovers. 
People who live with a partner report more social consequences of drinking and less health problems and drunkenness/hangovers. Effect of TGRA is significant for social problems and drunkenness/hangovers. A significant interaction term appears for having children by TGRA. In order to interpret this term, note that it is known from table 4.1 that the average score on TGRA is about 2 . From this it follows that the effect of having children on social consequences is about zero on average (i.e. $2.00-2$ * .96), and that it varies significantly around this average by TGRA. This indicates that more drinkers with more traditional gender role attitudes are less often criticized by others when they have children at home, whereas their more egalitarian counterparts get criticized more often. Finally, TGRA by education interaction shows that more educated people with more traditional gender role attitudes report to get drunk or have a hangover less often.

\subsection{Discussion}

Our expectation, that differences between men and women are larger among people with more traditional gender role attitudes, was confirmed to some extent. More traditional gender-role attitudes are associated with lower abstinence rates and higher frequency of heavy drinking among men and with more abstinence and lower consumption among women. Gender by TGRA interaction effect on consumption and frequency of heavy drinking is not significant when abstainers are excluded from analysis. From this it can be concluded that gender role attitudes are associated with the choice either or not to drink rather than with the consumption level of drinkers. Our analysis made clear that the difference in abstinence operates in combination with employment: especially more employed men who hold more traditional gender role attitudes very rarely reported to be abstainers.

Effects of status factors age and social class (education) on consumption and frequency of heavy drinking were mediated through TGRA for some part. However, it was noted that this mediation effect accounted for only a small part of the total correlation. Mediation of status roles' effects was stronger among women, but even then it did not account for a large part of the total effect of social class on consumption. Most of the effect of status roles is direct effect. We conclude that the inclusion of TGRA adds some nuance to models, but it does not change their structure.

Contrary to results of earlier surveys, gender differences in abstinence, consumption, and frequency of heavy drinking are not smaller among older age groups. As expected, gender differences in drinking behavior are smaller among the higher educated.

Whereas age and education appear as significant predictors in almost every analysis, positional role variables have a more partial relevance. Women living with a partner drink more than other women, whereas the presence of a partner leads men to drink less. This result is in agreement with earlier observational studies among adolescents (e.g. Van de Goor, Knibbe and Drop, 1990). Having children has effect on alcohol related problems: among men, effect of having children on drinking problems was negative when consumption was controlled for. Among men, employment leads to higher consumption and more frequent heavy drinking. Employed men report less 
alcohol related problems, when consumption and frequency of heavy drinking are controlled for.

Contrary to what would be expected. from the perspective of the 'vulnerability hypothesis', men appeared to report higher prevalence of alcohol related problems, even when drinking behavior was controlled for. This is in agreement with findings in the baseline study (Knibbe et al. 1987), and with the 'cultural expectations' hypothesis. Also in agreement with expectation from the cultural expectations hypothesis, further analysis within the group of 'problem drinkers' showed that men especially report more negative reactions from others. Women, on the other hand, report significantly more health problems attributed to alcohol.

An interesting result of the further analysis of the separate problem drinking dimensions was evidence that effect of having children mainly occurred for social consequences, and that this effect interacted with traditional gender role attitudes. The more traditional the gender role attitudes, the smaller the chance that a drinker who has a family was criticized by significant others. This result, although now less than conclusive, warrants further investigation. Social consequences consist largely of disapproval from the partner. Alcohol education campaigns in the Netherlands often try to influence drinking behavior of men through the female partner. Therefore, educational work could be better informed if more was known about the way disapproval with excessive drinking behavior operates within more traditional and more egalitarian relationships. The inclusion of this dimension could add to research on drinking control within the family (e.g. Holmila, 1988).

The absence of effects of employment on any aspect of drinking behavior among women is contrary to expectation and contrary to earlier reports. A possible explanation for this deviation is that employment among women is strongly related to age and educational level, which may cause the effect of employment to be redundant in analyses that control for these variables. Especially in the age categories over 26 years, female employment is strongly associated with higher education (Neve, 1995). Furthermore, in the present sample, the female employment rate is somewhat lower than usual in Dutch general population surveys, which may be explained by the age range of this follow up survey, which excluded the categories under 26 years of age and included more older people.

Our analyses in the female subsample, especially those of separate alcohol related problems, yielded few significant results. This may be explained by pointing to the low prevalence of heavy drinking en alcohol related problems among women and to the fact that many women are abstainers. The latter leads to rather low numbers in analyses under exclusion of abstainers. By restricting the analysis to those who report any alcohol related problem, we were still able to answer our research question tentatively. However, in order to obtain more clarity with respect to the backgrounds and the consequences of drinking among women, it would be advisable to oversample heavier drinking women in future surveys, as was done earlier in a US study (Wilsnack et al., 1991).

Interestingly, our results concerning the effect of gender-role attitudes on both sexes are opposite to those of Parker and Harford (1992), who reported that more egalitarian gender role attitudes lead to higher levels of alcohol consumption among 
men and lower among women. Other than in our study, this was found among the employed, and especially when job competition was high. Several explanations for the difference in findings could be proposed. Parker and Harford's finding may be restricted to situations of heavy job competition. Difference in operationalization may be the cause of the divergence of results. Parker and Harford's operationalization of gender-role attitudes involves 3 items that relate very closely to the division of labor in the family. Our items reflect a more general type of traditionalism (Middendorp, 1978); they relate to the actual behavior of individual actors less directly than the items used by Parker and Harford. However, the divergence between Parker and Harford's and our own results still remains remarkable in view of the gradual difference between the operationalizations. Future surveys on gender differences in drinking behavior should contain more elaborate operationalizations of gender role attitudes, including more general items, as well as items more specific to alcohol use. In this way, the contradictory results on the relevance of gender role attitudes to alcohol use and alcohol related problems could be clarified.

\section{References.}

Adrian, M., Dini, C.M., MacGregor, L.J., Staduto, G. (1995) Substance use as a measure of social integration for women of different ethnocultural groups into mainstream culture in a pluralist society: the example of Canada, International Journal of the Addictions, 30, 699-734.

Alwin, D.F., Braun M., and Scott J. (1992) The separation of work and the family: attitudes towards Women's labour-force participation in Germany, Great-Britain and the United States. European Saciological Review, 8, 13-37.

Cahalan, D. (1970) Problem Drinkers. San Fransisco: Jossey-Bass.

Cahalan, D., Cisin, I.H., and Crossley, H.M. (1969) American Drinking Practices. New Brunswick, NJ: Rutgers Centre of Alcohol Studies.

Ferrence, R.G. (1980) Sex differences in the prevalence of problem drinking. In Kalant, O. Alcohol and Drug Problems in Women. Research Advances in Alcohol and Drug Problems, New York, Plienum Press 1980, 5, 69-124.

Fillmore, K.M. (1984) 'When angells fall', women's drinking as cultural preoccupation and as reality. In Wilsnack, S.C.y and Beckman, L.J. Alcohol problems in women, antecedents, consequences and intervention, New York/London: Guilford Press.

Fillmore, K.M., Golding, J.M., Kniep, S. et al. (1995) Gender differences in the risk of alcohol-related problems in multiple national contexts. Recent Developments in Alcoholism, 12, 409-439.

Gadourek, I. (1963) Riskante Gewoonten en Zorg voor Eigen Welzijn /Hazcordous habits and human well-Being]. Groningen, Netherlands: Wolters.

Gerhardt, U. (1971) Rollenanaiyse als Kritische Soziologie. Berlin: Luchterhand.

Gerson, K. (1993) No Man's Land, Men's Changing Commitments to Family and Work. New York: Basic Books.

Gomberg, E.S.L. (1982) Special populations. In Gomberg, E.S.L., White, H.R., and Carpenter, J.A. Alcohol, science \& society revisited. Ann Arbor, MI: University of Michigan Press.

Gomberg, E.S.L. (1991) Women and alcohol: psychosocial aspects. In Pittman, D.J, and White, H.R. Society, culture and drinking patterns reexamined. New Brunswick, NJ: Rutgers Centre of Alcohol Studies.

Hajema, K., Knibbe, R.A., and Drop, M.J. (1994) Chronische probleemdrinkers in de bevolking en probleendrinkers bij het CAD: een vergelijking (Chronic problem drinkers in the population and in treatment, a comparison). Maastricht: Rijksuniversiteit Limburg.

Holmila, M. (1988) Wives, husbands and alcohol: A study on informal drinking control within the fomily. Helsinki: Finnish Foundation for Alcohol Studies. 
Hosmer, D.W., and Lemeshow, S. (1989) Applied Logistic Regression. New York: Wiley.

Huselid, R.F., and Cooper, M.L. (1992) Gender roles as mediators of sex differences in adolescent Alcohol use and abuse. Journal of Health and Social Behowior, 33, 348-362.

Knibbe, R.A. (1982) Probleemdrinken in Limburg (Problem Drinking in Limburg), Maastricht, NL: University of Limburg.

Knibbe, R.A., Drop, M.J., and Muytjens, A. (1987) Correlates of stages in the progression from everyday drinking to problem drinking. Social Science and Medicine, 24, 463-73.

Knibbe, R.A., Drop MJ., Van Reek, J, and Saenger, G. (1985) The dewelopment of alcohol consumpm tion in the Netherlands: 1958-1981, British Joumal of Addiction, 80, 411-419.

Knupfer, G., and Room, R. (1964) Age, sex and social class as factors in amounts of drinking in a metropolitan community, Social Problems, 12, 224-240.

Markides, K.S., Krause, N.y and Mendes de Leon, C.F. (1988) Acculturation and alcohol consumption among Mexican Americans: a three generation study, American Journal of Public Health, 78, 1178 81 .

Middendorp, C.P. (1978) Progressiveness and Conservatism: the fundamental dimensions of ideological controversy and their relationship to sacial class, The Hague: Mouton.

Neve, R.J.M. (1992) Developments in the attitudes towards women's emancipation in the Netherlands from 1970 to 1985, a cohort analysis. In Becker H.A., Dynamics of Cohort and Generations Research. Amsterdam: Thesis Publishers.

Neve, R.J.M. (1995) Changes in attitudes towards women's emancipation in the Netherlands over two decades: unraveling a trend. Social Science Research, 24, 167-187.

Neve, R.J.M., Diederiks, J.P.M., Knibbe R.A., and Drop, M.J. (1993) Developments in drinking behavior in the Netherlands from 1958 to 1989 , a cohort analysis. Addiction, 88, 611-621.

Neve, R.J.M., Drop, M.J., Lemmens, P.H., and Swinkels, H. (1996) Gender differences in drinking behavior in the Netherlands: convergence or stability? Addiction, $91,357-373$.

Neve, R.J.M., Knibbe, R.A., Drop, M.J., and Diederiks, J.P.M.(1993) Alcohol use, the life course and the sociology of aging, an exploration of the literature. Paper presented at the 19th Annual

Epidemiology Symposium of the Kettil Bruun Society for Social and Epidemiological Research on Alcohol, Kraków, Poland, June, 1993.

Parker, D.A., and Harford, T.C. (1992) Gender-role attitudes, job competition and alcohol consumption among women and men. Alcoholism: Clinical and Experimental Research 16, 159-165.

Pedhazur, E.J., and Schmelkin, L.P. (1991) Measurement, Design and Analysis, An Integrated Approach, Hillsdale $\mathrm{NJ}$ : Lawrence Erlbaum.

Pittman, D.J., and Snyder, C.R., Eds. (1962) Society, Culture, and Drinking Patterns. New York: Willey.

Pittman, D.J., and White, H.R., Eds., (1991) Society, Culture, and Drinking Patterns Reexamined, New Brunswick, NJ: Rutgers Centre of Alcohol Studies.

Robbins, C.A. (1989) Sex differences in psychosocial consequences of alcohol and drug abuse. Joumal of Health and Social Behavior, 30, 117-130.

Robbins, C.A., and Martin, S.S. (1993) Gender, styles of deviance, and drinking problems. Journal of Health and Social Behavior, 34, 302-21.

Roman, P.M. (1988) Women and Alcohol Use: A Review of the Research Literature. Rockville, MD: Alcohol, Drug Abuse and Mental Health Administration.

Skinner, H. A. (1989) Butterfly wings flapping: do we need more 'chaos' in understanding addictions, British Journal of Addiction, 84, 353-56.

Social and Cultural Planning Office S.C.P. (1992) Social and Cultural Report 1992, Sociaal en Cultureel Planbureau. Den Haag, Netherlands: VUGA.

Van de Goor, L.A.M., Knibbe, R.A.y and Drop M.J. (1990) Adolescent drinking behaviour: an observational study. Joumal of Studies on Alcohol, 51, 548-555.

Wilsnack, S.C., Klassen, A.D., Schur, B.E., and Wilsnack, R.W (1991) Predicting onset and chronicuty of Women's problem drinking: a five-year Longitudinal analysis. American Journal of Public Health, 81, 305-18. 
Wilsnack, S.C., and Wilsnack, R.W. (1992) Women, work and alcohol: failures of simple theories, Alcoholism. Clinical and Experimental Research, 16, 1172-179. 


\title{
Changes in alcohol use and in drinking problems in relation to role transitions in different stages of the life course.
}

Submitted for publication

\begin{abstract}
From a sociological point of view, the life course may be viewed as a sequence of combinations of positional roles. In turn, the occupation of positional role obligations can be interpreted as putting restrictions on drinking. The number of positional roles occupied at a certain point in the life course is a measure for the structure of everyday life.
\end{abstract}

Earlier publications have shown that remission of drinking problems among younger people (especially young men) is associated with increased responsibility that results from having a career and a family. For this reason, this type of remission has been called 'maturing out'.

In the present paper, we compare older and younger generations with respect to the association of role transitions and alcohol use. Data were analyzed from a 9 year follow-up study of a general population of a southern province in the Netherlands. The hypothesis that loss of social roles at older age would lead to higher vulnerability to heavy drinking and alcohol related problems, was not confirmed. Instead, a significant interaction effect appeared, showing that the association of structure of everyday life with alcohol use and alcohol related problems is positive among the older genteration, and negative among the younger generation.

It is concluded that the theoretical framework from which our expectations were derived should be amended when used for research among older people. Associations found in general populations do not necessarily hold among the older age group. More specific attention to social roles, resources and coping mechanisms available at older age is warranted.

\subsection{Introduction}

Several explanations have been presented for the phenomenon that alcohol use changes across the life course, varying from psychological and genetic processes to environmental factors that induce changes in alcohol use (Fillmore, 1988). The aim of this paper is to explore the possibilities of an approach of individual changes in alcohol consumption that is grounded in life course sociology, which emphasizes transitions and trajectories in the life course (Elder, 1985). Therefore, it will focus on positions in families, social networks or organizations that people gain, maintain, and lose across the life course. These social characteristics that a person may or may not have can be distinguished from what will be called 'basic characteristics', which are more directly and permanently attached to a person, such as gender, ethnicity, social class and belonging to a certain birth cohort.

Specific changes in social positions tend to occur in a certain phase of the life course, and are therefore called life transitions or role transitions (O'Rand, 1990). The 
transition from school to college or work, getting married, and becoming a parent are examples of transitions that usually occur at earlier age. Retirement is restricted to older age, although the age range varies. Death of the spouse leading to widowhood is considered a fairly 'normal' transition at older age, whereas bereavement at younger age is considered abnormal. The latter example points to a specific domain of interest: "timely' versus 'untimely" life transitions (Hagestad, 1990), which will however not be explored further here. The relationship of this type of transitions with alcohol use is emphasized in research focusing on 'stressful life events' (for overviews see Allan and Cooke, 1985; O'Doherty and Davis, 1987; Temple et al., 1991).

In the present paper, alcohol use is studied in relation to age-related transitions in social positions. First, a brief review will be presented of explanations for changes in drinking behavior that have been suggested in studies of specific life transitions, such as marriage, and retirement. Second, a more general theoretical approach of alcohol use in relation to social positions will be presented, which exceeds the context of specific role transitions. Given the subject matter, social roles that structure the life course, it seems warranted to take role theory as a point of departure. The third part of the paper presents secondary analysis of a longitudinal data set. In this section, the association of alcohol use with distinct role transitions will be described, and the role theory developed here will be tested against empirical data.

\subsection{Review of studies on distinct role transitions and alcohol use or alcohol re- lated problems.}

In this section, studies of distinct life transitions are reviewed, and an inventory is made of mechanisms behind changes in drinking behavior as suggested by the authors. Because of its heuristic character, this review is restricted to longitudinal studies that explicitly analyze the impact of specific transitions in the adult life course. Psychlit was used for literature searches. Studies are roughly categorized by the life course domain in which the transition occurred: first, transitions in marital and parental roles are discussed, then work and career-related roles.

\subsubsection{Marital and parental roles.}

In their study "Marriage and alcohol use", Miller-Tutzauer, Leonard and Windle (1991) show that the causal mechanism in the relationship, often found between decreased alcohol use and marriage, lies in the transition of getting married. It appeared that young people decrease their drinking even prior to marriage. The authors speculate that people who have decided to get married "...may insulate themselves from the opportunities for heavy drinking that were so prevalent prior to the decision to marry (emphasis added)." This result is congruent with Power and Estaugh's (1990) study of a British cohort born in 1958, which reports decreasing alcohol use once people have decided to get married. Hanna, Faden and Harford (1993) explain their finding that women who get married decrease their alcohol consumption in terms of the shift towards a stable and secure social position. Wilsnack et al. (1991) report increased problem drinking among women who start cohabiting, whereas no effect is found for getting married. They argue that cohabitation and marriage should not be treated as a single category in analyses with marital status. 
The transition to parenthood is rarely studied separately, which seems a consequence of the fact that it usually follows quite soon after marriage. Power and Estaugh report on drinking behavior in relation to family formation and family dissolution patterns. Marriage and parenthood are most prevalent among those who reduced consumption or maintained the lighter drinking of their teens. The authors conclude on the basis of their analyses that "....family formation factors are among the most important" in changing drinking behavior (Powers and Estaugh, 1990: 527). They remain cautious on the causal direction of the association, but the lack of association between current marital status and earlier drinking does provide some support for the idea that family formation precedes drinking behavior. Richman, Rospenda and Kelley (1995) observe increasing problem drinking in a longitudinal study among married couples expecting their first child. Their results are congruent with a 'role deterioration' hypothesis. According to this concept, not only the presence or absence, but also the perceived quality of roles should be taken into account. The transition to parenthood may lead to a decrease in rewards (especially social support) derived from other social roles.

Wilsnack et al. (1991) report higher incidence of problem drinking among nonproblem drinking women who had divorced. However, among problem drinkers divorce is associated with remission. The authors speculate that the relief from a troubled marriage, which caused the drinking problem in the first place, may have lead to remission at follow-up. They call for more refined and focused analyses, distinguishing positive, gratifying role relationships from negative, frustrating role relationships. Prattala, Karisto and Berg (1994) found that unhealthy life-styles, involving heavy drinking, were most prevalent in divorced men with a low educational level. This finding illustrates that taking into account education and other variables can make a difference in the analysis of role changes. Hanna, Faden and Harford (1993) attribute increasing consumption among divorced women to the loss of status and. increased instability.

The transition to widowhood has been studied longitudinally by Zisook, Shuchter and Mulvihill (1990). Risk for increase in alcohol use appears especially high among those who report high earlier consumption; when depression was involved; and in case respondents did not have a satisfying social-emotional support system.

\subsubsection{Work and career-related roles.}

Aseltine and Gore (1993) observe an increase in drinking among high school graduates, which finding they interpret as reflections of a change in life style, rather than stress responses.

Becoming unemployed is included in the meta-analysis by Temple et al. (1991). When becoming unemployed between measurement points, older men and women decrease their alcohol consumption, whereas younger men show an increase in consumption at follow-up. Separate studies on this subject were not found.

Retirement from the employed status is without question the most extensively studied transition in this domain. Nevertheless, few longitudinal studies deal with it explicitly. Ekerdt et al. (1989) followed two groups of men, one group retired in the span of the study, whereas the other group remained employed. The retirees did not 
differ from other men in the development of average alcohol consumption. The variability of consumption, however, increased, so that more retirees were in the extremes of either abstinence or heavy drinking. Also, heavy episodic drinking and alcohol related problems increased among the retirees as compared to men who remained employed. The authors attribute increasing risk of drinking problems to loss of status and self-esteem on the one hand, and more leisure time and drinking opportumities for drinking on the other.

\subsubsection{Summary}

The studies reviewed here point at some plausible interpretations of changes in drinking in relation to life course transitions from one social position or role to the other. Possible causal factors mentioned include social support and social networks, stability of social position, peer pressure, opportunity structures, change in lifestyle, and changes in status, income and self-esteem. Some authors indicate that effects may vary according to basic characteristics such as gender, age or education. Most authors do not indicate to what extent their interpretations can be generalized towards other role transitions. A more comprehensive approach could structure the multitude of interpretations of results on role transitions and alcohol use. In the next section, an outline for such an approach is formulated, taking role theory as a point of departure.

\subsection{Role analysis and social positions}

A possibility for developing a broader perspective on alcohol use and social positions may be found in the elaboration of the distinction between 'basic characteristics' and 'social positions', described in the introduction of this paper. A specific version of role theory was introduced in alcohol research by Knibbe, Drop and Muytjens (1987), which elaborates this distinction in the concepts "status roles' and 'position roles" (Gerhardt, 1971). 'Status roles' are defined as social expectations attached to basic characteristics. This approach views status roles as 'prescriptive', that is, norms and expectations give boundaries to the range of behaviors, i.e. drinking behavior (quantity, frequency and context) that are considered appropriate. Knibbe was able to show that status roles are empirically connected with 'drinking styles'. Position roles, on the other hand, are treated as 'proscriptive' in the associations with alcohol consumption. Social positions in professional, relational, familial and parental domain involve specific obligations, during which' performance drinking is mostly not allowed. Thus, the occupation of one or more social positions decreases the opportunities for drinking. Moreover, involvement in social roles decreases the risk for drinking problems within consumption categories. The concept 'structure of everyday life' is used to signify the extent to which the occupation of position roles prevents persons from excessive drinking and problem drinking.

This approach of role theory also leads to the expectation that position roles can be 'taken together': more positional roles amounts to more structure of everyday life, and thus lower risk for drinking problems. Results of a cross-sectional study indicated that a more structured everyday life is associated with less alcohol problems, when consumption levels are controlled for (Knibbe et all, 1987). In a longitudinal approach, 
this finding implies the hypothesis that alcohol consumption, and the risk for problems, decreases with the occupation of more social roles, whereas it increases with the loss of social roles. Other authors follow a similar approach, but place more emphasis on age differences. For example, Wilsnack and Cheloha (1987) call for age-specific analyses, arguing that problem drinking is associated with different role configurations at different ages. Roman and Blum (1992) suggest that different constellations of social roles lead to differences in social control as well as in opportunity structures. Their focus is on role transitions ('status passages') in different age groups, which may provide 'age-related windows' that hopefully can be employed for effective preventive interventions.

The research questions of this study can now be formulated more specifically. 1. Do distinct role transitions, such as marriage, becoming a parent, retirement, etc., lead to changes in alcohol use?

2. Can changes in alcohol use associated with these role transitions be described in terms of 'structure of everyday life'?

3. Is the effect of occupying roles on alcohol use negative and homogeneous across different types of roles, as is expected on the basis of the role theory on structure of everyday life?

4. Is the effect of change in structure of everyday life on drinking behavior homogeneous across age categories?

These research questions are investigated in two separate empirical studies. In study 1 , the effect of distinct role transitions on drinking patterns and alcohol related problems is described. In study 2 , it is examined by multivariate analyses whether change in alcohol use is associated with 'structure of everyday life', and how this association changes when age is controlled for.

\subsection{Methods}

Data. Secondary analysis is conducted on data from a longitudinal study in the Netherlands (Hajema, Knibbe and Drop, 1997). 1980 persons from the general population of the Dutch province of Limburg, aged between 16 and 64, were interviewed in 1980. The response rate was $76 \%$ (Knibbe et al, 1987). From the baseline respondents, 1327 persons were followed-up in 1989 (response rate 67\%). Follow-up was done by mailed questionnaire. Those classified as problem drinkers in 1980 were interviewed face-to-face at follow-up, using the same questionnaire. The baseline sample was found representative for the population. 85 baseline respondents deceased before follow-up. Drop-out at follow-up was not related to baseline drinking patterns, nor to age or gender (for detailed non-response analyses, see Hajema et al., 1997).

\section{Measurements.}

Alcohol variables. Abstinence is defined as no alcohol consumption in the last six months. Abstainers at both baseline and follow-up $(n=132)$ are excluded from the analyses.

Consumption is measured by the 'weekly-recall' method, which adds up consumption in glasses for each day of the week preceding the day of measurement. Dutch standard glasses are considered to contain about 10 grams of alcohol. Frequency of drinking 6 
or more glasses, further denoted as 'heavy drinking', is assessed with an eight category format, ranging from 'never' to 'every day, and is recoded to a monthly frequency. Consumption and frequency of heavy drinking are log transformed in all analyses, but not in the presentation of means and change scores.

The drinking problems index is based on Cahalan's index (Cahalan, 1970; Hajema, Knibbe and Drop, 1994; Knibbe et al, 1987) and includes four distinct aspects: symptoms of alcohol dependence ( 7 items), social consequences ( 6 items), health problems. related to alcohol (4 items), and monthly or more frequent drunkenness and hangover ( 2 items). Each aspect accounts for maximal 2 points on the index, which consequently ranges from 0 to 8 points.

Basic characteristics and social positions. Age is included in the form of year of birth. Education has eight categories according to the Dutch educational system, which form an ordinal level variable, ranging from 1 , primary education maximal, to 8 , university degree. Social positions included are marital status (married, single, divorced, widowed), family status (children at home/no children at home), and work status (student, employed, unemployed, disabled, retired).

\section{Analysis.}

Study 1. The first part of the analysis concerns the association between distinct role transitions and changes in alcohol use and alcohol related problems. First, tables of social position variables 1989 by 1980 are examined in order to assess which role transitions had occurred in sufficient numbers for analysis. From those in a certain status in 1980, enough people should go to another status, in order to allow assessment of the effect of the transition. The lowest numbers included are for divorce (10 men, 8 women). The 'comparison group' consists of respondents who remained in the original status. The transitions thus defined are consistent with retrospective reports at followup, i.e. it has not occurred that a respondent experienced other transitions in between measurement points.

The role transition comparisons were homogenized by age, since this study focuses at age related transitions. In the role transition categories, outliers according to age were excluded. The SPSS program 'examine' was used to identify outliers, defined as 1.5 times the interquartile range outside the 25 th or the 75 th percentile (Norušis, 1993: 185). These are persons experiencing an 'untimely' transition. After exclusion of the outliers (maximum 7 in any analysis), people in the transition category were compared to respondents within the same range of birth years taken from the category remaining in the original 1980 social position. Thus, for example, people who retired are compared to those who were employed both in 1980 and in 1989 , etc. This procedure allowed for 9 comparisons of role transitions with stability in the original role. Some interesting transitions could not be analyzed this way, because too few respondents remained in the original position, resulting in a too small comparison group. Results on the transition from school or college to work are still included for the sake of completeness. All other respondents in the same age range are used as comparison group. Combinations of role transitions were also explored, which yielded only one combination that was numerically worthwhile: the category respondents who got 


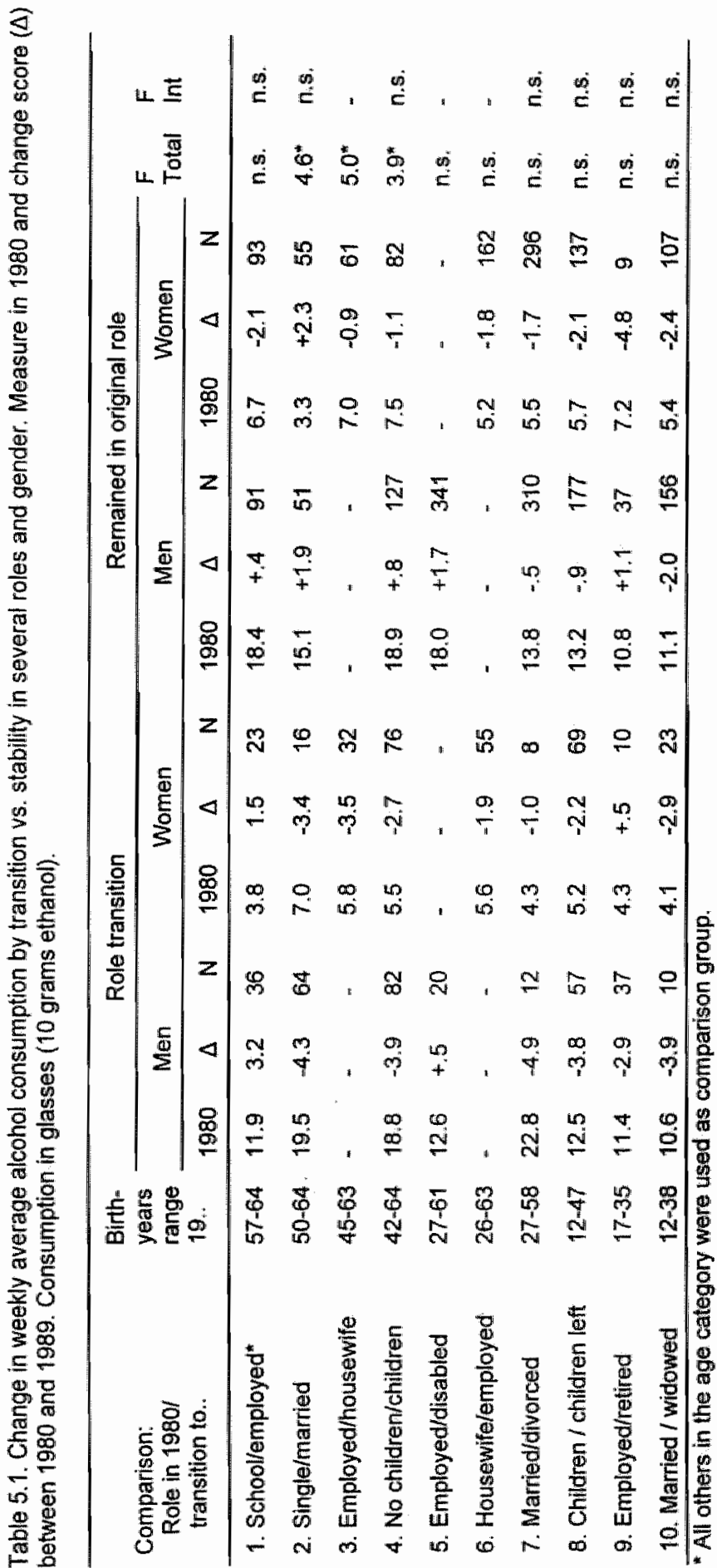


married and became parents during the follow-up period. Analysis with this combination showed that the effects of becoming married and becoming parent were additive.

Tables are presented for men and women separately. Statistical analysis (Anova) was done for the whole group, testing for gender interaction, and controlling for remaining within group variation of age and for education. Analyses are presented according to increasing age in which the transition occurred.

Study 2. Hypotheses on 'structure of everyday life'. In the second stage of the analyses, tests for consistency of effects across social roles were conducted. An index for 'change in structure of everydlay life' was constructed in congruence with the theory developed. On this index, living with a partner, taking care of children, and employment each account for 1 point. Gain of a role yields a point, and loss of a role also lead to a decrease of -1 index point. Combining the indices for the three rolle domains results in an index that ranges from -3 to +3 . Consumption, frequency of heavy drinking and score on the drinking problems index in 1989 were regressed on structure of everyday life, controlling for age, education, and for the alcohol variables in 1980. This procedure is equivalent to regression analysis of the residuals of the regression of the 1989 alcohol variables on the 1980 variables (Cronbach and Furby, 1970). Separate analyses were conducted for the three role domains, each score thus ranging from -1 to +1 , in order to account for inconsistency across roles. These analyses did not yield higher explained variance than the analysis with the compound 'change in structure of everyday life" index, and will be discussed only briefly.

Analyses were done separately for both genders and for generations, defined as those born before or after 1945. Interaction by generation was tested in a separate regression run for the entire sample, including a multiplicative term for generation and structure of everyday life. Separate analyses for men and women did not yield different results, and for this reason are not reported here. Gender is included as a control variable in analyses in the entire group en for generations.

\subsection{Results}

Study 1. Distinct transitions. Table 5.1 shows comparisons of change in weekly alcohol consumption of respondents who experienced distinct role transitions with those remaining in the original 1980 position. The right hand columns show the test for the entire group and for gender interaction. Role transitions are presented by descending order of average birth years of the transition category, which is equivalent to increasing age. Young men and women who were at school in 1980 showed an increase, compared to other respondents in their age range. Note that their 1980 consumption, on the other hand, was considerably lower, indicating that they are at the lower end of the age range within the group. Therefore, the difference is not significant when controlling for age. Significant effects are found only for transitions in marital and parental status that occur at young age. Men and women who got married decreased their drinking, whereas consumption of those who remained single increased. Women who become housewife after a period of employment decreased their drinking significantly more than women who remained working. The same applies to men and women who had their first child. Compared to those who remained childless, the difference is stronger for men, although the gender interaction is not significant. 


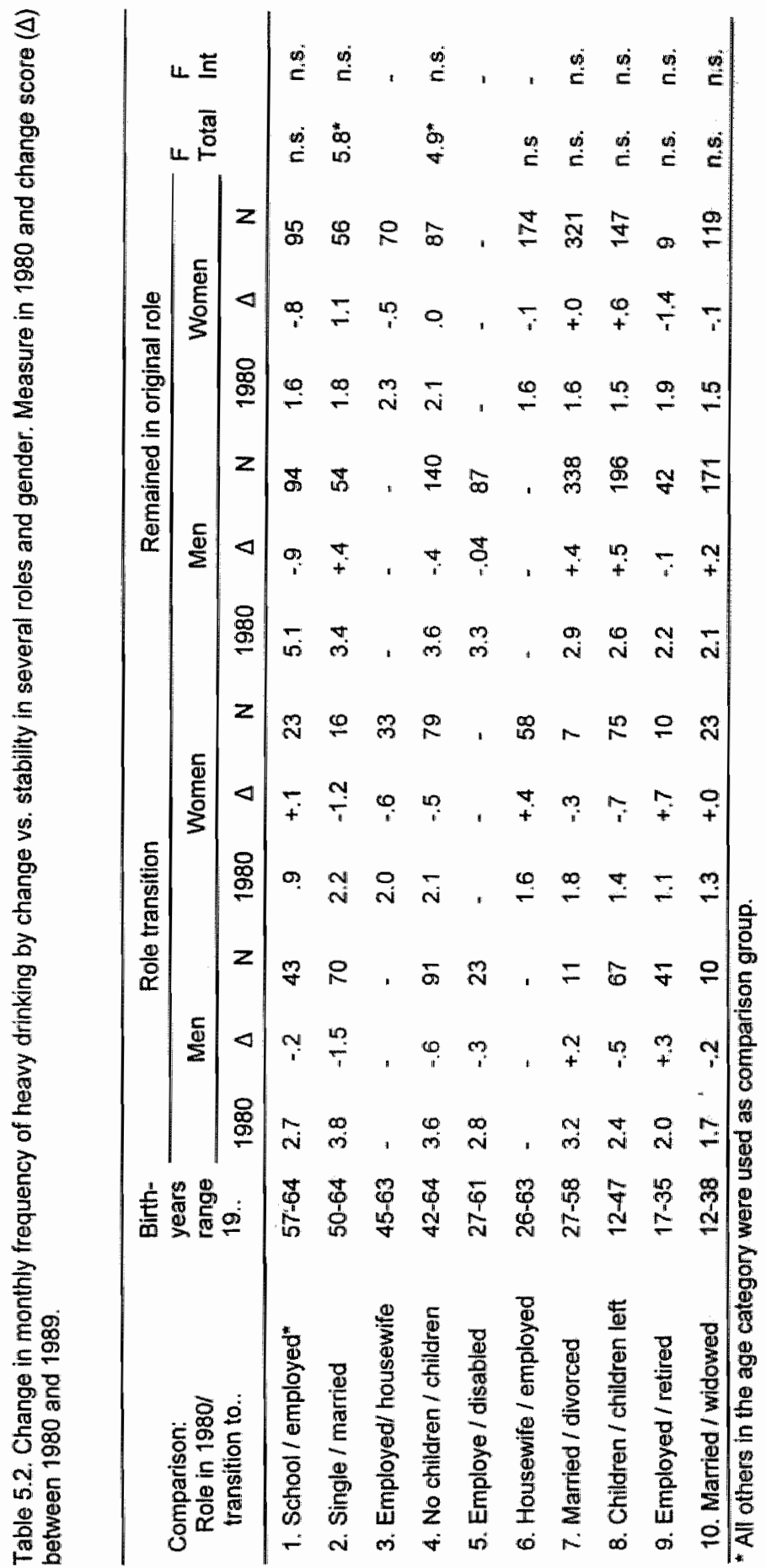




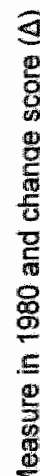

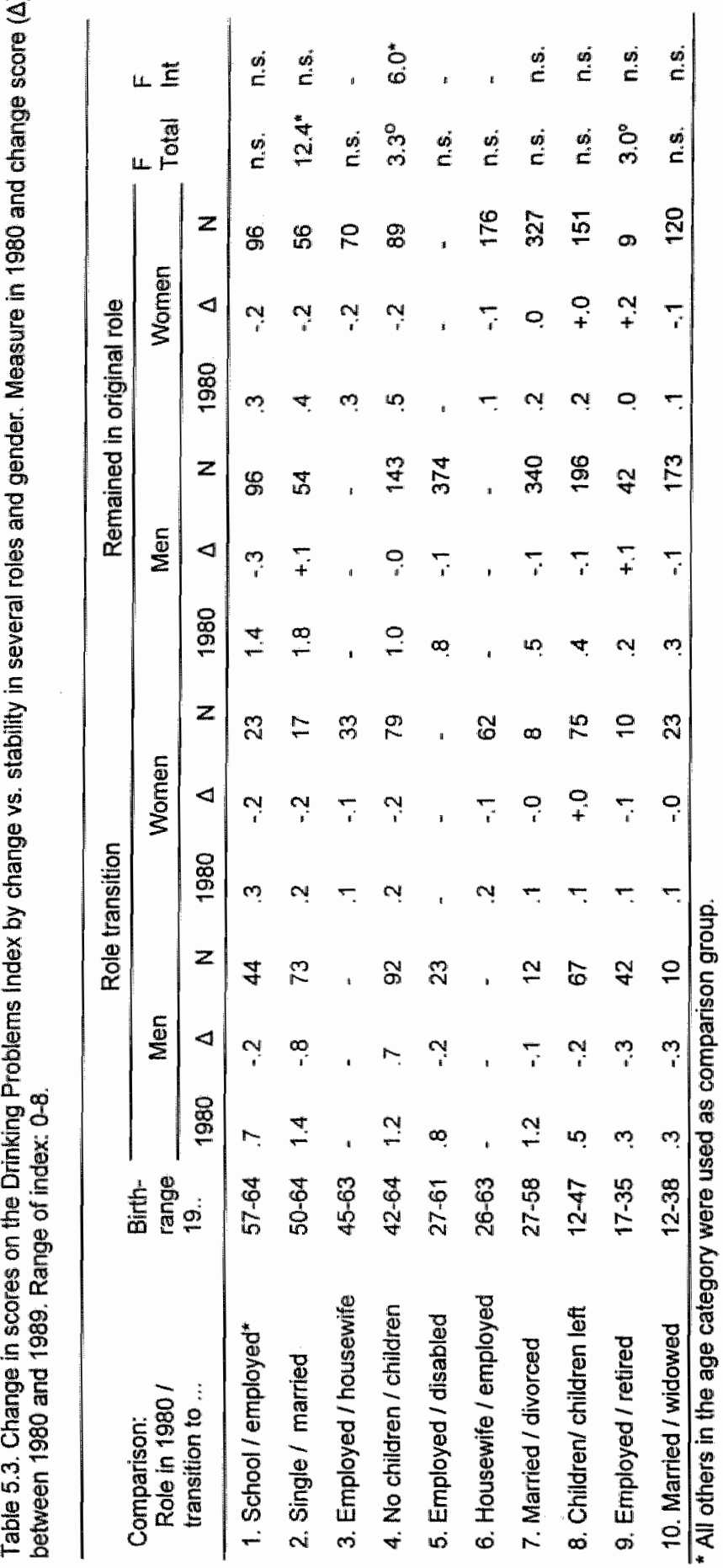


No differences at all are found for men who became disabled, compared to those stably employed, and for women who became employed after a period at home, compared to women who were housewives both at baseline and follow-up.

A few results are worth mentioning, although they do not reach statistical significance. These results suggest that divorce, retirement and children leaving home led to a decrease in consumption among men.

Significant decreases in frequency of heavy drinking are found for getting married, as compared to those remaining single, and for having one or more children, in comparison with those who remained childless (table 5.2). Children leaving home is associated with a decrease in frequency of heavy drinking, whereas people who had children at home at both baseline and follow-up report an increase. This result is not significant, but it is consistent across both genders.

Results on the drinking problems index are presented in table 5.3. Statistical testing (Anova) controlled for change scores in consumption and heavy drinking. Consistent with results on consumption and heavy drinking, people who got married decreased their drinking problems, compared with those who remained single. This seems to have occurred especially among men, although the interaction is not significant. A significant gender interaction occurred for having children. Note that the statistical analysis controlled for change in consumption and heavy drinking. Men who became fathers reported more alcohol related problems, compared to men without children both at baseline and at follow-up. Women who became mothers show no difference in the change score. Note however, that women who remained childless showed higher scores on the 1980 problem drinking index than those who became mothers. Results suggest that persons (especially men) who became retired showed a decrease in drinking problems, compared to people in the same age category who remained employed $(\mathrm{p}<.10)$.

Altogether, these analyses show that transitions at early age that involve an increase in role responsibilities are associated with a decrease in alcohol consumption, frequency of heavy drinking and alcohol related problems. An exception is formed by men who become fathers, as they report an increase in alcohol related problems. Life transitions at later age mostly involve a loss of social positions as worker, parent or partner. Results on these transitions were generally less strong. As far as a conclusion can be drawn, the results seem to suggest that older-age role transitions are associated with lower consumption, and in the case of retirement with less alcohol related problems.

Study 2. Analyses with an additive measure of role transitions. Table 5.4 to 5.6 show the results for regression on a quantitative measure of change in structure of everyday life.

No significant effect is found on alcohol consumption in the sample as a whole (table 5.4). However, separate analysis in age groups show that change in structure of everyday life is negatively rellated to weekly consumption among people who were 
Table 5.4. Multiple regression of consumption in 1989 on consumption 1980, change in structure of everyday life and status variables. Standardized regression coefficients.

\begin{tabular}{llcc}
\hline & All & Born before 1945 & $\begin{array}{c}\text { Born 1945 and } \\
\text { after }\end{array}$ \\
\hline Consumption 1980 & $.44^{* * *}$ & $.49^{* * *}$ & $.42^{* \star *}$ \\
Birth year & $.14^{* * *}$ & $.10^{* *}$ & .07 \\
Gender (male = 1, female $=0$ ) & $.24^{\star * *}$ & $.21^{* * *}$ & $.28^{* \star *}$ \\
Education & $.09^{* * *}$ & $.07^{*}$ & $.10^{* * *}$ \\
Change in structure of daily life & -.02 & .06 & $-.08^{\star *}$ \\
\hline $\mathrm{R}^{2}$ & .41 & .40 & .37 \\
\hline $\mathrm{N}$ & 1080 & 496 & 584 \\
\hline
\end{tabular}

Note: ${ }^{*} p<.05^{* *} p<01^{* \star *} p<.001$ i denotes interaction by generation significant $p<.01$

Table 5.5. Multiple regression of frequency of heavy drinking in 1989 on frequency 1980 , change in structure of everyday life and status variables. Standardized regression coefficients.

\begin{tabular}{|c|c|c|c|}
\hline & All & Born before 1945 & $\begin{array}{c}\text { Born } 1945 \text { and } \\
\text { after }\end{array}$ \\
\hline Frequency heavy dr. 1980 & $.43^{\star \star *}$ & $.43^{\star * * *}$ & $40^{* * * *}$ \\
\hline Birth year & $.15^{\text {*****}}$ & $.13^{\star *}$ & .02 \\
\hline Gender $($ male $=1$, female $=0)$ & $.21^{\star \star * *}$ & $.12^{* *}$ & $.31^{* * * *}$ \\
\hline Education & -.03 & .00 & -.05 \\
\hline Change in structure of daily life & -.01 & $.11^{* *}$ & $-.08 * i$ \\
\hline $\mathrm{R}^{2}$ & .33 & .27 & .36 \\
\hline $\mathbf{N}$ & 1162 & 534 & 628 \\
\hline
\end{tabular}


under 35 years of age at baseline (i.e. increase in structure of everyday life is associated with decrease in consumption). Among older people, the result is opposite, although not significant. The interaction term is statistically significant. Analysis with separate indicators (not reported here) showed that change in marital and parental status were significant, and in the same direction as the index, whereas change in employment status was not significant.

Table 5.5 shows that change in structure of every day life is positively related to frequency of heavy drinking among the older group, and negatively among the younger group. Both terms, as well as their interaction, yield significant regression coefficients. In the total group, no effect was found. Analyses for separate role dimensions yields coefficients with the same sign as the structure of everyday life index. However, only the coefficients for transitions in parenthood, and their interaction, reach significance.

Table 5.6 is consistent with tables 5.4 and 5.5 : change in structure of everyday life is positively associated with change in alcohol related problem among older people, and negatively among younger people. Interaction is strongly significant. Separate analyses for transitions in the domains of parenthood, relationship and employment show the same pattern, although the coefficients for the relationship dimension do not reach significance. Interactions for transitions in parenthood and work status are significant.

Control variables are not discussed separately, but note that in tables 5.5 and 5.6 , the gender effect is stronger among the younger age groups. This is consistent with observations in other data (Neve et al. 1996).

Table 5.6. Multiple regression of drinking problems 1989 on problems in 1980, change in structure of everyday life and status variables. Standardized regression coefficients.

\begin{tabular}{lccc}
\hline & All & Born before 1945 & $\begin{array}{c}\text { Born 1945 and } \\
\text { after }\end{array}$ \\
\hline Drinking prablems 1980 & $.33^{* * *}$ & $.39^{* * *}$ & $.39^{* * * *}$ \\
Birth year & $.14^{* * *}$ & $.12^{* * *}$ & $.12^{* * *}$ \\
Gender (male $=1$, female $=0$ ) & $.13^{* * *}$ & .08 & $.16^{\star * *}$ \\
Education & .02 & .02 & .04 \\
Change in consumption & $.09^{* *}$ & .07 & $.08^{*}$ \\
Change in frequency h.d. & $.09^{* *}$ & -.00 & $.12^{* *}$ \\
Change in structure of daily life & $-.08^{*}$ & $.10^{*}$ & $-.16^{* * * i}$ \\
\hline $\mathrm{R}^{2}$ & .22 & .19 & .23 \\
\hline $\mathrm{N}$ & 1063 & 490 & 573 \\
\hline
\end{tabular}

Note: ${ }^{*} p<.05^{\star \star *} p<01^{* \star \star} p<.001$ idenotes interaction by generation significant $p<.001$ 


\subsection{Discussion.}

Analyses of transitions in separate role domains showed that the transitions to parenthood and to marriage at early age tend to lead to a decrease in alcohol consumption, and in frequency of heavy drinking. Respondents who got married also reported less alcohol related problems, when consumption and frequency of heavy drinking were controlled for. Result on the drinking problems index showed that men who became fathers had more problems, whereas the problems index decreased for women who became mothers, as compared to those who remained without children. The transition for school or college to work could not be analyzed in comparison with remaining at school. However, it was shown that it had no effect after controlling for age in an analysis of the entire group within this age range.

Role transitions at older age did not yield results as clear and significant as those for marital and parental role transitions at younger age. Nevertheless, the results suggested that role loss at older age did not lead to an increase, but rather to a decrease in alcohol consumption. Retirement is associated with a decrease in alcohol related problems, when consumption is controlled for.

Multivariate analyses in the entire sample, divided only by age, showed that results are, by and large, congruent with a 'structure of every day life' perspective for the younger age category. A more structured daily life, as indicated by the occupation of multiple social positions, is associated with lower consumption and frequency of heavy drinking. Moreover, when changes in consumption and frequency of heavy drinking are controlled for, transitions towards a more regulated life are associated with fewer alcohol related problems. Although the effects are not large, they are consistent across role domains, as far as represented in the data. This indicates that the 'structure of everyday life' approach is at least a good starting point for a broad explanation of aggregate drinking patterns and alcohol related problems, at least in general population studies.

For the older age category, however, result are not in agreement with the structure of everyday life concept. Whereas it would be expected from this perspective that alcohol use would increase with the loss off life-structuring social positions, the results presented above rather indicated the opposite. Part of a possible explanation could be that position roles that are relevant at older age, such as the role of grandparent, are not represented in the data presented in this study. But probably more importantly, the results of this study show that the concept 'structure of everyday life' needs further refinement.

The role theory developed thus far included the idea that the same explanatory mechanisms operate behind transitions in different role domains and at different ages. All social positions involve some kind of obligations, which proscribe alcohol use. The analyses presented above, although perhaps incomplete, seem to indicate that this assumption does not hold for the older age category. Some of the explanations that were found in the literature review above can be used to strengthen the explanatory power of the theory. To conclude this paper, some proposals will be done for the inclusion of specific aspects associated with social positions. These aspects also partly cover the idea of "role quality' (Richman et al., 1995; Wilsnack et al, 1991). 
In the structure of everyday life approach, at least two dimension can be distinguished that constitute possible mechanisms, and that can be operationalized. First, social positions involve the meaningful allocation of time, which points to research questions concerning time spent in specific types of situations, which 'wetness' can also be measured. The issue was already raised by authors in the field of older drinkers (e.g. Ekerdt et al, 1989). When time allocation is operationalized, the notion that 'position roles' involve obligations that cannot be combined with drinking can be tested directly (an initial attempt was done by Van Gelooven, 1990). Secondly, social positions involve social networks, which in itself influence the drinking situations in which a person becomes involved. Among the youngest age categories, alcohol use may even constitute a form of 'social capital' (Bourdieu, 1980), since for many youngsters, a substantial part of the time with peers is spent in public drinking places, and 'going out' is also important in the relation market of this age category. For older age categories, on the other hand, it can be hypothesized that a loss of social positions involves a decrease in drinking situations with peers.

Social networks around certain social positions can not only be conceptualized as a platform for socializing with peers, but also as 'social support network' (Roberts, 1988). As was shown, the loss of social roles at older age is generally not associated with excessive drinking, nor with increasing alcohol problems. Clinical observation has it, however, that problem drinkers with 'late onset' sometimes started drinking heavily as self-medication for the stress of role loss. This points to a further distinction in role analysis: to what extent are role transitions associated with stress, and how do people cope with this stress. Thus, a 'stress and coping' framework should be incorporated in role analysis in order to increase its explanatory power. This seems especially relevant to loss-transitions at older age, but it can possibly be extended to other transitions that are experienced as stressful, such as divorce, and to transitions that are experienced as 'untimely, such as unplanned parenthood and early widowhood. The lack of people with the same problem in the same age category can make these types of events even more stressful, because of the lack of an understanding social suppott network (as was suggested by Zisook et al., 1990).

Further elaboration of role analysis in this sense and subsequent gathering of longitudinal data, in which all relevant aspects are included at baseline, might lead to more understanding of the dynamics of drinking behavior across the life course.

\section{References}

Allan, C.A. \& Cooke, D.J. (1985) Stressful life events and alcohol misuse in women: a critical review, Journal of Studies on Alicohol, 46, 147-152.

Aseltine R.H.and Gore, S. (1993) Mental health and social adaptation following the transition from high school. Special issue: Late adolescence and the transition to adulthood. Journal of Research on Adolescence, 3, 247-270.

Cahalan, D. (1970) Problem Drinkers. San Fransisco: Jossey-Bass.

Cronbach, L.J., and Furby, L. (1970) How should we measure change - Or should we? Psychological Bulletin, 1, 68-80.

Ekerdt, D.J., De Labry, L.O., Glynn, R.J. and Davis, R. W. (1989) Change in drinking behaviors with retirement: finding from the normative aging study, Jownal of Studies on Alcohol, 50, 347-353. 
Elder, G.H. Jr. Perspectives on the life course, In: Elder, G.H. Jr. (Ed.) Life Course Dynamics. Ithaka: Cornell University Press, pp. 23-49.

Fillmore, K.M. (1988) Alcohol use across the life course. Toronto: Addiction research Foundation. George, L.K. (1993) Sociological perspectives on life transitions, Amulal review of sociology, 19, 353-373.

Gerhardt, U. (1971) Rollenunalyse als kritische Soziologie, Berlin: Luchterhand.

Hagestad, O.O, (1990) Social Perspectives on the Life Course. In: R.H. Binstock \& L.K. George (Eds.), Handbook of Aging and the Social Sciences, (3th ed., pp. 151-168) San Diego Ca.: Academic Press.

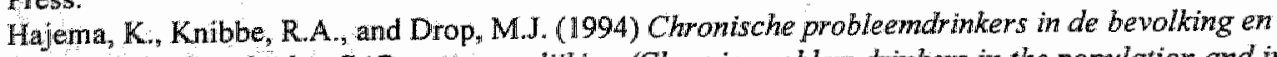
probleemirinkers bij het $C A D$. een vergelijking (Chronic problem drinkers in the population and in treatment, a comparison). Maastricht: Rijksuniversiteit Limburg.

Hajema, K., Knibbe, R.A., and Drop, M.J. (1997) Changes in alcohol consumption in a general population in The Netherlands: a 9-year follow-up study, Addiction, 92, 49-60.

Hanna,-Eleanor-Z, Faden,-Vivian-B.; Harford,-Thomas-C (1993) Marriage: Does it protect young women from alcoholism? Journal-of-Substance-Abuse; 1993 Vol 5(1) 1-14

Heath, D.B. (1991) Alcohol studies and anthropology, In: Pitman, D.J. and White, H.R. (Eds.), Society, Culture and Drinking Patterns Reexamined, New Brunswick, NJ: Rutgers Center of Alcohol Studíes.

Knibbe, R.A., Drop, M.J., and Muytjens, A. (1987) Correlates of stages in the progression from everyday drinking to problem drinking. Social Science and Medicine, 24, 463-73.

Neve, R.J.M., Diederiks ,J.P.M., Knibbe, R.A. and Drop, M.J. (1993) Developments of drinking behavior in the Netherlands from 1958 to 1989 a cohort analysis. Addiction, 88, 611-621.

Newe, Rudie J.M., Drop, Maria J., Lemmens, Paul H., Swinkels, H. (1996) Gender differences in drinking behavior in the Netherlands: convergence or stability? Addiction, 91, 357-373.

Miller-Tutzauer, C., Leonard, K.E., and Windle, M. (1991) Marriage and alcohol use: a longitudinal study of 'maturing out', Journal of Studies on Alcohol, 52, 434-440.

Norušis, M.J. (1993) SPSS for Windows Base System User's Guide Release 6.0, Chicago, 11: SPSS. O'Doherty, F., Davies, J.B., (1987) Life Events and Addiction: a critical review, British Journal of Addiction, 82, 127-137.

O'Rand, A.M. (1990) Stratification and the life course, In: Binstock, R.H., and George, L.K. (Eds.), Handbook of Aging and the Social Sciences, 3th Edition, San Diego: Academ ic Press.

Power,-C.; Estaugh, -V. (1990) The role of family formation and dissolution in shaping drinking bettaviour in early adulthood. British Joumal of Addiction, $85,521-530$

Prattala, R., Karisto, A and Berg, M.A. (1994) Consistency and variation in unhealthy behaviour among Finnish men, 1982-1990. Social Science and Medicine, 39, 115-122.

Richman, - Judith-A.; Rospenda.-Kathleen-M.; Kelley,-Michele-A. (1995) Gender roles and alcohol abuse across the transition to parenthood. Journal of Studies on Alcohol, 56, 553-557

Roberts, S.J. (1988) Social support and help seeking: Rewiew of the literature. Advances in Nursing Science, 10, 1-1॥.

Ryder, N.B. (1965) The cohort as a concept in the study of social change, American Sociological Review, 30, 843-861.

Temple, MT. Fillmore, K.M., Hartka, E., Johnstone, B, Leino, E.V. and Motoyosho, M. (1991) A meta-analysis of change in marital and employment status as predictors of alcohol consumption on a typical occasion., British Joumal of Addiction, 86, 1269-1281.

Turner, J.H. (1991) The structure of sociological theory, Fifth Edition, Belmont, Ca: Wadsworth. Wilsnack, R.W. and Cheloha, R. (1987) Women's roles and problem drinking across the life span, Social Problems, 34, 231-248.

Wilsnack, R.W. and Wilsnack, S.C. (1992) Women, work and alcohol: failure of simple theories, Alcoholism: Clinical and Experimental Research, 16, 172-179.

Wilsnack, S.C., Klassen, A.D., Schur, B.E., and Wilsnack, R.W. (1991) Predicting onset and chronicity of Women's problem drinking: a five-year Longitudinal analysis. American Joumal of Public Health, 81, 305-18. 


\title{
Older and younger male alcoholics in outpatient treatment: a comparison of type and severity of drinking problems and treatment career.
}

\author{
Submitted. Rudie J.M. Neve, Paul H. Lemmens and Maria J. Drop
}

\begin{abstract}
.
In the coming decades, the proportion of the older age groups in the total population, and therefore in the alcoholic population, will be increasing. The aim of the study is to assess to what extent older alcoholics form a distinct group within the problem drinking population. Alcoholics in outpatient treatment of over 50 years of age $(n=52)$ are compared with those from the modal age group (ages 35-44, $n=55$ ). Results indicate that problems with alcohol are less severe among older alcoholics. Contrary to expectation, older alcoholics did not report more health problems. No differences were observed in the duration of the treatment career. It is concluded that older alcoholics show the same types of problems, but less so than younger alcoholics. Further research is indicated regarding late onset, older alcoholics with multiple diagnosis, and drinking problems in the age group over 70.
\end{abstract}

Key words: older age, alcoholism, alcohol, social consequences, age of onset, outpatient treatment.

\subsection{Introduction.}

A large proportion of studies on alcoholism have focused on the modal group within treatment populations: males, and more specific males in their thirties and forties. Some justification for this may be found in treatment statistics: in the Netherlands, this group forms the majority within the population of outpatient alcoholism treatment agencies (Knibbe and Meyers, 1988; Hajema, Knibbe and Drop, 1994). Nevertheless, drinking problems and alcoholism do occur among older people (Gomberg, 1985; Maddox, Robins and Rosenberg, 1985). Research interest in drinking problems among older people is justified by their increased vulnerability to alcohol because of changes in metabolism as well as in social roles (Maddox, 1988). Furthermore, ongoing demographic changes warrant focusing research on drinking problems in older age groups. In most countries of Europe and North America, the proportion of the population in older age categories will increase in the next decades. Other things being equal, the number of older problem drinkers will increase likewise (Smart and Liban, 1981). It might be expected that specific characteristics of cohorts that reach older age in the next decades add to this development. For instance, cohorts born after 1950 reached drinking age in a far more 'wet' environment than cohorts born earlier. However, although some studies report cohort effects (e.g. Glynn et al., 1985), most available studies show no strong cohort effects as yet (e.g. Adams et al., 1990; Neve et al., 1993). Therefore, it seems reasonable to assume that present comparisons between age groups have some generalizability towards the future. In the present study, such a 
comparison is conducted within the category of problem drinkers who are 'patients' or "clients' of treatment agencies. For this reason, the population under study will be called 'alcoholics', without this implying any particular position with respect to alcoholism as a progressive disease. The aim of the study is to assess to what extent older male treated alcoholics form a distinct group within the group of people in treatment for drinking problems with respect to type and severity of their drinking problems, and with respect to several characteristics of their treatment career.

\section{Alcohol problems and age.}

For the purpose of the present study, four aspects of drinking problems may be distinguished. Firstly, a person may show symptoms of alcohol dependence, a narrowing of the behavioral repertoire in which the use of alcohol has priority over other aspects of life that would normally be more important (Gorman, 1987; WHO, 1982). Specific reports in the literature with respect to differences in dependence symptoms among age groups are lacking. Secondly, drinkers may experience problems in their relationships with significant others, such as spouse, family or friends. Sometimes drinking leads to problems at work, it can cause financial problems, or it may bring a person in conflict with the law. These problems may vary from disapproval from others to the loss of important social ties. Earlier studies reported that social consequences are less prevalent among older problem drinkers, as compared to younger problem drinkers (Maddox, Robins and Rosenberg, 1985; Schuckit and Pastor, 1978). According to Graham (1986) alcohol related social problems are less unequivocal among older persons, because they are entangled with problems that may result from the aging process itself. This process is characterized by decrease of social networks through widowhood and retirement, as well as a generally lower activity level. Thirdly, excessive alcohol use over longer periods of time may cause health problems. Older problem drinkers may be expected to suffer more alcohol related health problems, because of greater vulnerability, as well as a longer history of excessive drinking. Problematic drinking among older people may, however, also exacerbate already existing health problems, which may lead to difficulties in assessing the "alcohol-relatedness" of health complaints (Schuckit and Pastor, 1978). Finally, acute consequences of alcohol abuse, such as frequent drunkenness or hangovers, may occur in relation to drinking large quantities at a time. In view of the finding that older people generally show more regular drinking patterns (e.g. less weekend drinking and more daily drinking) in comparison to younger people, one would expect that the prevalence of drunkenness and hangovers is higher among younger problem drinkers (Van Gelooven, 1990).

\section{Drinking Career and Treatment career.}

In the general literature on 'drinking careers' and on the 'natural history of alcoholism' (Edwards, 1984; Jellinek, 1952; Rudy, 1986; Skog and Duckert, 1993; Vaillant, 1983), little interest for differentiation by age groups can be found. Vaillant's (1983) work on the natural history of alcoholism suggests that the course of the drinking problem does not differ across age groups. Gomberg (1982) compared younger (under 30 ) and comparable older ( 40 and over) alcoholics and concluded that the problems showed by both groups were "variations on a single theme". In the seminal work of 
Schuckit and Pastor (1978), the course of alcoholism among older populations is connected to the issue of early versus late onset of alcoholism. On the basis of a literature review, the authors state that most active alcoholics over 60 years of age had begun their heavy drinking career after age 40 . Cases of 'early onset' alcoholism, often end in either abstinence or premature death. This implies that surviving older alcoholics with early onset can hardly be encountered in studies that are limited to older treatment populations.

Seeking treatment has been viewed as a specific aspect of the drinking career, related to self-identification as a problem drinker or alcoholic (Edwards, 1984). Contrary to this view, it has been reported that older problem drinkers are often put under pressure to seek treatment, and initial contact with the treatment agency is often made by persons other than the alcoholic himself (Gomberg, 1985). Many older problem drinkers are referred to alcoholism treatment agencies after first presenting with apparently alcohol related somatical complaints at general practitioners or hospitals (Schuckit and Pastor, 1978). Thus, the literature gives the impression that self-identification as a problem drinker or alcoholic is not necessarily connected directly to first intake for treatment, but may be expected to occur in the course of treatment in many cases.

The duration of the treatment career depends on onset of drinking problems and on the length of time that passes between onset and intake for treatment. Both factors may vary by age group. In the case of problem drinkers with late onset, it would be expected that the length of the treatment career would not differ across age groups of problem drinkers. Alcoholics with early onset, however, would be expected to have a long history of treatment in various agencies.

If older alcoholics differed systematically from younger alcoholics with respect to type and severity of their drinking problems and with respect to their treatment history, this would have profound policy implications. Treatment agencies should consider the need to design special methods for this group. Policy makers may design new prevention strategies, which take into account that alcohol problems not only occur among the younger generation to which their efforts are now largely focused. Monitoring the trends in alcohol problems among older age groups would be given more priority in epidemiological research.

A comparison is made between male alcoholics in treatment over 50 years of age and a group of modal age counterparts, 35 to 44 years old, in order to answer the following questions:

- Do older alcoholics, compared with younger ones, show different drinking patterns with respect to beverage choice, drinking context and drinking quantity and frequency?

- Do older alcoholics experience different types of problems or do they differ gradually in severity of their drinking problems, compared to the modal age group?

- Is the treatment career of older alcoholics longer than that of younger alcoholics, and did they use the same type of agencies?

- Apart from questions directly related to drinking, perceived health is included as a variable in the study, in order to answer the question whether older alcoholics show more health problems than younger alcoholics. 
differences were also tested with t-tests.

In order to know whether it would make a difference when only recent cases would have been included, comparisons were also done within the older alcoholics group, by age of onset of problems and by recentness of onset.

\subsection{Results.}

\subsubsection{Socio-demographic characteristics.}

The mean age of the older alcoholics group, age range 50-71, was 56.0 (st.dev. 5.7), the mean age among the younger alcoholics, ages $35-44$, was 39.8 (st.dev. 3.0). Table 6.1 shows significant differences in socio-demographic characteristics of both groups of treated alcoholics. A larger percentage of the older alcoholics group report having children. A significant difference in employment status between older and younger alcoholics is entirely due to retirement in the older group. Older alcoholics more often than younger alcoholies consider themselves a member of a church, predominantly Roman Catholic.

Other characteristics, such as educational level and marital status, did not show significant differences. Less educated respondents were over represented: over $60 \%$ in both groups had only primary or vocational education.

\subsubsection{Health.}

No significant differences between both groups were found in self-reported general health characteristics. $40 \%$ of older and $38 \%$ of younger alcoholics reported a chronic disease. Within this group, a larger percentage of older alcoholics said that the disease had a strong influence on their daily life ( $21 \%$ vs, $13 \%$ ), although the difference was not significant. Both groups showed high prevalence of use of sleeping pills and tranquilizers ( $31 \%$ vs $26 \%$ ).

\subsubsection{Qualitative aspects of drinking behavior.}

A clear preference for beer as alcoholic beverage is reported by a majority of younger alcoholics ( $57 \%$ vs. $29 \%$, which difference is significant at .01 level when beverage choice is dichotomized). $46 \%$ of older alcoholics and $33 \%$ of the younger alcoholics reported that they drink several beverages without a strong preference. Only few respondents reported a preference for wine and somewhat more reported a preference for spirits (17\% in the older group vs. $11 \%$ in the younger group, n.s.).

Over $80 \%$ of both groups mentioned their home as a context in which alcohol was drunk weekly or more often. Drinking at other people's home (15\% vs. $31 \%$ ) and in public drinking places ( $46 \%$ vs. $62 \%$ ) was less prevalent among older alcoholics, although the differences were not significant.

\subsubsection{Quantity and frequency of drinking.}

Daily drinking was reported by $80 \%$ of respondents in both age groups. Weekend drinking was rare in both groups (14\% vs. $16 \%$ ), and the remaining category reported drinking several days per week. 
Table 6.2. Drinking patterns and volume in two groups of treated alcoholics 50 and older (TA $50+)$ and 35 to 44 years of age (TA $35-44$ ). Percentages.

Frequency drinking 6 or more on one occasion*

Daily

Several days per week

Less then weekly

Quantity per drinking day in glasses (quartiles)*
51.9

38.5

9.6

34.0

28.0

26.0

12.0
TA. $35-44$
$3.0-9.3$

$10.0-17.0$

$17.1-25.0$

$25.1-71.0$

Note: * $p<.05$ (chi square test)

The frequency of heavy drinking, here defined as drinking 6 or more glasses on one occasion, was lower among older alcoholics than in the younger age category, where a majority reported doing so daily (table 6.2).

Clearly, 6 glasses is not a particularly high consumption volume among alcoholics. This obvious fact is once more confirmed by the lower part of table 6.2 , where the quantity consumed on a typical drinking day is reported in the form of quartiles. 6 glasses is close to the midpoint of the first quartile. The fourth quartile has a broad range, due to the skewness of the distribution. The differences in the first and fourth quartile show that consumption is higher among younger alcoholics than in the older group. A t-test, for which consumption was log-transformed in order to mitigate skewness, showed that the difference in consumption quantity per drinking day is significant at .01 level.

\subsubsection{Drinking problems.}

Table 6.3 shows the four aspects of problem drinking by age group. About $80 \%$ of both groups of alcoholics reported severe symptoms of alcohol dependence. Difference in this problem dimension was not significant. Disapproval by others was significantly more prevalent among the younger group. Alcohol related health problems were reported by a large majority of both groups. Whereas moderate health problems were more prevalent in the older group, the younger group reported higher prevalence of severe health problems. However, these differences were not statistically significant. Drunkenness and hangovers, the fourth problem drinking dimension, are clearly far more prevalent in the younger age group, of whom over $80 \%$ reported severe problems, defined as weekly or more frequent occurrence. 
Table 6.3. Drinking problems in two groups of treated alcoholics: 50 and older (TA 50+) and 35 to 44 (TA $35-44)$ years of age. Percentages.

TA $50+$

TA 35-44

Symptoms of alcohol dependence

None

7.7

3.6

Moderate

9.6

18.2

Severe

82.7

78.2

Disapproval of significant others*

None

Moderate

28.8

23.6

Severe

57.7

74.5

Alcohol related health problems

None

10.9

Moderate

67.3

50.9

Severe

28.8

38.2

Acute problems: Drunkenness and hangovers ${ }^{* *}$

None

44.2

Moderate

10.9

Severe

55.8

81.8

Note: ${ }^{\star} p<.05{ }^{\star *} p<.01$ (chi square test)

6.3.6 Self reported age of onset of alcohol problems.

Over $80 \%$ of the older alcoholics recalled that they realized having a problem with alcohol at an age older than 40 . A large minority (28\%) of the younger alcoholics reported that they had an alcohol problem before age $30(\mathrm{p}<.01)$. The number of years that passed since the moment that the respondent realized having a problem was about the same in both groups.

A small minority of both groups ( $8 \%$ vs. $9 \%$ ) reported that they realized having a problem with alcohol only after first intake for treatment. A sizeable minority (38 versus $33 \%$ ) reported having known that they had an alcohol problem for longer than 3 years before seeking treatment. For this variable, results in both groups are nearly identical.

\subsubsection{Treatment career.}

More older than younger alcoholics reported not to have been in any treatment before the present treatment at the outpatient agency ( $65 \%$ versus $47 \%$, n.s.). Also, more younger alcoholics reported to have been in treatment more than twice before. $A$ majority ( $55 \%$ ) of the older alcoholics reported presently being in treatment for more 
than a year, which was a significantly larger percentage than among the younger group $(35 \%)$. With respect to the length of the entire treatment career, no significant differences were found.

A large majority of both older and younger respondents reported that they had received their first treatment for their drinking problem in an outpatient agency like the one in which the study was performed: $83 \%$ versus $71 \%$. A smaller percentage avoided treatment until admittance to an inpatient alcohol clinic was indicated. Among the younger age group, a large part of even those who received their first treatment in an outpatient agency were admitted to an inpatient clinic at some point in their treatment career: $38 \%$, versus $15 \%$ among the older age group $(\mathbf{p}<.01)$. Institutions other than those specializing in treatment of problem drinking or alcoholism were rarely mentioned.

\subsubsection{Comparison by age of onset and by recentness of onset.}

Among the older alcoholics, the self-report of the number of years that passed since respondent realized that he had an alcohol problem, ranged up to over 30 years. It was shown above, that older and younger alcoholics do differ significantly in self-reported age of onset but not in how long ago they recalled that they realized they had an alcohol problem. One could argue that it would have been better to include only recent cases. In order to investigate this, comparisons were made within the older alcoholics category by age of onset (younger vs. older than 50 ) as well as by recentness of onset (less than 4 years ago vs. 4 years or more).

More recent cases more often reported chronic diseases $(55 \%$ vs. $27 \%, \mathrm{p}<.05)$. The time that passed from the moment that respondent realized that he had an alcohol problem and intake for treatment was shorter among more recent cases ( $5 \%$ longer than 3 years) than among earlier cases ( $65 \%$ longer than 3 years). Total duration of treatment also was shorter.

Comparisons by age of onset showed that cases with later age of onset less often were employed ( $9 \%$ vs. $62 \%, p<.01$, which remained significant when controlling for age). Cases with later onset less often reported severe social problems $(37 \%$ vs. $77 \%, p<$ $.05)$ and more often reported being in treatment for the first time, and the duration of this treatment episode was shorter. Later age of onset cases also less often reported to be referred for treatment by their general practitioner $(5 \%$ vs. $27 \%, \mathrm{p}<.05)$. Whereas recentness of onset was not related to consumption in the last phase before treatment, older age of onset was related to significantly lower consumption in the last phase before the present treatment episode (mean 66 vs. 138 glasses weekly, $p<.01$ in test with log-transformed data).

\subsection{Discussion.}

Results of the comparison of older problem drinkers with the 'modal' age group, 35 to 44 years old, are summarized and discussed briefly. Differences in socio-demographic characteristic are in agreement with age differences that are found in general populations. Older problem drinkers more often consider themselves part of a church, which result is in agreement with age differences in religious affiliation in the general population (Becker and Vink, 1994). Compared to younger alcoholics, a smaller 
percentage of the older group showed a marked preference for beer and for drinking in public drinking places. Both are normal age gradients in alcohol consumption, which are found in general population studies as well (Hupkens et al, 1993; Van Gelooven, 1990). The result that younger problem drinkers less often have children could be related to their alcohol problems: these problems may have prevented family formation for a number of younger alcoholics, whereas some of the older alcoholics probably already had families when their drinking became problematic.

A number of significant differences indicate that drinking problems are less severe among the older alcoholics, as compared to the modal age group. Frequency of heavy drinking and amount of alcohol consumed per drinking occasion are lower among older alcoholics. Alcohol related problems with significant others, as well as acute consequences (drunkenness and hangovers) were less severe among the older group in our study. Especially older alcoholics with later onset reported less severe social consequences. Older alcoholics also less often reported admissions in inpatient alcohol clinics.

Both groups of alcoholics resembled each other with respect to drinking pattern (frequency of drinking), symptoms of alcohol dependence and alcohol related health problems. The latter is contrary to expectation, which had it that alcohol would cause more health damage in older alcoholics because of increased physical vulnerability.

The total length of treatment careers and in the initial type of treatment were also similar in both groups. Most striking perhaps were the similarities in how long ago it was that respondents had realized they had a drinking problem, and how long they waited from that time before seeking treatment. Of course, it might be questioned whether a person's answer on a single question is at all reliable. The moment of realization might be 'telescoped" from an earlier actual 'onset' of alcohol problems. However, the fact that there was hardly any difference at all in the distribution of this variable seems to lend some confidence to the result of this study, that older and younger problem drinkers do not differ in the time it takes between realizing that one has an alcohol problem and seeking treatment. A substantial part of both groups appears to hesitate several years before seeking treatment. For the present paper, it is of interest that older alcoholics as a whole do not seem to differ from younger alcoholics with respect to the time it takes before treatment is sought. However, more recent cases among the older alcoholics reported a longer period between the moment they realized that they had an alcohol problem and seeking treatment.

It may be concluded that older male problem drinkers show less severe drinking problems when compared with the modal age group of problem drinkers, and that other differences, except those directly related to age, are unimportant. Differences in drinking problems between older and younger alcoholics appear to exist in severity, rather than in type of problems. This conclusion is in agreement with an earlier study by Gomberg (1982), who also reported that differences between age groups with respect to drinking problems are gradual, rather than fundamental. The differences seem to parallel differences in alcohol use and problem drinking among the general population, where older people have been reported to show lower consumption and prevalence of problem drinking than younger people (Cahalan, 1970; Knibbe, Drop and Muytjens, 1987). 
Comparisons by age of onset within the older alcoholics group showed that later onset is associated with lower consumption and less severe social consequences. Onset of serious drinking problems in later life may create a special category of alcoholics that could benefit from specific prevention and treatment strategies. A study is forthcoming, in which the drinking careers of older problem drinkers will be investigated in detail in order to illuminate this issue.

The population from which our sample was taken were male problem drinkers in outpatient treatment, who have presented an alcohol problem primarily. The alcoholics studied here are a selection of the whole population with drinking problems. This indicates some final remarks about the external validity of this study, some of which point to a need for further research.

Some people may seek treatment or counseling for other problems, while they also have a drinking problem. It has been argued that alcoholism takes the form of comorbidity with other diagnoses among older psychiatric patients (Speer and Bates, 1992). More research is necessary in different settings, such as psychiatric institutions, in order to get a grip on the group with multiple diagnosis, whether alcohol is the main problem or diagnosed as 'comorbidity'.

The present study involved mainly male problem drinkers from the not-very-old age group. People over 70 years old were rare in the study. Nevertheless, this is the age group that will grow most explosively in the next decades. According to Smart and Liban (1981) a relatively large percentage of the very old in residential care, compared to those who remain living at their home, may have drinking problems. Drinking problems among people over 70 need further study.

It should also be mentioned that older women are very rare in the type of treatment setting in which this study was conducted. It is likely that older female severe problem drinkers or alcoholics seek treatment elsewhere.

It should be noted that treatment careers may be influenced by specific treatment systems in a country. Moreover, cultural dimensions may enhance or limit the possibilities of problem drinkers' opting for seeking help. Results presented above, such as the similarity in the time it takes before seeking treatment, may not necessarily be generalizable to other cultures. Some studies have shown that help-seeking behavior is variable across ethnic groups and religions (e.g. Takeuchi, Leaf and Kuo, 1988; Yeung and Greenwald, 1992). Cross-cultural studies are lacking and may reveal the differences and similarities in help-seeking behavior across cultures.

Finally, to return to the issue raised in the introduction of this paper, it may be questioned to what extent knowledge about the present generation of older problem drinkers may be extrapolated towards future demographic situations, i.e. the large age cohort that will reach older age in the beginning of the next century. The present study did not yield much direct evidence in support of special prevention or treatment measures directed at older people. Some indications were found, especially with respect to older onset, but the study left many questions unanswered. The best way to proceed seems to be to follow the developments in the older age groups as close as possible, looking at specific institutional situations as well as at the general population, and to take account of changes relevant to specific age cohorts as they may occur in the near future. 


\section{References.}

Adams, W.L., Garry, P.J., Rhyne, R., Hunt, W.C., and Goodwin, J.S. (1990) Alcohol intake in the healthy elderly. Changes with age in a cross-sectional and longitudinal study, Journal of the American Geriatric Society, 38, 211-216.

Becker, J.W. and Vink, R. (1994) Secularisatie in Nederland, 1966-1991 (Secularization in the Nerherlands, 1966-1991), Rijswijk: Sociaal en Cultureel Planbureau.

Birren, J.E. and Birren, B.A. (1990) The concepts, models, and history of the psychology of aging, in: Birren, J.E and Schaie, K.W. (eds.) Handbook of the Psychology of Aging, Third Edition, pp. 3-20, San Diego: Acadernic Press.

Brennan, P.L. and Moose, R.H. (1991) Functioning, life context, and help-seeking among late-onset problem drinkers: Comparisons with non-problem and early-onset problem drinkers, British Joumal of Addiction, 86, 1139-1150.

Cahalan, D. (1970) Problem Drinkers: A National Survey, San Francisco: Jossey Bass.

Edwards, G. (1984) Drinking in Longitudinal Perspective: Career and Natural History. British Journal of Addiction, $79,175-183$.

Glynn, R.J., Bouchard, G.R., Locastro, J.S. and Laird, N.M. (1985) Aging and generational effects on drinking behaviors in men: Results from the normative aging study, American Joumal of Public Health, 75, 1413-1419.

Gomberg, E.L. (1982) The young male alcoholic: a pilot study, Joumal of Studies on Alcohol, 43, $683-701$.

Gomberg, E.L. (1985) Gerontology and alcohol studies, in: Gottheil, E., Druley, K.A., Skoloda, T.E. and Waxman, H.M. (eds.) The Combined Problems of Alcoholism, Drug Addiction and Aging, pp. 5173, Springfield, Il:, Chas. C. Thomas.

Gomberg, E.L. (1991) Women and alcohol, psychosocial aspects, In.: Pittman D.J. and White H.R. (eds.) Society, Culture and Drinking Patterns Reexanined, pp. 263-284 (New Brunswick, Rutgers. Centre of Alcohol Studies).

Gorman, D.M. (1987) Measuring onset of 'caseness' in studies of stressful life events and alcohol abuse, British Journal of Addiction, 82, 1017-1020.

Graham, K. (1986) Identifying and measuring alcohol abuse among the elderly: serious problems with existing Instrumentation, Journal of Studies on Alcohol, 47, 322-326.

Hajema, K.J., Knibbe, R.A. and Drop, M.J. (1994) Chronische probleemdrinkers in de bevolking en bij het CAD. een vergelijking (Chronic problem drinkers in the general population and in the Consultation Bureau for Alcohol and Drugs: a comparison), Maastricht: Lniversity of Limburg. Hupkens, C.L.H., Knibbe, R.A. and Drop, M.J. (1993) Alcohol consumption in the European Community: uniformity and diversity in drinking patterns, Addiction, 88, 1391-1404.

Jellinek, E.M. (1952) Phases of Alcohol Addiction, Quarterly Journal of Studies on Alcohol, 13, 673. 684.

Kribbe, R.A., Drop, M.J. and Muytjens A. (1987) Correlates of stages in the progression from everyday drinking to problem drinking, Social Science and Medicine, 24, 463-473. 
Knibbe, R.A. and Swinkels, H. (1992) Alcoholgebruik in Nederland: een analyse van gegevens uit de CBS-gezondheidsenquête 1989 (Alcohol use in the Netherlands, an analysis of data of the Central Bureau of Statistics" Health Survey 1989), Tijdschrift woor Alcohol en Drugs, 18, 124-138.

Maddox, G. (1988) Aging, drinking and alcohol abuse, Generations, 12, 14-16.

Maddox, G., Robins, L and Rosenberg, N. (1985) Nature and Extent of Alcohol Problems among the Elderly, New York: Springer Publishing Company.

Metsemakers, J.F.M., Höppener, P., Knottnerus, J.A., Kocken, R.J.J. and Limonard, C.B.G. (1992) Computerized health information in the Netherlands: a registration network of family practices, British Journal of General Practice, 42, 102-106.

Neve, R.J.M., Diederiks, J.P.M., Knibbe, R.A. and Drop, M.J. (1993) Developments of drinking behavior in the Netherlands from 1958 to 1989, a cohort analysis, Addiction, 88, 611-621.

Romelsjö, A., Leifman, H. and Nyström, S. (1995) A comparative study of two methods for the measurement of alcohol consumption in the general population, International Journal of Epidemiol$\circ g y, 24,929-936$.

Rudy, David R. (1986) Becoming Alcoholic, Carbondale and Edwardsville: Southern Illinois University Press.

Schuckit, M.A. and Pastor, P.A. (1978) The elderly as a unique population: alcoholism, Alcoholisin: Clinical and Experimental Research, 2, 31-38.

Skog, OJ. and Duckert, F. (1993) The development of alcoholics and heavy drinkers" consumption: a longitudinal study, Joumal of Studies on Alcohol, 54, 178-188.

Smart, R. and Liban, C. (1981) Predictors of problem drinking among elderly, middle-aged and youthful drinkers, Journal of Psychoactive Drugs, 13,43-53.

Speer, D.C. and Bates, K. (1992) Comorbid mental and substance use disorders among older psychiatric patients, Journal of the American Geriatrics Saciety, 40, 886-890.

Takeuchi, D.T., Leaf, P.J. and Kuo, H.S. (1988) Ethnic differences in the perception of barriers to help-seeking, Social Psychiaty and Psychiatric Epidemiology, 23, 273-280.

Vaillant, G.E. (1983) The Natural History of Alcoholism, Cambridge: Harvard University Press. Van Gelooven, R.M.W. (1990) Drinksituaties en drinkgedrag, alcoholgebruik in het dagelijks leven (Drinking siruations and drinking behavior, alcohol use in daily life), Maastricht: Uniwersity of Limburg (dissertation).

WHO (1982) Nomenclature and clssification of drug- and alcohol-related problems: a shortened version of a WHO memorandurn, British Journal of Addiction, 77, 3-20.

Yeung, P.P. and Greenwald, S. (1992) Jewish Americans and mental health: Results of the NIMH Epidemiological Catchment Area Study, Social Psychiatry and Psychiatric Epidemiology, 27, 292297. 


\section{Drinking careers of older male alcoholics in treatment as compared to younger alcoholics and social drinkers of the same} age.'

Rudie J.M. Neve, M.A., Paul H. Lemmens, PH.D., Maria J. Drop, PH.D.

Reprinted with permission from Journal of Studies on Alcohol, Vol. 58, pp. 303-311, 1997. Copyright by Alcohol Research Documentation, Inc., Rutgers Center of Alcohol Studies, Piscataway, NJ 08855

\section{Abstract.}

Objective: In order to answer the question whether older alcoholics form a distinct group among problem drinkers and within their age cohort, drinking histories of alcoholics in treatment over 50 years of age $(n=51)$ are compared to those of younger alcoholics $(n=55)$, and to those of older social drinkers $(n=46)$. Within the older alcoholics category, comparisons are made by age of onset. Changes in consumption volume, and onset and remission of heovy drinking, morning drinking and solitary drinking are related to events in other spheres of life. Method: In face-to-face interviews, respondents were asked to report drinking behavior in subsequent drinking phases, from the beginning of regular drinking to the present. Events that marked a transition to a new drinking phase, as well as the impact that these events had on the general well-being of the respondents were assessed using a semi-structured interview format. Results: Compared to younger alcoholics, older alcoholics were older when they started drinking regularly, and they report later age at onset of heavy drinking. Older alcoholics and social drinkers were similar with respect to the first years of their drinking career. Older alcoholics with onset of heavy drinking before the age of 35 were similar to younger alcoholics, while older alcoholics with later onset of heavy drinking resemble social drinkers with respect to their earlier drinking history. Alcoholics with later onset more often report onset in connection with events such as marital disruption. Conclusion: Among older alcoholics, a distinct group can be distinguished that may benefit from specific prevention and treatment measures.

\subsection{Introduction.}

The drinking history of individuals has been an issue of great interest in alcohol research and alcoholism treatment practice for a long time. In order to gain more understanding of the development of problem drinking or alcoholism, and the commonalities and variabilities in this development across categories and individuals, psychiatrists and social scientists have tried to follow drinking careers of patients and non-patients. Epidemiologists have tried to reconstruct drinking histories in order to

'The authors would like to thank W. Meulders and P. Gottmer of the Consultation Bureau for Alcohol and other Drugs (CAD) for making data collection possible and two anonymous reviewers for their insightful comments on an earlier version of this paper. 
estimate total lifetime alcohol consumption, which measure can be used in risk models for certain health problems, such as cancer and heart disease. Some authors have concentrated their efforts on certain age groups, such as the elderly (Schuckit and Pastor, 1978). Nevertheless, in the general literature on drinking careers and on the natural history of alcoholism (e.g. Edwards, 1984; Jellinek, 1952; Vaillant, 1983), interest for variability across age groups is remarkably absent. These studies imply that the course of drinking careers does not differ across age cohorts.

From a theoretical point of view, aging as well as cohort related (or generational) factors may lead to differences between age groups with respect to drinking careers (Neve et al., 1993). Social and psychological aspects of aging may lead to different backgrounds of problem drinking among age groups. Cultural changes in drinking volumes and in drinking patterns over time lead to differential socialization into drinking and problem drinking across cohorts. Besides theoretical considerations, questions on differences in drinking histories among age groups have recently become more relevant due to ongoing population developments. The proportion of the population in older age categories is expected to increase dramatically in the coming decades (Leering and Lerou, 1990). Other circumstances being equal, this will lead to an increase in the proportion of older people among problem drinkers as well. Therefore, this study will assess whether older problem drinkers form a distinct group within the problem drinking population, as well as within their age cohort, with respect to their drinking careers.

\section{Drinking career, onset, and life events.}

Central in this study is the concept of 'drinking career', used here in a tentative way. No a priori theoretical expectations are formulated about the 'natural history' of problem drinking or alcoholism. The drinking career is conceptually distinguished from the 'life course' as a whole, and from other careers in certain role domains, such as the employment career, residential career, family career etc. In a drinking career, as well as in any other career, several phases may be identified, which are defined by transitions (Edwards, 1984). The extent to which transitions in the drinking career, such as onset of problem drinking, are connected with transitions in other aspects of life is the domain of the 'life events' research perspective in the alcohol field (for reviews, see: Allan and Cooke, 1985; O'Doherty and Davies, 1987). The life events perspective bears resemblance to one approach of older problem drinkers, which distinguishes 'early' and 'late' onset of problem drinking (Gomberg, 1988; Schonfeld and Dupree, 1991). Early onset, or 'long term chronic' problem drinking, starts in youth and is thought to be possibly related to genetic factors, while "late onset' or 'reactive' problem drinking is thought to be related to the stressful events inherent to later life. Self-medication with alcohol may be used as an inadequate coping behavior, which may lead to problem drinking or alcoholism. On the other hand, several authors have explained the finding that most 'active' (i.e. not remitted) older alcoholics have experienced late onset by selection through either premature death or recovery among early-onset alcoholics (e.g. Schuckit and Pastor, 1978; Vaillant, 1983). 
In the present paper, phases of the drinking career as well as transitions and accompanying life events will be studied from a life course perspective. The aim of the study is to clarify to what extent older problem drinkers show different drinking careers, in terms of their phases and transitions, compared with younger problem drinkers. Because these problem drinkers are contacted through the alcohol treatment system, they will also be called 'alcoholics', without this implying any particular view on alcoholism as a progressive disease. Further, the paper will assess to what extent changes in drinking behavior are connected to changes in other aspects of life as perceived by the drinkers themselves. Through systematic comparison of older problem drinkers with younger problem drinkers, as well as with non-problematic drinkers of their own age from the general population, the study will assess whether, and in what ways, older problem drinkers show specific drinking careers. This will answer the question: to what extent do older problem drinkers, with respect to their drinking history, form a distinct group within the problem drinker population and/or within their age cohort?

\subsection{Methods.}

\subsubsection{Sample and procedure.}

Data were collected from two groups of male outpatients of an alcohol treatment agency. The age category $35-44(\mathrm{~N}=55)$ forms the modal age group among the male clients with $37 \%$ of the total male population. Within the agency, clients over 50 years of age $(\mathrm{N}=52)$ can be considered the older age group, with $21 \%$ of the total. $6 \%$ of male alcohol clients is over 60 , and $1 \%$ is over 70 . The agency employs no clinical criteria for admission to treatment. However,all participants in this study score on a problem drinking index (see under measurement), which has substantial overlap with diagnostic criteria, such as MAST and DSM (Vaillant et al., 1982). Patients referred for treatment by court decision were excluded from the study. Respondents in both age groups were sampled randomly from the agency's registration system at the start of the project. The sample formed a majority of all clients who met the inclusion criteria. Part of the selected clients were replaced by others in the process of approaching the respondents, e.g. because people were no longer in treatment. This was done by the treatment agency on the basis of the inclusion criteria, without involvement of the research team. Respondents were contacted via their direct counselors, who also obtained informed consent. Fieldwork was done by trained female interviewers. Interviews were held between June 1993 and April 1994.

A comparison group of social drinkers $(n=47)$, of the same ages as the older alcoholics in treatment, was selected from a general practice registration system (Metsemakers et al., 1992). Persons known to the physician as problem drinkers and persons with alcohol related diagnoses in their file were excluded from the sample frame. The social drinkers group was matched to the older problem drinking group by frequency distribution of age, education and degree of urbanization. Long time abstainers, who had not consumed alcohol in the past ten years, were excluded from the study. Because it was not possible to exclude this group from the sampling frame, 
they were identified with a few screening questions at the first approach by telephone. Interviews with social drinkers were held in April and May 1994.

The interview was preceded by a mailed questionnaire that was filled out and handed to the interviewer. The questionnaire contained questions on socio-demographics, such as education and professional activities. Interviews for social drinkers were identical to those for alcoholics, except for questions on treatment. The interviews lasted one hour and 15 minutes on average.

\subsubsection{Measurement}

A retrospective methodology was used for data collection on drinking careers. Recently, the Lifetime Drinking History (Skinner, 1979; Skinner and Sheu, 1982) has gained credibility as a feasible method for retrospective assessment of phases as well as of transitions in the drinking career (Harris et al., 1994; York, 1995). In this interview schedule, several aspects of drinking behavior are assessed for every distinct phase in the drinking career. Respondents are invited to recall life events only in so far as they are considered relevant to changes in drinking behavior. In other words, causal attributions on the part of the respondent play a role in the method.

The original questions of the Lifetime Drinking History (Skinner, 1979) were used. In order allow comparison with other Dutch research, an 8 category format was used for frequency variables (drinking and heavy drinking), ranging from 'every day' to 'never'. The interview started with the question: "How old were you when you first started drinking alcohol regularly?", without further specification of a certain frequency. Type of beverage, frequency and quantity of drinking, frequency of heavy drinking (defined as drinking 6 or more units per drinking day), solitary drinking, and morning drinking were assessed for every drinking phase separately. The end of the drinking phases was assessed by asking whether an event had occurred that altered drinking habits, and whether this event was evaluated as "positive', 'neutral' or 'negative'. Events that were mentioned have been categorized as family and marital events, work related events, treatment events and other events. The age at which the change occurred marks the beginning of the next episode.

After all units (cans, bottles etc.) were converted to standard units (hereafter denoted as 'glasses') of 10 grams ethanol, consumption volume for each drinking phase was computed with the QFV method (Lemmens et al., 1992). In the present study, only consumption of the first drinking phase and in the last drinking phase before intake is used as such, expressed in glasses per week. Changes in drinking between adjacent drinking phases are categorized as increase, stability and decrease. After inspection of the distributions of the change scores (in glasses annual), the cutoff points for increase and decrease were chosen with the goal of the study in mind. Not the extremity of changes, but the way in which they relate to life events are of crucial interest. The cut-off point was set at 1000 glasses annual for alcoholics and at 500 glasses for social drinkers. A majority of respondents in the three groups reported increases and decreases that met these criteria. 
Table 7.1. Characteristics of Drinking Phases.

\section{Phase number}

\begin{tabular}{llllllll}
\hline 1 & 2 & 3 & 4 & 5 & 6 & 7 & 8 \\
\hline
\end{tabular}

Alcoholics $50+$.

\begin{tabular}{lrrrrrrr} 
Total N & \multicolumn{1}{c}{52} & \multicolumn{1}{c}{51} & \multicolumn{1}{c}{50} & \multicolumn{1}{c}{43} & \multicolumn{1}{c}{36} & 17 & \multicolumn{1}{c}{10} \\
Duration (yrs) & 8.0 & 11.2 & 8.5 & 4.9 & 3.2 & 2.4 & 2.8 \\
(St. Dev.) & $(6.6)$ & $(9.7)$ & $(7.4)$ & $(4.4)$ & $(4.5)$ & $(2.6)$ & $(3.4)$ \\
\%Abstainers & 0.0 & 3.9 & 4.0 & 11.6 & 27.8 & 38.9 & 44.4 \\
\%Heavy dr. & 15.4 & 39.2 & 66.0 & 58.1 & 38.9 & 27.8 & 33.3 \\
\%Solitary dr. & 3.8 & 9.8 & 26.0 & 34.1 & 22.9 & 29.4 & 0.0 \\
\%Morning dr. & 11.5 & 6.1 & 32.0 & 33.3 & 25.7 & 17.6 & 20.0
\end{tabular}

Alcoholics 35-44.

\begin{tabular}{lrrrrrrrr} 
Total N & \multicolumn{1}{c}{55} & \multicolumn{1}{c}{55} & \multicolumn{1}{c}{55} & \multicolumn{1}{c}{50} & \multicolumn{1}{c}{42} & 34 & 18 & 10 \\
Duration & 4.8 & 5.6 & 4.4 & 3.2 & 2.7 & 1.5 & 2.8 & 2.3 \\
(St. Dev.) & $(3.8)$ & $(4.3)$ & $(3.7)$ & $(3.2)$ & $12.5)$ & $(1.4)$ & $(2.1)$ & $(2.2)$ \\
\%Abstainers & 0.0 & 1.8 & 18.2 & 8.0 & 23.8 & 23.5 & 35.3 & 10.0 \\
\%Heavy dr. & 20.0 & 80.0 & 60.0 & 74.0 & 57.1 & 52.9 & 47.1 & 70.0 \\
\%Solitary dr. & 5.5 & 14.5 & 25.5 & 26.0 & 40.5 & 30.3 & 27.8 & 40.0 \\
\%Morning dr. & 10.9 & 20.0 & 25.0 & 32.7 & 26.8 & 31.3 & 22.2 & 20.0
\end{tabular}

Social drinkers $50+$.

\begin{tabular}{lrrrr} 
Total N & \multicolumn{1}{c}{46} & \multicolumn{1}{c}{43} & \multicolumn{1}{c}{25} & 1.4 \\
Duration & 12.3 & 13.6 & 16.0 & 9.9 \\
(St. Dev.) & $(11.3)$ & $(11.1)$ & $(9.1)$ & $(8.6)$ \\
\%Abstainers & 0.0 & 7.0 & 0.0 & 14.3 \\
\%Heavy dr. & 6.5 & 9.3 & 12.0 & 0.0 \\
\%Solitary dr. & 4.3 & 9.8 & 4.0 & 14.3 \\
\%Morning dr. & 10.9 & 0.0 & 3.8 & 7.1
\end{tabular}

Note: The figure 'total $N$ ' refers to all who completed the questionnaire up to the specified drinking phase. Phases with $\mathrm{N}$ less than 10 are not reported in the table. In parentheses: standard deviation of duration. 
Special attention was given to intermediate abstinent phases, whether or not they coincided with a treatment episode. An attempt at abstinence is considered a sign that a problem drinker has realized that he has taken his drinking too far.

For the purpose of this paper, the variable onset of heavy drinking is defined as the beginning of the first drinking phase in which the respondent reported consumption of 6 or more glasses on at least three days per week.

Severity of alcohol problems was assessed with a Problem Drinking Index, a 19 item version of Cahalan's (1976) index (Knibbe, Muytjens and Drop, 1987; Hajema, Knibbe and Drop, 1994). The index ranges from 0 to 8 points. Respondents were asked to report alcohol problems in the last period before intake in treatment.

\subsubsection{Analysis.}

Older alcoholics (50 years and older) were compared with younger allcoholics (ages 35-44) and to social drinkers of their own age. Within the group of older alcoholics, comparisons were conducted by age of onset of heavy drinking, with the mean ( 35 years) as the cut-off point for early onset and late onset. $\chi^{2}$ tests were conducted for differences in percentages, $T$-tests for differences in means. Graphical representation was used to study change in consumption across the life course (figures 6.1 and 6.2).

\subsection{Results.}

\subsubsection{Socio-demographics.}

Compared to younger alcoholics (51\%), older alcoholics more often had children $(73 \%)$. Other differences were not significant. Compared to social drinkers, older alcoholics were more often divorced or never married ( $35 \%$ versus $6 \%$ ); they less often had children ( $73 \%$ vs. $89 \%)$; more often received benefits because of incapacity $(27 \%$ vs. $17 \%)$ and less often considered themselves members of a church $(67 \%$ vs. $87 \%)$.

\subsubsection{Phases in the Drinking History.}

Characteristics of separate drinking phases are reported in table 7.1. Since the number of drinking phases per respondent was left free in the interviews, and some respondents reported only few changes in consumption, the number of subjects logically decreased with higher phase number. When the number of subjects included decreased below 10 , no data on further drinking phases were presented.

Compared with younger alcoholics, alcoholics aged older than 50 reported one drinking phase less, and the duration per drinking phase was longer. The second phase was the longest, and percentages of abstainers increased with later drinking phase in both groups of alcoholics. Prevalence of heavy drinking, solitary drinking, and morning drinking decrease in later drinking phases in both groups, but more pronounced among older alcoholics for heavy drinking and solitary drinking. A marked difference in prevalence of heavy drinking between both groups of alcoholics occurred in the second drinking phase, in which $80 \%$ of the younger group reported heavy drinking, against $39.2 \%$ among older alcoholics. 

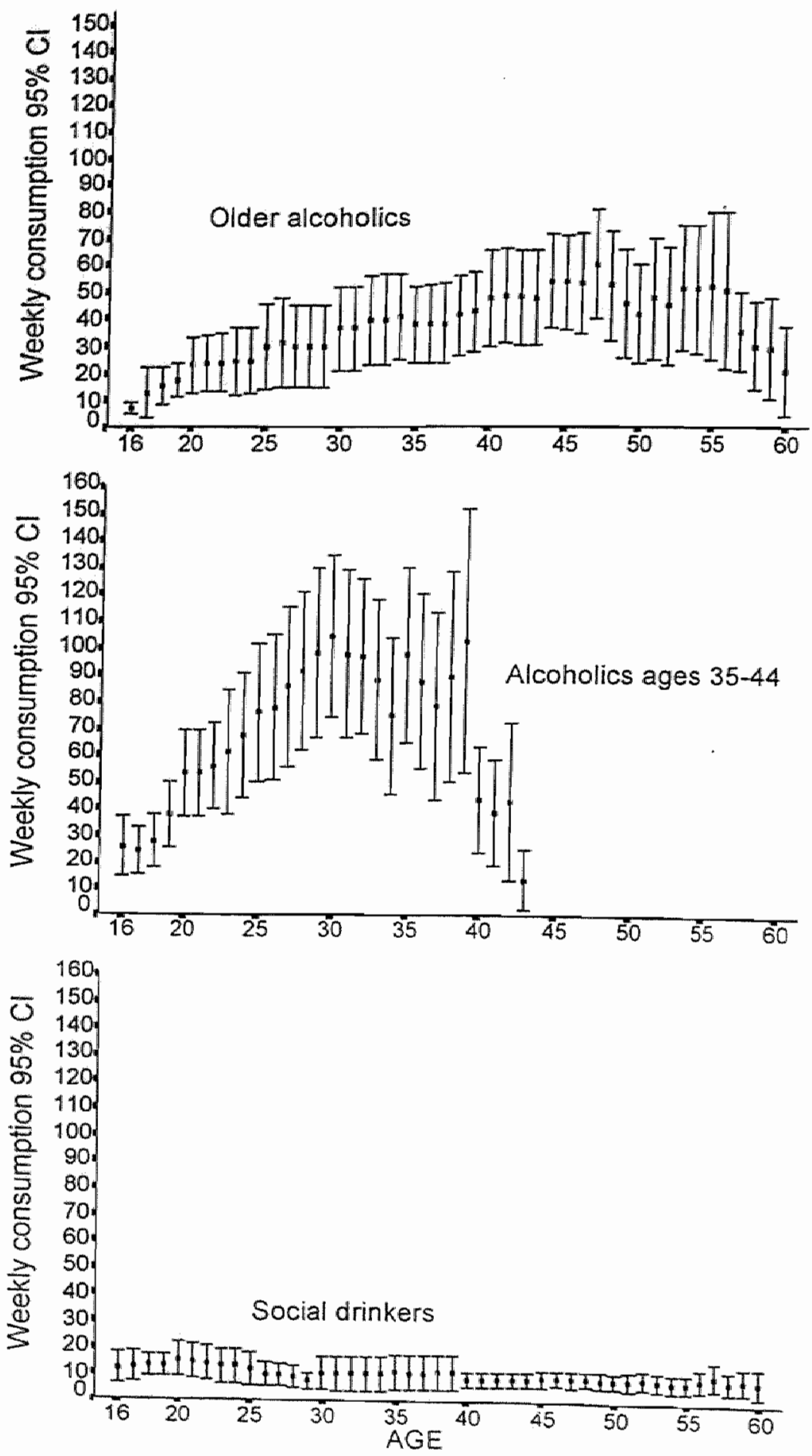

Figure 7.1. Consumption by age, as computed from consumption in drinking phases, in older alcoholics $(50+)$, younger alcoholics $(35-44)$ and social drinkers $(50+)$. 
Comparison of older alcoholics with social drinkers in the same age category shows that the latter reported less (and thus longer) drinking phases. Abstinent phases occurred among few social drinkers, and this aspect shows no clear pattern across the drinking phases. Prevalence of problematic drinking behaviors was smaller among social drinkers, compared to the older alcoholics. Percentage of social drinkers who drink 6 glasses or more at least three times per week (heavy drinking) was maximal $12 \%$ in the third drinking phase, which is lower than in any drinking phase among older alcoholics.

\subsubsection{Consumption across the life course.}

Consumption in every year of the life course was derived from the consumption in each drinking phase. Compared to younger alcoholics, older alcoholics reported lower consumption at age 16 (figure 7.1). Older alcoholics showed a rather steady increase of consumption until age 45 and a decrease in later years. This pattern differs strongly from the one among younger alcoholics, which showed very strong increase until age

Table 7.2. Characteristics of the Drinking Career.

\begin{tabular}{|c|c|c|c|c|c|}
\hline & $\begin{array}{l}\text { Alcoholics } \\
50 \text { and older }\end{array}$ & $\begin{array}{l}\text { Alcoholics } \\
\text { ages } 35-44\end{array}$ & $\begin{array}{c}\text { Difference } \\
\text { with alder alc. }\end{array}$ & $\begin{array}{c}\text { Social } \\
\text { Drinkers }\end{array}$ & $\begin{array}{c}\text { Difference } \\
\text { with older alc. }\end{array}$ \\
\hline Age at interview & $56.0( \pm 5.7))$ & $39.8( \pm 3.0)$ & $t=18.18,76.3 \mathrm{df}, p=.00^{\circ}$ & $56.9( \pm 4.5)$ & n.s. \\
\hline Number of phases & $5.2( \pm 2.0)$ & $6.1( \pm 2.2)$ & $t=-2.12,105 d t, p=.04$ & $3.0( \pm 1.3)$ & $t=6.71,97 . d t_{n} p=.00$ \\
\hline Age first reg. drinking & $19.9( \pm 5.8)$ & $17.1( \pm 3.4)$ & $t=3.07,81.8 \mathrm{df}, p=.00^{3}$ & $18.9( \pm 4.9)$ & n.s. \\
\hline Age onset of heavy dr. & $34.9( \pm 14.5)$ & $22.6( \pm 6.6)$ & $t=5.47,67.7 \mathrm{df}, p=.00^{9}$ & $24.0( \pm 9.9)$ & $t=2.04,56 \mathrm{df}, \mathrm{p}=.05$ \\
\hline Consumption*. in first phase & $12.9( \pm 15.5)$ & $23.4( \pm 34.9)$ & $t=-2.03,75.4 d f_{a} p=.05^{a}$ & $12.4( \pm 11.8)$ & n.s. \\
\hline \multicolumn{6}{|l|}{ Consumption in last phase } \\
\hline before treatment ${ }^{* *}$ & $50.5( \pm 66.3)$ & $96.2( \pm 107.1)$ & $=2.58 .9 .6 \mathrm{dt}, \mathrm{p}=.0 z$ & $8.0( \pm 9.5)$ & 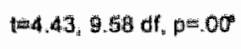 \\
\hline \multicolumn{2}{|c|}{ Drinking Problems Index $(0-8) 5.6( \pm 1.9)$} & $6.5( \pm 1.5)$ & $t=-283,105 \mathrm{df}_{i} p=00$ & & \\
\hline Intermediate abstinence $(\%)$ & 17.3 & 25.5 & n.s. & 6.4 & $x^{2}=2,8 ; 1 d f_{1} p=10$ \\
\hline \multicolumn{6}{|l|}{ Intermediate abstinence, } \\
\hline no treatment $(\%)$ & 11.5 & 10.9 & n.s. & 6.4 & n.s. \\
\hline Earlier treatment $(\%)$ & 53.8 & 65.5 & nis. & 0.0 & $x^{2}=35.3,1 d t_{n}=00$ \\
\hline Ever morning drinking $(\%)$ & 75.0 & 67.3 & n.s. & 12.8 & $x^{2}=38.6,1 d t, p=00$ \\
\hline Ever solitary drinking $(\%)$ & 38.5 & 40.0 & n.s. & 2.1 & $x^{2}=19.5,1 \mathrm{df}, p=00$ \\
\hline N & 52 & 55 & & 46 & \\
\hline
\end{tabular}

Note: Tested are differences in comparison to older alcoholics. Standard deviations in parenthesis.

n.s.: $p>10$

: t-test for unequal variance between groups

* weekly consumption in glasses of 10 grams ethanol

**. last drinking phase for social drinkers. 
30 and decrease in the fourth life decade. Sociall drinkers started drinking at about the same level as older alcoholics. Consumption in the first years of the drinking career developed in the same way in both groups. Whereas consumption among older alcoholics remained increasing, the drinking career of social drinking respondents was characterized by decrease from their early twenties onward.

\subsubsection{Aspects of the drinking history as a whole.}

Table 7.2 shows some aspects of the drinking career as a whole, aggregated across the drinking phases. Younger alcoholics started drinking regularly almost three years earlier than older alcoholics. Younger alcoholics on average report one more drinking phase than older alcoholics. Onset of heavy drinking occurred at considerably later age among older alcoholics. Consumption in the first drinking phase, as well as in the last drinking phase before treatment, was significantly lower among older alcoholics compared with younger alcoholics.

Compared with social drinkers, the average number of drinking phases is higher among older alcoholics, but the age at which they reported to have started drinking regularly is not different. Eight social drinkers reported heavy drinking in any drinking phase. The average age at which heavy drinking first occurred among this group was 24 years, which is about 11 years younger than alcoholics of the same age, and which is about the same age as among younger alcoholics. Difference in consumption in the first drinking phase between social drinkers and older alcoholics was not significant.

In table 7.1, no specific 'treatment phases' were identified. However, it was asked which phases started with an admission for treatment. Both groups of alcoholics reported intermediate abstinent phases, part of which did not coincide with an admission for treatment. Differences between both groups of alcoholics in earlier treatment, nor in morning drinking and solitary drinking were significant.

The percentage of social drinkers that reported intermediate abstinent phases $(6.4 \%)$ did not differ significantly from the older alcoholics. All clearly problematic aspects of the drinking career, such as treatment, drinking in the morning and solitary drinking, were reported much less often among social drinkers. Nevertheless, $12.8 \%$ of them reported drinking in the morning in some phase of their drinking career.

\subsubsection{Changes in drinking and events.}

As was explained in the method section above, in the Lifetime Drinking History, the end of every drinking phase was assessed by the question whether something happened that made the respondent change his drinking habits. A specific event was mentioned in relation to more than 4 in every 5 transitions reported by the respondents in all three groups. Most events were evaluated by respondents as either positive or negative. However, social drinkers were more inclined to evaluate events in connection to a transition as 'neutral' (34\%, against $15 \%$ among older alcoholics and $18 \%$ in younger alcoholics). Events were categorized as marital, work-related, treatmentrelated and 'other'. Marital events were mentioned most often: about $30 \%$ of all transitions in all three groups involved marital events ( $28 \%$ among older alcoholics, 
$26 \%$ among younger alcoholics and $33 \%$ among social drinkers). Only the most salient comparisons are reported here. Complete tables with all 120 comparisons are available from the authors for interested readers.

Both groups of alcoholics did not differ significantly in the occurrence of changes in alcohol consumption, associated with either negative or positive events. Negative events were more often mentioned in connection with increases in consumption ( $56 \%$ in the older vs. $47 \%$ in the younger group), and positive events were associated with decreases in consumption ( $44 \%$ vs. $49 \%$ ). Most negative events associated with increases in consumption were marital events ( $25 \%$ in both groups). Most of the positive events mentioned in connection with decreases in consumption were treatment events (predominantly admission). Positively evaluated events were also mentioned in connection with increases in consumption ( $31 \%$ older vs. $44 \%$ younger) and negative events were related to decreases in consumption ( $31 \%$ vs. $36 \%$ ). Positive events mentioned in connection with an increase in consumption were most often marital events, especially among the younger alcoholics ( $8 \%$ vs. $18 \%$ ). Decrease in consumption was more often related to treatment than to other kinds of events.

Differences between older alcoholics and social drinkers were mostly significant. Among the social drinkers group, 4 respondents reported increases in consumption in connection with negative events; no increases in drinking were reported that were associated with positively evaluated events. One in four social drinkers reported a decrease in consumption related to a positive event. This percentage does not differ from the older alcoholics group. Other decreases in alcohol consumption associated with specific events were rare among social drinkers.

Patterns in percentages that reported onset or remission of heavy drinking, in connection with life events were remarkably similar for both groups of alcoholics. Only one difference appears to be significant: a majority of older alcoholics $(56 \%)$ reported onset of heavy drinking in connection with a negatively evaluated event, against $33 \%$ among the younger group $\left(\chi^{2} 5.8,1 \mathrm{df}, \mathrm{p}<.05\right)$. Marital events, such as divorce and separation, were mentioned most often in both groups. Almost one in every three respondents in both alcoholic groups reported onset of heavy drinking in relation to a positively evaluated event.

Among the eight social drinkers who reported heavy drinking episodes, three $(6.4 \%)$ reported an event in relation to onset, all of which were negative events. Two reported remission in connection with a positively evaluated marital event, and one in connection with a negatively evaluated marital event.

Onset and remission of morning drinking and solitary drinking, associated with life events, are reported for alcoholics only. Morning drinking in a phase marked by a negatively evaluated life event was reported most often by older alcoholics ( $48 \%$ ), and the difference with younger alcoholics $(27 \%)$ was significant $\left(\chi^{2} 4.9,1 \mathrm{df}\right.$, $\mathrm{p}<.05$ ). $18 \%$ of the younger alcoholics reported onset in relation to positive events, against $4 \%$ among the older group $\left(\chi^{2} 5.5,1 \mathrm{df}, \mathrm{p}<.05\right)$. No significant differences between older and younger alcoholics were observed in remission of moming drinking. Remission of morning drinking, associated with positive life events, treatment events mostly, was reported by $25 \%$ of older alcoholics and $31 \%$ of younger 

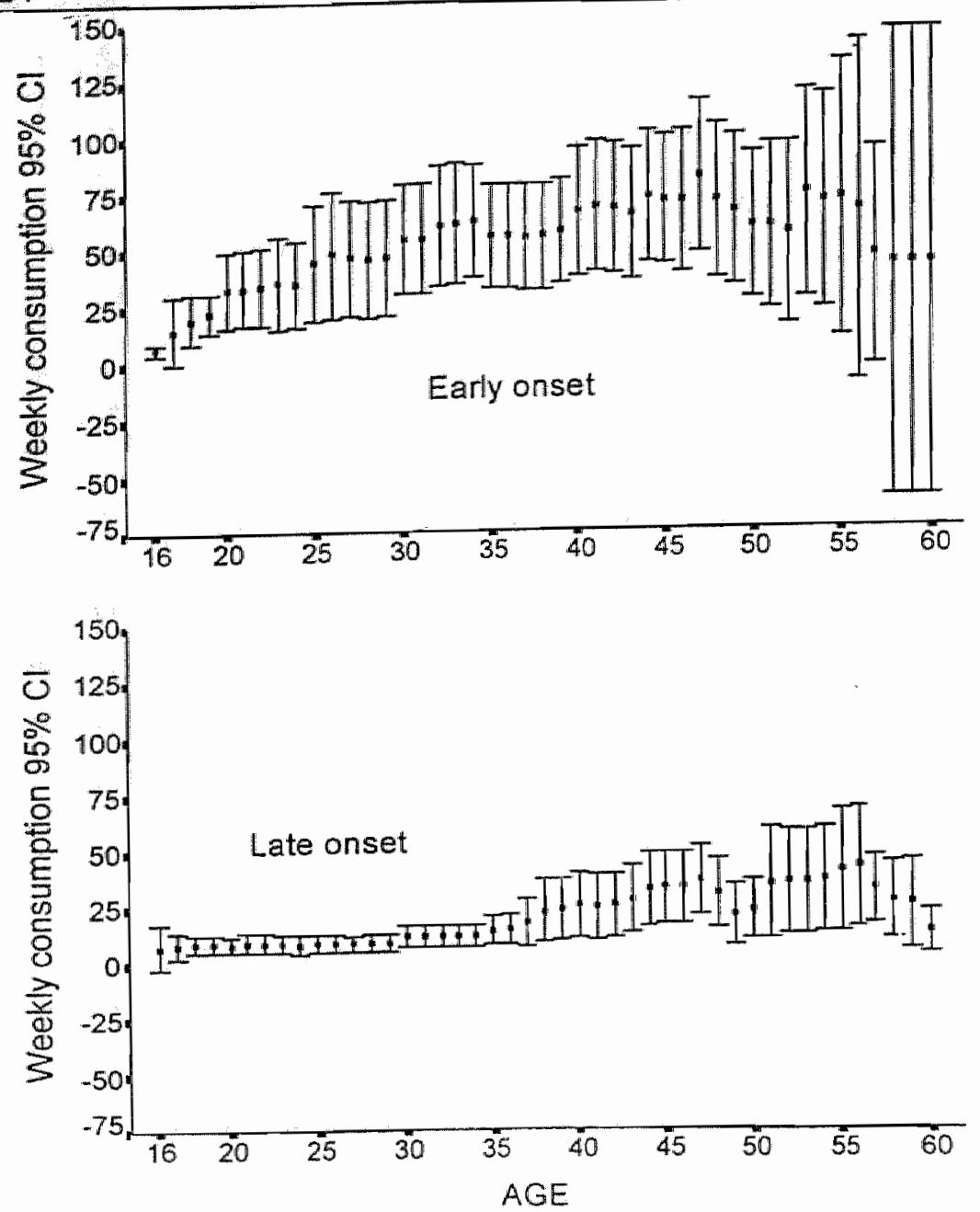

Figure 7.2. Consumption by age, as computed from consumption in de drinking phases, in older alcoholics with early (before age 35) and late (age 35 or later) onset of heavy drinking.

alcoholics. Negative events were associated with remission of morning drinking by $15 \%$ of older alcoholics and $18 \%$ of younger alcoholics. Again, most of these negative events were treatment events.

No significant differences in either onset or remission of solitary drinking were observed between both groups of alcoholics. As with morning drinking, onset of solitary drinking was reported mostly in connection with negatively evaluated events. Also, younger alcoholics more often reported onset of solitary drinking in connection with positive events. Different from the results on morning drinking, older alcoholics reported remission of solitary drinking as often in relation to negative events as in relation to positive events. Younger alcoholics more often reported remission in relation to positive events, predominantly related to treatment. 
7.3.6 Variability by age of onset of heavy drinking among older alcoholics.

Table 7.2 showed that the average age of onset of heavy drinking among older alcoholics was 35 years, which was much later than among younger alcoholics and than among social drinkers that ever experienced heavy drinking episodes. Since age of onset of heavy drinking is a crucial point in the drinking career, the associations between this variable and other aspects of the drinking career were analyzed within the group of older alcoholics. The older alcoholic group was split in two smaller groups, with age of onset under 35 years $(n=28)$ and 35 years and older $(n=24)$, for which all analyses presented above were repeated. No significant differences between both groups were found in education, employment, marital status or religious affiliation.

Analysis of the separate drinking phases showed that the second drinking phase was longer among the 'late onset' cases ( 16.1 years against 7.2 years in early onset respondents, $t-3.57,32.1 \mathrm{df}, \mathrm{p}<.01) .28 .6 \%$ of early onset cases, and none of the late onset group, reported heavy drinking in the first drinking phase $\left(\chi^{2} 8.1,1 \mathrm{df}, \mathrm{p}<.01\right)$. Corresponding figures for the second drinking phase were $57.1 \%$ and $17.4 \%\left(\chi^{2} 8.4\right.$, $1 \mathrm{df}, \mathrm{p}<.01)$. For other characteristics of separate drinking phases, the results were quite similar. Figure 7.2 shows that average weekly consumption among older alcoholics with early onset not only (by definition) increased at earlier age than among those with late onset, but remains at higher levels at later ages as well.

Table 7.3 shows significant differences between both groups of older alcoholics analogous to table 7.2. The results show that older alcoholics with early onset of heavy drinking were younger and started drinking regularly earlier and at higher consumption consumption level. They also reported more drinking phases: 5.8 against 4.5 among the 'later onset' respondents. In the last period before intake, alcohol problems were slightly more severe among older alcoholics with early onset, but this difference is not significant at .05 level. Percentages of abstainers, heavy drinkers, morning drinking and solitary drinking were similar.

Separate analyses of changes in drinking behavior in relation to positive and negative life events ( 80 comparisons, tables available upon request) resulted in 18 significant differences. With one exception, all these comparisons showed that older

Table 7.3. Aspects of the drinking career by age of onset of heavy drinking, older alcoholics only.

\begin{tabular}{lccc}
\hline & Onset before age 35 & Onset at age 35 and older & T-test \\
\hline Age at interview & $54.2(4.3)$ & $58.1(6.5)$ & $t=-2.45,39.0 \mathrm{df}, \mathrm{p}=02$ \\
Number of phases & $5.8(2.3)$ & $4.5(1.2)$ & $\mathrm{t}=2.56,42.2 \mathrm{df}, \mathrm{p}=.01$ \\
Age first regular drinking & $18.4(4.1)$ & $21.6(7.0)$ & $t=-1.96,36.2 \mathrm{df}, \mathrm{p}=.06$ \\
Age onset of heavy drinking & $24.1(5.8)$ & $48.6(9.7)$ & $t=-10.5,32.5 \mathrm{df}, \mathrm{p}<.001$ \\
Conumption* in first phase & $17.3(19.6)$ & $7.8(5.5)$ & $\mathrm{t}=2.44,31.9 \mathrm{df}, \mathrm{p}=02$ \\
Drinking problems (0-8) & $6.0( \pm 1.7)$ & $5.0( \pm 2.0)$ & $t=1.84,45.3 \mathrm{df}, \mathrm{p}=.07$ \\
N & 28 & 24 & \\
\hline
\end{tabular}

Note: Standard deviation in parenthesis. T-test for unequal variance between groups.

*: weekly consumption in glasses of 10 grams ethanol 
alcoholics with earlier onset of heavy drinking more often reported changes in drinking behavior in relation to life events. The one exception was that respondents with later onset more often reported onset of heavy drinking in connection with a negatively evaluated marital event $(41.7 \%$ against $7.1 \%$ among the earlier onset group; $\chi^{2} 8.68,1 \mathrm{df}, \mathrm{p}<.01$ ).

\subsection{Discussion.}

\subsubsection{Methodological comments.}

According to Simpura and Poikolainen (1983) social drinkers strongly overestimated their earlier consumption, which led the authors to question the relevance of retrospective questioning. Simpura and Poikolainen's study showed that reporting on past behavior was influenced by general historical changes that occurred, predominantly a large increase in per capita consumption of alcohol. In the Netherlands, an increase in per capita consumption occurred that was similar to the Finnish, which suggests that this mechanism occurs in this country as well (Lemmens, Neve and De Haan, presented at the 21 st Annual Alcohol Epidemiology Symposium, Porto, June 1995). Simpura and Poikolainen also reported a significant, although unspecified, (rank) correlation between original measurement and recall. Even if retrospective reporting leads to an overestimation of total lifetime consumption (relative to the normal coverage in survey research), it does not necessarily affect recall of the overall development of the drinking career, in terms of changes in drinking patterns and related events in other spheres of life.

A difference between our version of the Lifetime Drinking History and the original by Skinner is that we did not specify a frequency of drinking in the first question that assesses the age of first regular drinking. Alcoholics, who probably associate 'regular' drinking with a higher frequency than social drinkers, may report a higher age of onset of drinking with the present format than with the original. In other words, they may 'skip' a first phase of light drinking, which they do not view as 'regular' drinking. If this would be the case, one would also expect them to report higher consumption in the first drinking phase, as compared to social drinkers.

In this study, the connection between life events and changes in the drinking career is made by respondents. Thus, events may vary in the extent to which they can be a consequence of, rather than an antecedent to changes in drinking. For instance, conscription for millitary service will not be influenced by drinking (although some very early alcoholics may not be conscripted because of their drinking), whereas marital problems may be expected to result from alcohol problems in many cases. Therefore, we will only draw tentative conclusions here with respect to the causal connection between events and changes in the drinking career.

Another remark is to be made on the evaluation on the part of respondents of life events, especially treatment. An admission for treatment may be evaluated positively (decision to solve a serious problem) but also negatively (showed how bad the problem was), dependent on the degree of acceptation on the part of the subject. The use of a time frame would improve the evaluations: it could make a difference to 
specify whether the respondent evaluated an event as positive or negative at the time when it occurred or from the perspective of the present situation.

\subsubsection{Summary and conclusions.}

Differences between older alcoholics in treatment and their counterparts in the modal age category ( 35 to 44 years old) can be summed up briefly. Older alcoholics reported less drinking phases, later age of first regular drinking, later onset of heavy drinking, more often onset of heavy drinking and morning drinking in connection with a negatively evaluated life event, and they less often associated onset of morning drinking and solitary drinking with a positively evaluated life event.

Compared with older problem drinkers, social drinkers showed lower prevalence in all problematic aspects of drinking behavior. Whereas among alcoholics increase in consumption and onset of heavy drinking, morning drinking and solitary drinking were sometimes connected with positive events (although less often in older than in younger alcoholics), a shift towards more problematic drinking behavior among social drinkers (which occurred far less often in the first place) was connected to negative events only. For those who reported any phases with heavy drinking in their lifetime, the average age of onset of heavy drinking was much younger among the social drinkers group than among older alcoholics and similar to younger alcoholics. Age of first regular drinking and level of consumption in the first drinking phases of older alcoholics and social drinkers were similar. Part of the differences between older and younger alcoholics can be related directly to the age difference as such. Earlier age of regular drinking among younger alcoholics may reflect cohort related changes in the general population, where the drinking age is likely to have decreased in the last decades, although exact figures are not available. Higher average age of onset of heavy drinking among older alcoholics may be due in part to the difference in age range with younger alcoholics. However, the difference in age of onset of heavy drinking between older and younger alcoholics is large, so that it may be concluded that older alcoholics actually experienced later onset of heavy drinking than younger alcoholics.

Compared with younger alcoholics, older alcoholics' reporting of life events in relation to transitions in the drinking career is more in agreement with common sense expectation. A change in drinking behavior in the direction of more problematic drinking behavior would be expected to coincide with events that had a negative impact on the life of a person. However, compared to their older counterparts, younger alcoholics less often reported onset of heavy drinking and morning drinking in relation to negative events and more often onset of moming drinking and solitary drinking in relation to negative events. One explanation might be that younger alcoholics, on the whole, report more drinking phases and more events than older alcoholics and therefore may be expected to show more heterogeneity in events and in evaluations of events.

Unlike a recent US study (York, 1995), we did not find differences between older alcoholics and social drinkers with respect the first drinking phase. Other than York, we did not find difference in age of first regular drinking, which may be due to 
difference in questioning, as was indicated above. However, other differences cannot be attributed to methodological differences between the studies. Especially alcoholics with late onset started drinking in quite the same manner as men who remained social drinkers. Difference between older alcoholics and social drinkers in morning drinking were less pronounced than in York's study. In the initial drinking phase, $11 \%$ of both alcoholics and social drinkers reported drinking in the morning in this drinking phase, whereas York reported 9.3\% for alcoholics and $2.1 \%$ for social drinkers. Cultural difference between the Netherlands (especially the Limburg region) and the US may be the explanation for this difference. Drinking in the morning is not necessarily related to relief drinking, and Sunday morning pub visits are not unusual. However, in later drinking phases, morning drinking is far more prevalent among alcoholics. As York remarks, this is in agreement with the notion that morning drinking is an important aspect of problematic drinking (see also: Mulford and Miller, 1960; Cahalan, 1976).

The average age of onset of heavy drinking among older alcoholics was 35 years, which was much later than among younger alcoholics. It may be disputed whether this would be labeled 'late onset'. Clearly, criteria that would define onset of alcoholism as a clinical syndrome would in most cases lead to a later age of onset than the consumption based criterion used here. However, it is of interest that this group actually resembled 'late onset alcoholism' as described in the literature. Older alcoholics reported 'normal' age of first regular drinking, as well as normal consumption level in the first drinking phase, at least compared to social drinkers. When the group of older alcoholics was split by age of onset, the resemblance of problem drinkers with late onset and social drinkers in this respect became even more marked. Whereas older alcoholics with onset of heavy drinking before age 35 more closely resemble younger alcoholics, older alcoholics with later age of onset more closely resemble social drinkers in their own age group with respect to the age when they started drinking and the amount consumed in the first drinking phase. In later drinking phases, their consumption was considerably lower than early onset alcoholics, although finally their drinking problems were only slightly less severe.

Contrary to older alcoholics, all social drinkers that reported heavy drinking episodes reported early onset. Part of these social drinkers explicitly reported "maturing out", that is, they quit drinking heavily when they started a relationship or got
married. This transient heavy drinking in youth among social drinkers resembles the
youthful problem drinking that was described by youthful problem drinking that was described by Room (1975, quoted in Edwards,
$1984)$ as 'a kind of normal or tolerated deviance'. Older alcoholics with early onset on average report the same age of onset as former heavy drinkers among the social first onset of heavy drinking in relation to marital disruption. This raises the question whether certain life events play a different role in the drinking careers of different types of drinkers. It seems that some drinkers start off with drinking heavily, and come to entertain more moderate patterns when they get married, while others drink moderately throughout their life, until they start drinking problematically. The causal 
order of marital problems and alcohol problems among older alcoholics with late onset warrants further investigation. Cause and effect may be exchanged by some alcoholics in search of a reasonable explanation for their behavior. On the other hand, drinking as a negative coping behavior may play a role. Gomberg (1988) has described 'reactive problem drinking' among older people, and Brennan and Moos (1991) have shown that 'avoidance coping' is prevalent among older alcoholics with late onset. In future studies, coping methods (Finney and Moos, 1984) should be explicitly included, as well as a check on the time order of events by using collateral reports.

The results presented above show that part of the older alcoholics show an image of chronic addiction, alcoholism that started right from youth and went out of hand in later phases of the life course. On the other hand, another part does form a distinct group. Marked differences were observed in this study: these respondents started drinking heavily at later age, and developed severe drinking problems at a lower consumption level than other alcoholics. There are signs of reactive drinking in this group, which should be investigated further in order to better inform prevention efforts. Treatment providers could take advantage of recognizing this group with specific characteristics when they present themselves at the agencies seeking help for their alcohol problems.

\section{References.}

Allan, C.A., and Cooke, D.J. (1985). Stressful life events and alcohol misuse in women, a critical review. Journall of Studies on Alcohol 46, 147-152.

Brennan, P.L. and Moos, R.H. (1991) Functioning, life context, and help-seeking among late-onset problem drinkers, comparisons with nonproblem and early-onset problem drinkers. British Journal of Addiction 86, 1139-1150.

Cahalan, D. (1976) Problem Drinkers, San Franisico, Jossey-Bass.

Edwards, G. (1984) Drinking in longitudinal perspective, career and natural history. British Journall of Addiction 79, 175-183.

Finney, J.W. and Moos, R.W. (1984) Life stressors and problem drinking among older adults. Recent Developments in Allcoholism 2, 267-288.

Gomberg E.S.L. (1988) Overview, issues of alcohol use and abuse in the elderly population. Joumal of the Pride Institute Long Term Home Health Care 7, 4-17.

Hajema, K.J., Knibbe, R.A. and Drop, M.J. (1994) Chronische probleemdrinkers in de bevolking en bij het $\mathrm{CAD}$, een vergelijking (Chronic problem drinkers in the general population and in the Consultation Bureau for Alcohol and Drugs, a comparison), Maastricht, NL, University of Limburg. Harris, T.R., Wilsnack, R.W. and K.lassen A.W. (1994) Reliability of retrospective self-reports of alcohol consumption among women, data from a U.S. national sample. Journal of Studies on Alcohol 
$55,309-314$.

Jellinek, E.M. Phases of alcohol addiction. Quart. Journal of Studies on Alcohol 13,673-684, 1952.

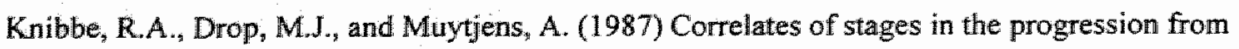
everyday drinking to problem drinking. Social Science and Medicine 24, 463-73.

Leering, $T_{\text {. and Lerou, } W .}$ (1990) Verkenning van de veroudering in Nederland,

Bevolkingsprognoses ten behoeve van de planning van voorzieningen voor ouderen (Investigation of aging in the Netherlands, Population prognosis on behalf of planning of services for the elderly),

Rijswijk, Ministerie van Welzijn, Volksgezondheid en Cultuur.

Lemmens, P.H., Tan E.S. and Knibbe, R.A. (1992) Measuring quantity and frequency of drinking in al general population survey, a comparison of five indices. Journal of Studies on Alcohol 53, 476-486.

Metsemakers, J.F.M., Höppener, P., Knottnerus, J.A., Kocken, R.J.J. and Limonard, C.B.G. (1992)

Computerized health information in the Netherlands, a registration network of family practices.

British Journal of General Practice. 42, 102-106.

Mulford, H.A. and Miller, D.E. (1960) Drinking in Lowa. IV. Preoccupation with drinking, heavy drinking, and trouble due to drinking. Quarterly Journal of Studies on Alcohol 21, 312-320.

Neve, R.J.M., Diederiks ,J.P.M., Kuibbe, R.A. and Drop, M.J. (1993) Developments of drinking behavior in the Netherlands from 1958 to 1989, a cohort analysis. Addiction 88, 611-621.

O'Doherty, F. and Davies, J.B. (1987) Life Events and Addiction, a critical review. British Journal of Addiction, 82, 127-137.

Schonfeld, L, and Dupree, L.W. (1992) Antecedents of drinking for early-and late-onset elderly alcohol abusers. Journal of Studies on Alcohol 52, 587-592.

Schuckit, M.A. and Pastor, P.A. (1978) The elderly as a unique population, alcoholism. Alcoholism: Clinincal and Experimental Research 2, 31-38.

Simpura, and Poikolainen, K. (1983) Accuracy of retrospective measurement of individual alcohol consumption in men; a reinterview after 18 years. Journal of Studies on Alcohol 44, 911-917.

Skinner H.A. (1979) Lifetime Drinking History, Administration and Scoring Guidelines, Toronto, Addiction Research Foundation.

Skinner H.A. and Sheu W.J. (1982) Reliability of Alcohol Use Indices, The Lifetime Drinking History and the MAST. Journal of Studies on Alcohol 43, 1157-1170.

Vaillant, G.E. (1983) The Natural History of Alcoholism, Cambridge, Harvard University Press. Vaillant, G.E., Gale, L. and Milofsky, E.S. (1982) Natural history of male alcoholism II. The relationship between different diagnositic dimensions. Journal of Studies on Allcohol 43, 216-232. York, J.L. (1995) Progression of Alcohol Consumption across the Drinking Career in Alcoholics and Social Drinkers. Journal of Studies on Alcohol 56, 328-336. 


\section{Main results and conclusions.}

\subsection{Introduction.}

In the following paragraphs, the main results of all studies reported in this thesis are briefly summarized. Finally, some general conclusions from the project as a whole are presented, and discussed in terms of their empirical and theoretical impact.

\subsection{Cohort analysis of trends in alcohol consumption.}

The aim of the first study (Chapter 2) was to investigate the possibility that in the near future older people would show increased levels of alcohol related problems, relative to present cohorts. The Netherlands saw an exceptionally rapid increase of per capita consumption in the period from 1960 to 1975 . Therefore, the cohorts that reached drinking age in this period are unique with respect to acquisition of drinking habits. It was already known from surveys that the increase of alcohol consumption among young people, especially young men, had been higher than in other age categories. If this age-cohort would remain drinking at this relatively high consumption level, an increase of alcohol related problems among the elderly could be expected in the near future. This would add to demographic changes also affecting the age distribution of the case load of treatment centers: in 1990, the percentage of people over 65 in the year 2035 was projected at $24 \%$, a doubling compared to 1990 (Leering and Lerou, 1990).

Within the framework of Skog's social interaction theory (Skog, 1980, 1985), a cohort effect was hypothesized under the condition that the social networks of older and younger people would be relatively separated. Such a network separation was plausible because of the 'generation gap' experienced by the cohort of interest. It could therefore be expected that the younger generation would develop a separate 'drinking culture', relatively independent from the rest of the adult population.

It was thought that stable differences between cohorts over the years, or a development of alcohol consumption in the cohorts born in the 1940s deviant from other cohorts, would support the hypothesis of elevated alcohol problems among the elderly in the next decades. Therefore, survey data gathered over the years from 1958 to 1989 were combined and analyzed following the method of cohort analysis proposed by Glenn (1977). This method seeks to separate age, period and cohort effects. As the data did not contain measures of alcohol related problems, dependent variables in the analyses were abstinence, weekly alcohol consumption in glasses and heavier drinking, here defined as drinking more than 21 glasses per week for men and drinking more than 14 glasses per week for women.

Results on abstinence showed stable differences according to age over the years: older people more often abstain from alcohol than younger people. The percentage of abstainers among women was more than twice as high as among men in the four survey years. Fluctuations in the overall percentages abstainers over the years were interpreted as due to slightly different ways of questioning. Thus, no evidence for period effects, nor for cohort effects was found. 
Results on average weekly consumption showed that the development of per capita consumption was roughly reflected in all cohorts. The cohort most of interest for the study, born in the 1940s, deviated from the total picture in 1970, but appeared to have joined the 'main stream' again in later years. The oldest cohort present in the data, born before 1910, showed lower consumption in 1970, compared with cohorts in middle age in that year. Except for these temporary deviations, the development of drinking behavior is characterized in cohort analysis terms as 'pure period effects'. In all age categories, male drinkers consume about twice as much as female drinkers. Results on heavier drinking were quite similar to those on average weekly consumption. However, it appeared that differences between men and women were declining somewhat after 1970. In older female age cohorts, the linear increase of consumption persisted throughout the $1980 \mathrm{~s}$, when consumption in other categories of the population stabilized or even showed some decrease. This finding is elaborated in Chapters 3 and 4. The general conclusion of the study is that there is no evidence for an increase in alcohol related problems among the older population in the near future.

\subsection{Convergence or stability in gender difference in drinking behavior??}

In Chapter 2, it was reported that gender difference in alcohol consumption declined somewhat in the 1980's, especially in older age cohorts. In Chapter 3, this finding is elaborated and related to the discussion on 'convergence' of male and female drinking. The convergence hypothesis claims that as women would become more like men in many respects, they would also take over negative behaviors that used to be typical for men, such as heavy drinking. Thus, when women take up 'male' social roles it is expected that heavy drinking and problem drinking among women would increase to similar levels as are prevalent among men.

A review of the literature showed that at least some evidence could be found for diminishing male-female differences in consumption. Evidence for convergence in problem drinking or alcoholism was very weak in general populations. In college populations, some evidence was reported for a smaller decline in problem drinking among women than among men.

Only a few studies consistently rejated gender differences in alcohol use to roles and positions in society. The most consistent finding from the literature was that employed women drink more than housewives. Other things being equal, this would cause convergence of male and female differences in consumption, provided that the proportion of employed women would increase, which has been the case in many industrialized countries. Thus, convergence should be linked to actual changes of women's position in society.

Description of changes in societal positions of men and women with respect to variables that were known to be related to alcohol consumption led to a number of hypotheses.

First, the convergence hypothesis predicts that a decrease in differences in drinking behavior between men and women will be observed over the last three decades. Furthermore, it was predicted that convergence would be stronger among the young, among employed women rather than housewives, among the higher educated, and among the non-religious and Catholics rather than among Protestants. Also, it was 
expected that taking care of children would decrease in importance as a determinant of drinking behavior among women and would gain in importance among men.

Analyses were done on the same data as in Chapter 2, but this time including as independent variables role variables, as specified in the hypotheses. Dependent variables were abstinence, weekly average consumption and weekly heavy drinking ( 6 or more glasses on one occasion at least once per week).

Results showed no convergence in abstinence and weekly heavy drinking, either in the entire population or in sub-populations. Some convergence in average consumption per drinker was observed in the second half of the $1980 \mathrm{~s}$. While consumption increased slightly among women, it did not increase among men. However, although this convergence appeared clearly visible when the data were presented graphically, gender-by-time interaction was hardly significant in a multivariate test.

Findings on average consumption with respect to convergence by age are ambivalent. Convergence of male-female differences in consumption seem to occur not so much as a development in time, but rather as people get older: gender differences in consumption are smaller in older age categories than in younger age categories. Especially women in their forties showed relatively high consumption in the $1980 \mathrm{~s}$. Employment does not account for any convergence of male and female consumption. In fact, the increase in consumption among housewives was higher than among employed women. Convergence of consumption occurred among the higher educated in the 1980 s, due to decreasing consumption among men.

Contrary to expectation, convergence of alcohol consumption is not related to being either catholic, protestant or non-religious. Still in the 1980 s, parenthood was related to lower consumption among women but not among men. On the whole, stability in differences between men and women has predominated in the period since 1958 .

Closer analysis of the lessening of male-female differences in alcohol consumption in the 1980s showed that two developments form the basis of it: decrease among men, especially higher educated men, and increase among women over 40 years of age. A general decrease in consumption in the Netherlands in the 1980 s, after a long period of increasing consumption, appears to have occurred mostly among men, and especially among higher educated men, whereas women's consumption continued to increase. In other words, the trend has changed among men but not among women. Apparently, convergence in the 1980s should be explained more by developments among men than by changes in women's roles and positions. A possible explanation is that a general decrease has occurred among men because of an increase awareness of the risk of alcohol. Among younger women, concern about alcohol and health (especially related to pregnancy) may have had an impact. All this is less relevant to women over 40 , whom consumed little alcohol compared to other groups at the start of the general decrease in per capita consumption, and therefore could still increase their consumption. Thus, the result for this group warrants continued interest from alcohol researchers. Altogether, it is concluded in Chapter 3 that generally there is no reason for special concern about women's drinking in the near future. 


\subsection{Gender role attitudes added to role theory.}

The issue of changing differences between men and women in relation to change in women's roles is related to women's emancipation more directly in Chapter 4 . In this chapter, a cross-sectional analysis of survey data on the general population of the Dutch province of Limburg is presented. It is argued that gender differences in alcohol use have socio-cultural backgrounds, although biological differences are not denied. Two perspectives on gender differences in drinking are presented: "role theory' is supplemented with a perspective on beliefs with respect to appropriate male and female behavior. It would be expected that gender difference in drinking behavior is smaller when men and women are viewed as more equal with respect to rights and obligations in other respects. Therefore, a scale that measured traditional attitudes with respect to gender roles (TGRA) is included in the analyses. The four items in the scale are general statements that express a traditional view on women's role in the family and in work organizations.

Specific hypotheses were formulated with respect to social disapproval of drinking. The widespread belief that women's drinking is more frowned upon than men's is denoted as the 'vulnerability hypothesis'. A distinction was made between disapproval of women's heavy drinking in general and disapproval of drinking by one's own female relatives and acquaintances. According to the 'cultural expectations' hypothesis, the image of female drunkenness is so negative that it is very difficult for women, even when they drink heavily, to fit this image. As a result, women's problem drinking may be denied rather than disapproved of by friends and relatives. Another aspect of cultural expectation is that drinking problems, primarily a male phenomenon, are associated with violence and acting-out behavior in the public view. Women, however, even those who drink heavily, often are able to display rather controlled behavior, to which the 'problem drinking' label is not easily attached.

From the perspective of the vulnerability hypothesis, it would be expected that social disapproval of female drinking is stronger among those who think traditionally about women's roles. On the other hand, denial of women's drinking should be more prevalent among traditional people from the perspective of the 'social expectations"
hypothesis.

Results appeared to confirm to some extent the expectation that differences between men and women are larger among people with more traditional gender role attitudes. More traditional gender-role attitudes are associated with lower abstinence rates and higher frequency of heavy drinking among men and with more abstinence and lower consumption among women. However, gender by TGRA interaction effect on consumption and frequency of heavy drinking is not significant when abstainers are excluded from analysis. This led to the conclusion that gender role attitudes are associated with the choice either or not to drink rather than with the consumption level of drinkers. The analysis made clear that the difference in abstinence operates in combination with employment: especially employed men who hold more traditional gender role attitudes very rarely reported to be abstainers.

Effects of status factors age and social class (education) on consumption and frequency of heavy drinking were mediated through TGRA for only a small part. The 
conclusion was that the inclusion of TGRA modifies the parameters of a role-theory model somewhat, but it does not really change its structure.

In agreement with the 'cultural expectations hypothesis', men appeared to report higher prevalence of alcohol related problems, even when drinking behavior was controlled for. Among those who reported any drinking problems, men especially report more negative reactions from others, whereas women report more health problems attributed to alcohol. Attitudes toward gender roles did not significantly influence drinking problems, when consumption was controlled for.

\subsection{Changes in drinking behavior in relation to life course role transitions.}

Chapter 5 analyzed changes in alcohol use and in alcohol related problems in relation to role transitions in different stages of the life course. Social positions or social 'roles' were distinguished from more stable and basic characteristics of persons, such as gender, religion and social class. Although the meaning of these basic characteristics can vary over time, their 'time-boundedness' is quite different from transitional social positions that mark the 'rhythm' of the life course. Marriage, parenthood and employment occur mostly in early life and constitute the occupation of new social roles to the individual. Other transitions occur mostly later in life and involve the loss of social roles, such as retirement and widowhood.

The association between social roles and alcohol use can be studied in two ways. First, some studies report on specific life transitions and often offer ex-post-facto explanations for their results. The conformities across these explanations can be used to increase the insight in the mechanisms. Secondly, theoretical considerations could offer possible mechanisms behind role transitions. In chapter 5 , role analysis was taken as a point of departure.

A review of longitudinal studies on specific role transitions yielded a number of possible mechanisms as suggested by the authors. Social roles had been associated with stability of relationships, socialization, opportunities for drinking, leisure time, social status, social support and changes in life-style. Alcohol use as self-medication had been reported in relation to late life problem drinking. Some researchers argued that not just the characteristics of certain roles, but also the qualities of roles and their combinations should be studied. The interpretations offered by the authors of the reviewed articles fall in three classes: firstly, social roles regulate the allocation of time to situations that allow drinking in various degrees, secondly, positions are associated with a network of sociall relationships in which alcohol can serve various purposes, and, thirdly, role transitions can be associated with stress, that have to be coped with, which may involve the use of alcohol.

A more theoretical approach was offered by Knibbe, Muytjens and Drop (1987), who elaborated on the distinction between basic characteristics and social positions, using the concepts 'status roles' and 'position roles'. The latter concept is especially relevant for a life course approach, because the life course can be viewed as a sequence of position roles. Knibbe's approach departs from role theory in the strict sense, in that it searches for specific mechanisms that influence the behavior of persons occupying a certain social position role. Social positions are viewed as 'structure everyday life' through specific obligations, that mostly cannot be combined with 
alcohol consumption. Although this approach is as yet somewhat one- dimensional and unelaborated, it offers an opportunity to specify mechanisms, and to formulate testable propositions concerning social roles and drinking behavior.

The theory developed by now already suggests one testable proposition: the occupation of position roles is negatively associated with alcohol consumption and with alcohol related problems. Thus, the occupation of more social roles should lead to lower consumption. In longitudinal terms, transitions involving a gain in roles should be associated with a decrease in alcohol consumption, and vice versa. Inspired by the work of others, it was tested whether this association is homogeneous across age categories.

In the empirical section of the chapter, data were analyzed from a 9 year follow-up study in the Dutch province of Limburg. In the first part of the analyses, the impact of distinct role transitions on alcohol consumption, frequency of heavy drinking and alcohol related problems was assessed. The second part tested the hypothesis that structure of everyday life is negatively associated with alcohol use.

Transitions to parenthood and to marriage at early age appeared to lead to a decrease in alcohol consumption and in frequency of heavy drinking. This result indicates that a comprehensive approach of social roles has potential for research among the younger age category, in which role transitions mostly involve an increase in 'structure of everyday life'. For the older age group, however, results were weak and opposite to expectations. It was concluded that both for the younger and for the older age categories, the concept 'structure of everyday life' should be further elaborated in distinct aspects, which were already suggested by the literature review of mechanisms found in studies on distinct role transitions, such as time allocation for social situations, and the position in social networks associated with certain social roles. Further, it seems that especially in the older age groups, coping with the loss of social roles should be incorporated in theories on role transitions and alcohol use.

\subsection{Type and severity of drinking problems and treatment careers of male alco- holics in treatment compared by age.}

In Chapter 6 and 7 , the interest turns to a specific population relevant to the study of alcohol problems: those who are in treatment for their alcohol problems at a specialized agency. These problem drinkers are denoted as 'alcoholics' in the chapters, without this indicating a certain position with respect to the 'natural history' of a "disease'. A comparison is made between alcoholics over 50 years of age, and alcoholics from the modal age category in treatment agencies, which is about 35 to 45 years old. It is argued that such a comparison can be generalized to the coming decades, since no cohort differences in drinking behavior were found in Chapter 2 of the present thesis nor in most other studies concerning cohort effects on alcohol use. Differences in problem drinking careers between age groups of alcoholics are relevant to policy: when growing numbers of older problem drinkers systematically deviate from younger problem drinkers with respect to types of problems, treatment agencies should develop special treatment facilities for older clients. 
In Chapter 6 , older and younger alcoholics are compared with respect to drinking problems as well as with respect to treatment careers. Four aspects of drinking problems were assessed in the study: symptoms of dependence, disapproval from significant others, health problems and frequent drunkenness or hangovers. Health problems were expected to occur more often among older alcoholics, whereas problems with others and drunkenness were expected to occur less often. The drinking career was assessed retrospectively. For the purpose of this study, first intake for treatment was taken as the starting point of the treatment career, which may not necessarily be the same as the problem drinking career. It was expected that alcoholics with early onset had a longer treatment career in more different treatment agencies.

50 alcoholics in both groups were sampled from the Consultation Bureaus for Alcohol and Drugs (CAD) in the south-east of the Netherlands. Analyses were conducted on type and severity of drinking problems and length of the treatment career and diversity of agencies of admission. The study also analyzed various aspects of alcohol consumption, such as beverage choice and frequency and quantity of drinking, and perceived health. The latter was included in order to test the hypothesis that older alcoholics show more health problems than younger alcoholics.

Most differences found between both groups were parallel to general population differences known from survey research. As expected, consumption levels were less high, and drinking problems were less severe among older alcoholics. Especially older alcoholics with later onset of problems reported less disapproval from significant others. However, no difference was found in health problems attributed to alcohol.

Striking similarities were observed in the length of the treatment career and in the number of years that passed since respondents had realized that they had a problem with alcohol. In both groups, most respondents had known that they had an alcohol problem for several years before intake into treatment. More recent cases among the older alcoholics reported a shorter period between recognition of an alcohol problem and seeking treatment.

The general conclusion is that results of the study do not support idea of special measures for treatment and/or prevention of drinking problems among the older age group.

The results are discussed as preliminary and inconclusive, since the sample was limited to relatively 'young-old' alcoholics in one type of treatment setting. More research is needed concerning drinking problems among persons over 70 years old, people in residential care and those who present other problems to care givers that can be related to or combined with alcohol misuse. Moreover, results are restricted to men.

\subsection{A comparison of drinking careers of older and younger male alcoholics and older social drinkers.}

In this chapter, drinking careers are studied from a life-course perspective. A retrospective interview, the Lifetime Drinking History ( $\mathrm{LDH}$ ), was used to collect data on changes in the drinking history of both age groups of male alcoholics from Chapter 6 , as well as a category of social drinkers of the same age as the older alcoholics (over 50 years of age). Changes in drinking were linked to role transitions and other life events. 
The aim of the study was to assess whether older problem drinkers form a distinct category within the problem drinking population, as well as within their age cohort, with respect to their drinking careers.

In 'life events' research, changes in drinking career, such as increases or decreases in consumption, and onset or remission of problem drinking, are linked to life transitions. In studies among the older population, a distinction is made between problem drinkers with 'early onset' and 'late onset'. Especially problem drinking with late onset (also called 'reactive') is thought to be related to the stressful events inherent to later life, such as loss and bereavement. Other than in the longitudinal study reported in Chapter 5 , in the retrospective approach of the LDH interview respondents themselves are invited to link changes in drinking to life transitions or life events. Thus, causal attributions on the part of the respondent play a role in the analysis.

Changes in drinking included in the study were: increase and decrease in weekly average consumption and frequency of heavy drinking (defined is drinking 6 or more glasses on a drinking day), onset of morning drinking and solitary drinking. Respondents were asked whether a change in drinking was accompanied by a life transition event. Life events were categorized as work-related events, marital events, and events related to treatment. Furthermore, respondents were asked whether an event was experienced as positive, negative or neutral.

Compared with their younger counterparts, older alcoholics reported fewer distinct drinking phases, later age of first regular drinking, and later onset of heavy drinking. They also relatively more often reported onset of heavy drinking and morning drinking in connection with a negatively evaluated life event, and they less often associated onset of morning drinking and solitary drinking with a positively evaluated life event.

For those who reported any phases with heavy drinking in their lifetime, the average age of onset of heavy drinking was much younger among the social drinkers category than among older alcoholics and similar to younger alcoholics. On the other hand, age of first regular drinking and level of consumption in the first drinking phases of older alcoholics and social drinkers were similar.

Higher average age of onset of heavy drinking among older alcoholics may be due in part to the difference in age range with younger alcoholics. Since the difference in age of onset of heavy drinking was larger than would be expected on the basis of the age difference alone, it was concluded that older alcoholics actually experienced later onset of heavy drinking than younger alcoholics.

The average age of onset of heavy drinking among older alcoholics was 35 years, which was much later than among younger alcoholics, but still much younger than would be found when onset of alcoholism as a clinical syndrome would have been used as a criterion. This category actually did resemble 'late onset alcoholism' as described in the literature: 'normal' age of first regular drinking, as well as a moderate consumption level in the first drinking phase. When the category of older alcoholics was split by age of onset, this resemblance of problem drinkers with late onset and social drinkers was even stronger. It was concluded that older alcoholics with onset of heavy drinking before age 35 more closely resembled younger alcoholics, and older alcoholics with later age of onset more closely resembled social drinkers in their own 
age category with respect to the age when they started drinking and the amount consumed in the first drinking phases. In later drinking phases, consumption of "late onset" alcoholics was considerably lower than early onset alcoholics, although finally their drinking problems were only slightly less severe.

Many older alcoholics with late onset of heavy drinking reported negative marital events at the beginning of the first heavy drinking episode. This result cannot be taken for granted, and more research in this topic is needed. On the one hand, the causal connection could be reversed by some in order to arrive at a 'reasonable' explanation for their drinking behavior. On the other hand, it can be conceived of that drinking can be used as an (inadequate) coping strategy in late-life stressful situations. It was concluded that part of the older alcoholics show an image of chronic, earlyonset alcoholism, with much the same characteristics as the modal age category. Others, however, form a distinct category that started drinking heavily at a later age, and developed severe drinking problems at a lower consumption level than other alcoholics.

\subsection{General conclusion and recommendations.}

\subsubsection{Aging, cohorts and alcohol use.}

The research project reported in this thesis showed that the relationship between age and alcohol consumption varies with the aspect of drinking involved. Whereas abstinence is strongly and positively related to age, the correlation with level of consumption is weak (chapter 2). Among problem drinkers in treatment, however, consumption is negatively related to age (Chapter 7). This may indicate that a negative association between alcohol consumption and age is stronger in the higher consumption categories.

The results presented in chapter 2 clearly indicate that cohort differences in alcohol use are unimportant. This means that little can be said about future developments in specific cohorts. Age differences that were observed in abstinence, heavy frequent drinking, and weekly average consumption (in order of importance) are relatively stable across the years, and therefore can be expected to persist in the near future as well. In cross-sectional age comparisons in later chapters, this result is used as a basis for the generalizability of the results to the near future.

Social interaction theory was used as a theoretical frame of reference. Although the study was not intended to test the validity of this theory, the combination of empirical undertakings and theoretical reflection has led to some new insights which" merits could be tested in further research. Social interaction theory does not 'explain' drinking behavior as such, but offers insight in how changes in drinking come to being. Because individuals influence each other throughout social networks, and 'drinking cultures' form such social networks, it can be said that populations 'move in concert' on the consumption scale. In as far as categories of the population, such as birth cohorts, form distinct 'drinking cultures', the development of drinking behavior may take a different form. 


\subsubsection{Gender differences in alcohol consumption and drinking problems.}

Information on gender differences was included in Chapter 2 with respect to general trends, and in Chapters 3 and 4 more specifically. Only little evidence was found for convergence of alcohol consumption. Linear increasing trends in older female cohorts (Chapter 2) were also found in Chapter 3 . Whereas a generally slightly decreasing trend in consumption was observed during the $1980 \mathrm{~s}$, an increase in consumption persisted for women over 40 in data from repeated surveys. It should be noted that consumption of women over 40 used to be low in earlier years, for which reason this increase should not directly lead to worries for an epidemic of alcohol problems in this category. Nevertheless, the prevalence of alcohol related problems among older women will probably increase when this trend persists in the coming years. Recently, figures have been presented from treatment agencies, indicating that the percentage of women among alcohol clients gradually increased from $19 \%$ to $25 \%$ in the last ten years. These figures also show that women are over-represented in the age categories older than 40 years. This combination of results shows the need for more sophisticated research on the prevalence of heavy drinking and problem drinking among the general female population.

\subsubsection{Women's emancipation and the convergence hypothesis.}

As was summarized in the former section, the evidence for convergence of male and female drinking was not very strong. Moreover, the analysis in chapter 3 showed that the backgrounds were different from the expectations associated with the "convergence hypothesis'. Consumption increased among homemakers rather than among employed women, although the latter still drink more. It can be concluded that the developments in alcohol consumption of men and women in the Netherlands is generally not in agreement with the convergence hypothesis.

Further probing on women's positions in society in relation to alcohol use was done in chapter 4 , in which a scale on traditional gender role attitudes (TGRA) was included in the analyses. Some evidence was found that differences in alcohol use were larger among those who hold more traditional gender role attitudes. Especially gender differences in abstinence seem to be associated with TGRA: employed men with traditional gender role attitudes very rarely are abstainers. Results on consumption and frequency of heavy drinking were weaker. The results presented in chapter 4 were contrary to other reports in the literature. Therefore, the approaches from different studies should be integrated in a new study. The analysis in Chapter 4 is only preliminary, with a very general instrument, and should be replicated with more elaborate operationalizations of gender role attitudes. Two avenues of explanation can be followed. First, differences in abstinence may be associated with more general conservatism. Second, more specific items on gender role attitudes in relation to women's positions in, for instance, work organizations and in the family could be employed. In combination with more specific role analyses, insight in women"s alcohol use can be improved this way. This will involve including a number of items in a more general survey on women's heavy drinking and problem drinking.

The analyses presented have shown that the theoretical assumptions behind the 'convergence hypothesis' are not valid for the Netherlands. Although some evidence 
for convergence was found, it occurred in other categories of the population than would be expected from the point of view of the convergence hypothesis, e.g. relative high increase of alcohol consumption would be expected among employed women, rather than homemakers.

On the basis of the insights presented in this thesis, it is suggested to study social roles and position of women in society more closely, looking at specific characteristics of roles occupied by men and women. This issue is discussed in the next section.

\subsubsection{Role analysis and alcohol use.}

In this thesis, an attempt was undertaken to give the study of alcohol use across the life course more depth by relating it to changes in roles and positions that give structure to the life course. Role analysis has played a role in chapters $3,4,5$ and 6 of this thesis. In chapters 3 and 4 it was found that basic characteristics of persons, such as age, gender and social status, are associated with alcohol use, and this result was consistent over the years.

From a life course perspective, transitional social positions are most emphasized, since sequences of such social positions form the structure of the life course. Variables related to position roles, however, were associated less consistently with alcohol use. In cross-sectional analyses presented in chapter 4 it was found that effects of position roles varied by gender and according to different aspects of alcohol use. Among men, having children and employment are associated with less drinking problems. Women living with a partner show higher consumption than other women, which is opposite to the results among men. Chapter 5 showed that transitions that involve an increase in 'structure of everyday life' lead to some decrease in alcoholl consumption and frequent heavy drinking, as well as a decrease in alcohol related problems, among younger people. For older people, results were weaker and opposite. On the whole, the results of analyses with position roles were rather modest. In chapter 5 it was proposed not to discard role analysis altogether, but to refine it by operationalizing the concept of 'structure of everyday life' more precisely. This can be achieved by inclusion in future studies of indicators of specific role involvement, such as time budgets and social networks, and also by including coping styles in relation to specific role transitions, especially in later life. In doing so, a step can be taken towards theory driven analyses of differences in drinking patterns between categories of the population.

\subsubsection{Older problem drinkers, a specific group?}

Problem drinkers in treatment were the subjects of chapters 6 and 7. Among this category, age gradients in alcohol consumption indicators, beverage choice, and alcohol related problems were in agreement with findings in general population studies. Compared with their younger counterparts, older problem drinkers drink less, and less often heavily; they are less often criticized by other and they less often report admission to an alcohol treatment clinic. Other results are more specific for this group. In the retrospective study, older problem drinkers in treatment report fewer separate phases in the Lifetime Drinking History, later onset of heavy drinking and problem drinking and more often onset of heavy drinking in relation to a 'negatively evaluated marital event', mostly divorce and separation. 
In specific analyses, a distinction was made between older problem drinkers with early versus late onset of heavy drinking. It was shown that the earlier drinking phases of older problem drinkers with late onset were comparable to those of a comparison group of older social drinkers. The earlier drinking phases of older problem drinkers with early onset were more comparable to those of younger problem drinkers. This has led to the tentative conclusion that older problem drinkers in treatment with later onset of heavy drinking form a specific category. The backgrounds of this group should be further investigated, using more in-depth research methods, including collaterals especially with respect to the "life events" to which many of this group attribute the onset of their drinking problem. This investigation can lead to specific adaptation in the treatment systems for this group.

\section{References.}

Glenn, N.D: (1977) Cohort Analysis (Beverly Hills and London, Sage Publications).

Leering, T. \& Lerou, W. (1990) Verkenning van de veroudering in Nederland, Bevolkingsprognoses ten behoeve van de plaming van voorzieningen voor ouderen (Rijswijk, Ministerie van Welzijn, Volksgezondheild en Cultuur).

Skog, O.-J. (1980) Social interaction and the distribution of alcohol consumption, Journal of Drig Issues, 10, 1, 79-92.

Skog, O.-J. (1985) The Collectivity of Drinking Cultures: a Theory of the Distribution of Alcohol Consumption, British Journal of Addiction, 80, 83-99. 


\section{Samenvatting.}

In dit proefschrift, waarin alcoholgebruik en aan alcohol gerelateerde problemen worden onderzocht in relatie tot verschillende aspecten van de levensloop en naar geslacht, zijn globaal drie delen te onderscheiden. Het eerste gedeelte bevat artikelen over ontwikkelingen in alcoholgebruik in de loop van de jaren, zoals geregistreerd door middel van verkoopcijfers, maar vooral door survey-onderzoek. In Nederland zijn sinds 1958 surveys gehouden bij steekproeven uit de algemene bevolking. In het tweede gedeelte zijn artikelen opgenomen die ingaan op alcoholgebruik in relatie tot specifieke, aan geslacht en levensfase gebonden rollen. Het derde deel bevat artikelen die een vergelijking maken tussen oudere en jongere probleemdrinkers. Alle drie de delen van het proefschrift zullen hierna kort worden besproken.

In de ontwikkeling van het alcoholgebruik in Nederland sinds de jaren ' 50 zijn twee perioden te onderscheiden. Tot ongeveer 1980 was er sprake van een zeer sterke toename van de per capita consumptie van alcohol in de vorm van bier, wijn en gedestilleerd. Sinds 1980 is het alcoholgebruik gestabiliseerd en er is zelfs een kleine daling opgetreden, die echter in geen verhouding staat tot de stijging van eerdere jaren. In dezelfde periode deed zich een drastische verandering in de leeftijdsopbouw van de (Nederlandse) bevolking voor, die bekend is onder de namen 'ontgroening' en 'vergrijzing'. Een andere verandering die zich voordeed in de samenleving betrof de positie van vrouwen. Het aantal kinderen per vrouw is sterk gedaald, de leeftijd bij geboorte van het eerste kind sterk gestegen. Tegelijk hebben grote aantallen vrouwen zich op de arbeidsmarkt begeven.

Een van de eerste onderzoeksvragen van het project was of degenen, die begonnen zijn met drinken in de periode van sterke stijging van het alcoholgebruik, ook op latere leeftijd door zouden gaan met relatief 'zwaar' drinken. Dit zou op korte termijn kunnen leiden tot een extra toename in het aantal oudere 'probleemdrinkers', bovenop de toename die al verwacht kan worden op grond van de vergrijzing van de bevolking. Uit de gepresenteerde analyses blijkt echter dat van een dergelijk 'cohort-effect' geen sprake is. In alle leeftijdskategorieën was sprake van een stijging van de zelf gerapporteerde consumptie, die in hoge mate overeenkomt met de trend in de per capita consumptie (verkoopgegevens). Er was dus vooral sprake van 'periode-effect'. Een afzonderlijk aspect van drinkgedrag wordt gevormd door het niet-drinken. Het percentage niet-drinkers is in Nederland zeer stabiel in de tijd en het blijkt vooral met leeftijd samen te hangen. Het percentage niet-drinkers bereikt in alle jaren waarin het onderzoek werd gehouden een minimum in de leeftijdskategorie tussen 20 en 30 jaar, waarna het toeneemt met de leeftijd. In de jongste leeftijdsgroep is dus een kategorie die pas na het twintigste jaar alsnog zal beginnen met drinken. Al met al lijkt er geen reden voor grote ongerustheid met betrekking tot het drinkgedrag van ouderen in de komende decennia, gegeven de afwezigheid van cohort effecten, de licht dalende trend in consumptie en de stabiliteit in het percentage niet-drinkers.

Speciale aandacht is ook gegeven aan verschillen tussen mannen en vrouwen. In een eerste trend-analyse bleek dat onder vrouwen, met name in de oudste leeftijdskategorieën, de stijging van de alcoholconsumptie was voortgezet, ook nadat de stabilisering in de totale per capita consumptie was ingezet. Dit zou kunnen duiden op een 
systematische verkleining van de verschillen in drankgebruik tussen mannen en vrouwen, hetgeen in overeenstemming zou zijn met de zg. convergentie-hypothese. Deze uit de VS afkomstige hypothese voorspelt dat vrouwen, naarmate zij meer overeenkomst met mannen gaan vertonen in hun positie in de samenleving, ook meer overeenkomst met mannen zullen gaan krijgen in termen van criminaliteit, en gebruik van alcohol en drugs. Aan de hand van een beschrijving van concrete veranderingen in de maatschappelijke positie van vrouwen, ten aanzien van werk, relatie, gezin, en kinderen, zijn een aantal specifieke hypothesen geformuleerd welke getoetst zijn aan de ter beschikking staande survey gegevens. Enige convergentie werd gevonden in de gegevens voor de tweede helft van de jaren '80. Deze ontwikkelling bleek bij nadere beschouwing vooral gebaseerd op een daling in het alcoholgebruik bij hoger opgeleide mannen enerzijds, en een stijging bij vrouwen boven 40 jaar anderzijds. Voor deze laatstgenoemde groep geldt dat het gaat om vrouwen die traditioneel (zeer) weinig alcohol gebruiken, en van wie het gebruik zeer matig genoemd kan worden. Hieruit is geconcludeerd dat er geen reden is voor speciale preventieve maatregelen gericht op deze groep, hoewel een voortgaande stijging van consumptie toch wel zou kunnen leiden tot een toename van aan alcohol gerelateerde problemen.

In het tweede deel van het proefschrift staan sociale 'rollen' van mannen en vrouwen centraal. Twee perspectieven werden gehanteerd: roltheorie en attitudes ten aanzien van de rollen van mannen en vrouwen. De verwachting was dat verschillen in alcoholgebruik tussen mannen en vrouwen kleiner zijn in groeperingen waarin vrouwen en mannen in meer algemene zin worden gezien als gelijken in rechten en plichten. Daarom werd een meetinstrument 'Houding ten aanzien van vrouwenemancipatie' opgenomen in een studie onder de algemene bevolking van de provincie Limburg. Uit de resultaten bleek dat mannen met een traditionele benadering van vrouwenemancipatie minder vaak geheelonthouder zijn en vaker grotere hoeveelheden alcohol gebruiken (meer dan zes glazen). Vrouwen bleken juist minder consumptie te rapporteren en vaker niet te drinken. Het ging echter om marginale verschillen. De attitude ten aanzien van vrouwenemancipatie hangt eerder samen met de keuze al of niet te drinken dan met het consumptieniveau onder drinkers. Het effect van basiskenmerken als leeftijd en sociale klasse op sekseverschillen bleek slechts voor een zeer gering gedeelte gemedieerd te worden door verschillen in attitude ten aanzien van vrouwenemancipatie. Een model afgeleid van roltheorie wordt slecht marginaal beïnvloed door de opname van attitude ten aanzien van vrouwenemancipatie. Roltheorie blijkt een aanzienlijk belangrijkere verklarende factor te zijn. Roltheorie is gebruikt bij het uiteenleggen van verschillen tussen mannen en vrouwen en als analysekader voor de levensloop.

Binnen de roltheorie worden positierollen onderscheiden van 'statusrollen', welke gerelateerd zijn aan elementaire eigenschappen van individuen, zoals geslacht, leeftijd, ethniciteit, sociale status, etc. Zowel status- als positierollen zijn theoretisch van belang voor de studie van alcoholgebruik. Statusrollen zijn gerelateerd aan bepaalde leefstijlen, waarbinnen alcoholgebruik in zijn verschillende aspecten, zoals de keuze van soorten drank, de gelegenheden waarbij gewoonlijk wordt gedronken en ook de hoeveelheid die bij een gelegenheid wordt genuttigd, een rol kan spelen. Statusrollen 
bleken van belang bij de studie van sekseverschillen in alcoholgebruik. Bij de analyse van verschillen tussen mannen en vrouwen werd aanvankelijk verwacht dat deze verschillen zouden afnemen met oudere leefijd. Dit bleek echter niet het geval. Wel is sprake van kleinere sekseverschillen in alcoholgebruik onder mensen met een hogere sociale status. Positierollen zijn vooral van belang bij de studie van alcoholgebruik in relatie tot de levensloop. Vanuit een sociologische optiek wordt de levensloop van mannen en vrouwen gezien als een opeenvolging van sociale posities in verschillende domeinen, waarvan relatie, gezin en arbeid de belangrijkste ziin. Aan deze sociale posities, zoals "vader", "echtgenote" of "afdelingschef zijn bepaalde verwachtingen en verplichtingen verbonden, die aangeduid worden als 'positierollen'. Positierollen zijn - vergeleken met statusrollen eerder gedefinieerd in termen van verantwoordelikheden en verplichtingen, die zich meestal slecht verhouden met alcoholgebruik. Daarom werd verwacht dat een grotere mate van maatschappelijke verantwoordelijkheid, tot uiting komend in een of meer positierollen, samenhangt met een lager alcoholgebruik. Het verband tussen positierollen en alcoholgebruik is in dit proefschrift zowel cross-sectioneel als longitudinaal onderzocht. Het onderzoeken van verbanden in gegevens over een "dwarsdoorsnede" van de bevolking op een bepaald moment geeft informatie over verschillen tussen kategorieën personen. Door middel van longitudinaal onderzoek wordt de tijdsdimensie ingebracht. Ook het effect van veranderingen in positierollen op individueel niveau (roltransities) kan dan worden onderzocht.

Het effect van verschil in positierollen op alcoholgebruik bleek te variëren naar geslacht en naar specifieke aspecten van alcoholgebruik. Vrouwen die gehuwd zijn of samenwonen blijken meer te drinken dan andere vrouwen. Bij mannen is dit juist andersom: mannelijke vrijgezellen drinken meer dan gehuwde of samenwonende mannen. De achtergrond van dit resultaat wordt ongetwijfeld gevormd door het gegeven dat mannen een veel hoger gemiddeld alcoholgebruik kennen dan vrouwen.

Een effect van het hebben van werk werd gevonden bij mannen: mannen met een baan drinken aanzienlijk meer dan mannen die werkloos of arbeidsongeschikt zijn. Tevens werd onderzocht of er verschil tussen sociale posities bestaat in negatieve gevolgen van alcoholgebruik, onder constanthouding van het volume van allcoholgebruik. Bij mannen bleken dergelijke effecten voor te komen: mannen die kinderen hebben en mannen met een baan hebben minder last van nadelige effecten van alcoholgebruik dan andere mannen, ook als die evenveel alcohol gebruiken.

Bij de longitudinale analyses werd een onderscheid gemaakt tussen roltransities op jongere en op oudere leeftijd. Deze analyses lieten zien dat mensen die trouwen en/of kinderen krijgen minder gaan drinken. Bij transities op oudere leeftijd is als regel sprake van het verlies van sociale posities door pensionering, vertrek van kinderen uit de ouderlijke woning en het overlijden van de partner. Door sommige onderzoekers is gesteld dat deze gebeurtenissen een risico voor verhoogd alcoholgebruik. De resultaten van deze studie lieten echter zien dat eerder het tegenovergestelde het geval is: verlies van sociale rollen lijkt gepaard te gaan met minder drankgebruik.

Het derde deel van het proefschrift behandelt het thema alcohol en levensfase met de nadruk op mensen die in behandeling zijn voor problemen met alcohol. Door 
omstandigheden zijn in deze laatste studies alleen mannen opgenomen, en moest een vergelijking naar geslacht achterwege blijven. Hierbij staat de vraag centraal of oudere probleemdrinkers een specifieke groep vormen in termen van aard en intensiteit van de problemen, achtergronden en noodzakelijke behandeling. Hiertoe werd een vergelijking gemaakt tussen cliênten van het Consultatiebureau voor Alcohol en andere Drugs (CAD) van 50 jaar en ouder, en cliënten uit de modale leeftijdskategorie, van 30 tot 45 jaar.

Verschillen tussen beide groepen in termen van consumptieniveau, frequentie van zwaarder drinken, en aan alcohol gerelateerde problemen bleken parallel te lopen aan verschillen tussen leeftijdsgroepen in de algemene bevolking, zij het op een aanzienlijk hoger niveau. Ouderen drinken minder dan jongeren en hebben eveneens minder problemen. In het bijzonder oudere cliënten die rapporteerden op latere leeftijd te zijn begonnen met zwaar drinken, bleken minder vaak afkeuring te ondervinden van hun omgeving. Een onverwacht resultaat was dat er geen verschil was in aan alcohol toegeschreven gezondheidsklachten.

Opvallende overeenkomsten werden eveneens gevonden in de lengte van de behandelingscarrière, en in het aantal jaren dat was verstreken sinds de cliënt zichzelf realiseerde een alcoholprobleem te hebben. Zowel oudere als jongere cliënten zeiden dat er verschillende jaren verstreken tussen het moment dat men zich realiseert een alcoholprobleem te hebben en de eerste intake voor behandeling. Naarmate dit moment meer recent was, bleek de periode die verstrijkt voordat tot behandeling wordt besloten overigens korter.

In deze studie werd speciale aandacht besteed aan de drinkcarrière van deze CAD cliënten. De data hiervoor werden verzameld door middel van een retrospectief interview, de Lifetime Drinking History, waarin het alcoholgebruik globaal wordt gevolgd over het hele leven van de respondent. Hierbij wordt de drinkcarrière in fasen ingedeeld, welke gemarkeerd worden door gebeurtenissen, die naar het oordeel van de respondent zijn drinkgedrag hebben beïnvloed. In deze vergelijking werden niet alleen oudere $\mathrm{CAD}$ cliënten en hun tegenvoeters uit de modale leeftijdsgroep betrokken, maar eveneens een groep ouderen uit de algemene bevolking met een drinkpatroon dat niet gepaard gaat met problemen.

Vergeleken met jongere probleemdrinkers rapporteerden ouderen minder fasen in hun drinkcarrière, latere leeftijd waarop men voor het eerst met enige regelmaat ging
drinken, en latere aanvang van zwaar alcoholgebruik.

Err bleek een onderscheid gemaakt te kunnen worden in oudere cliënten met een vroege en met een late aanvang van het alcoholprobleem. In de literatuur wordt gesuggereerd dat alcoholproblemen die op latere leeftijd hun aanvang nemen vaak gerelateerd zijn aan stress door levensgebeurtenissen op oudere leeftijd, zoals verlies van baan en verlies van partner. Daarom wordt wel gesproken van 'reactief probleemdrinken'. De oudere probleemdrinkers met late aanvang van het alcoholprobleem waren relatief vaak van mening dat hun alcoholprobleem ontstaan was in samenhang met een echtscheiding of andere negatieve levensgebeurtenis, zoals overlijden van de partner. Opvallend was dat de eerste fasen van de drinkcarrière van oudere probleemdrinkers met een vroege aanvang sterk overeenkwam met de vroege
drinkcarrière van jongere probleemdrinkers. Bij oudere probleemdrinkers met late 
aanvang bleek de vroege drinkcarrière sterk overeen te komen met die van leeftijdgenoten met een 'gangbaar' drinkpatroon. De conclusie kan worden getrokken dat er een groep oudere probleemdrinkers met late aanvang van het alcoholprobleem bestaat. Deze groep vertoond tekenen van 'reactief' probleemdrinken, en ontwikkelde ernstige alcoholproblemen bij een relatief lage consumptie. Deze groep kan mogelijk belang hebben met een specifieke benadering vanuit de hulpverlening. 


\section{Acknowledgements:}

Promotor and inspiring project leader, who was involved in the details of the project over the years, and especially 'coached' the writing

Project supervision 1991-1993. Contributed strongly

to the first development and to Chapter 2.

Project supervision 1993-1994. Especially involved in the study and data collection among CAD-clients Copromotor and everyday supervision since 1993

'Paranimfen'

Riet Drop

Jos Diederiks

Ronald Knibbe

Paul Lemmens.

Rutger Engels

Klaas Jan Hajema

Thanks for making data collection possible

Wim Meulders

(CAD Limburg)

Peter Gottmer

(CAD Oost Brabant)

$\mathrm{CAD}$ clients and other respondents

Statistical advice

Gerard van Breukelen

Frans Tan

Lex Volovic

Research assistants

Mieke Derickx Vonca Schaffers

For being fine colleagues most of the time

Department of Medical Sociology, Maastricht University

Thanks for sharing an office for six years without a single fight

Christianne Hupkens

\section{Personal thanks to:}

I am very gratefull to my wife Ria Coumans for emotional support, warmth, and companionship. I dedicate my dissertation to Ivo, our son, and to his mother as well.

I also would like to thank my parents Johan Neve and Wies Neve-van Driessche for supporting me in various ways during my education, which is now finally closed, at least for the time being. 


\section{Curriculum vitae.}

The author was born and raised in Hulst in the Dutch part of Flanders. After finishing secondary education in 1976 he went to the College for Social Work in Breda, where he took the speciality of community development work. After several temporary jobs and voluntary work, studies in sociology followed from 1984 to 1990 at Tilburg University. Initially, studies concentrated on general theory and the sociology of culture. Later on, interest shifted towards research methodology, which resulted in a masters' thesis on secondary analysis of survey data on attitudes towards women's emancipation, with an emphasis on cohort analysis. During the final stage of his studies, an assistantship at Rotterdam Social Services' research department brought the necessary experience with the practice of empirical research. Early 1991 a transfer to Maastricht University was realized, where the department of Medical Sociology hosted the $\mathrm{PhD}$ project which resulted in this book. At present, the author is still working as a researcher in the field of substance use and as an assistant professor at Maastricht University. 


\section{List of Publications}

Neve, R. (1992) Nederlanders over vrouwenemancipatie 1970-1985, een cohort analyse, Sociale Wetenschappen, 35, 52-69.

Neve, R.J.M., Diederiks, J.P.M., Knibbe, R.A. and Drop, M.J., (1993) Developments in drinking behavior in the Netherlands from 1958 to 1989 , a cohort analysis, Addiction, 88 611-621.

Neve, R.J.M., Diederiks, J.P.M., Knibbe, R.A., (1994)

Ontwikkelingen in drinkgedrag naar leeftijd en geslacht in Nederland van 1958 tot 1989, een cohort analyse. Tijdschrift voor Alcohol, Drugs en andere Psychotrope Stoffen, Vol. 19 (2), $91-106$.

Neve, R.J.M., Knibbe, R.A., Swinkels, H. (1994)

Gaan de drinkgewoonten van vrouwen steeds meer lijken op die van mannen? Tijdschrift voor Alcohol, Drugs en andere Psychotrope Stoffen, Vol. 20 (2), 65-77.

Neve, Rudie (1994) Boekbespreking: B. Bieleman, A. Dias, G. Marlan en Ch.D. Kaplan, 'Lines Across Europe. Nature and Extent of Cocaine Use in Barcelona, Rotterdam and Turin' Tijdschrift voor Alcohol, Drugs en andere Psychotrope Stoffen, Vol. 20 (2), 122-125.

Neve, Rudie J.M. (1995) Changes in attitudes toward women's emancipation in the Netherlands over two decades: unraveling a trend. Social Science Research, 24, 167-187.

Neve, Rudie J.M., Drop, Maria J., Lemmens, Paul, H., Swinkels, H. (1996)

Gender differences in drinking behavior in the Netherlands: convergence or stability? Addiction, $91,357-373$.

Neve, Rudie J.M., Lemmens, Paul H., Drop, Maria.J. (1997)

Drinking careers of older male alcoholics in treatment as compared to younger alcoholics and social drinkers of the same age, Journal of Studies on Alcohol, 58, 303-311

Neve, R.J.M. (1997)

Analyse en interpretatie van leeftijd-, periode- en cohorteffecten in alcohol en drugs onderzoek. In: Van de Goor, L.A.M., Bongers, I (Red.) Onderzoek naar ontwikkelingen en beloop van middelenverslaving: mogelijkheden en beperkingen van onderzoek naar een verslavingscarrière, Rotterdam: Platform Sociaal Epidemiologisch Verslavingsonderzoek.

Knibbe, R.A., Neve, R.J.M. (1997)

Ontwikkelingen in drankgebruik van mannen en vrouwen in de algemene bevolking. In: Van de Goor, L.A.M. en Knibbe, R.A. (Red) Sekse, Alcohol en Verslaving, Rotterdam: Platform Sociaal Epidemiologisch Verslavingsonderzoek.

Neve, Rudie J.M., Lemmens, Paul H., Drop, Maria, J. (1997)

Gender differences in alcohol use and alcohol problems: mediation by social roles and genderrole attitudes, Substance use and misuse, 32(11), 1.439-1459. 